\author{
Universidade de São Paulo \\ Escola de Engenharia de São Carlos \\ Departamento de Engenharia Elétrica
}

\title{
Fibras Ópticas Microestruturadas: Modelagem e Aplicações
}

\section{Carlos Alberto De Francisco}

Tese apresentada à Escola de Engenharia de São Carlos, da Universidade de São Paulo, como parte dos requisitos para obtenção do Título de Doutor em Engenharia Elétrica.

\author{
Orientador: Prof. Dr. Murilo Araujo Romero \\ Co-Orientador: Prof. Dr. Ben-Hur Viana Borges
}

São Carlos

2004 
"O terrível progresso conseguido pelo homem, não apenas na imensidão do espaço como também na infinitude das partículas subatômicas, parece conduzir à destruição total do nosso universo, a menos que façamos grandes progressos na compreensão e no tratamento das tensões interpessoais e intergrupais."

Carl R. Rogers, 1961 
À minha esposa Mirela e à minha filha Nicole por terem suportado tudo ao meu lado. 


\section{AGRADECIMENTOS}

À minha esposa Mirela por ter superado todos os percalços ao meu lado com amor e compreensão.

À minha filha Nicole por ter sido minha inspiração.

Aos meus pais Walter e Regina pelo apoio e incentivo.

Aos meus sogros Antenor e Irene por terem me apoiado sempre, incondicionalmente.

Ao Prof. Murilo Araujo Romero pela amizade, pelo brilhantismo com que orientou este trabalho e por ter ido muito além.

Ao Prof. Ben-Hur Viana Borges pela orientação e pelas prazerosas horas de discussão.

Ao Prof. Amílcar Carelli César pelo incentivo e pelas valiosas sugestões.

Ao meu amigo e colega Danilo Henrique Spadoti pela amizade e por ter me acolhido em sua casa.

Ao amigo Valtemir Emerêncio do Nascimento, pela amizade e companheirismo durante o trajeto.

Ao amigo Licínius Dimitri Sá de Alcântara pela amizade e pelo exemplo de profissionalismo e dedicação. 
À FAPESP pelo suporte financeiro que tornou possível a realização deste trabalho.

À todos meus familiares, amigos, funcionários, docentes e colegas que de uma forma ou de outra me apoiaram nestes quatro anos. 


\section{SUMÁRIO}

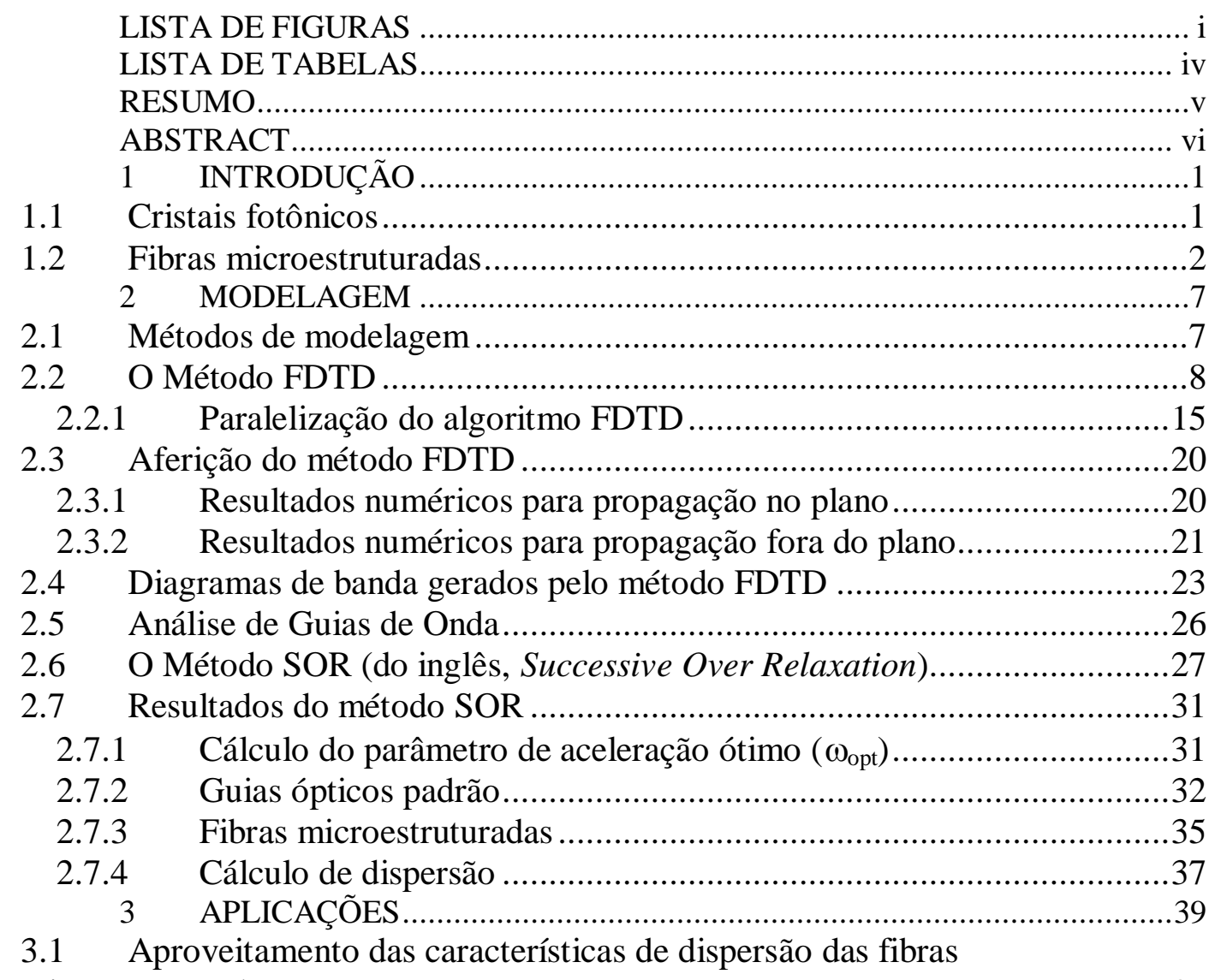

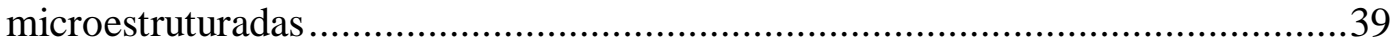

3.1.1 Análise de sensitividade em fibras com baixa dispersão ..................39

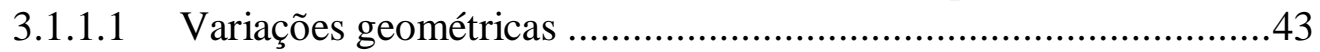

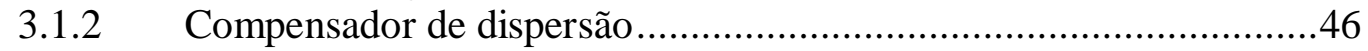

3.1.3 Metodologia de Projeto .................................................................46

3.1.4 Compensação de dispersão em banda larga ......................................49

3.1.5 Considerações relativas à implementação prática ............................50

3.2 Aplicação das Fibras microestruturadas em amplificadores Raman..........53

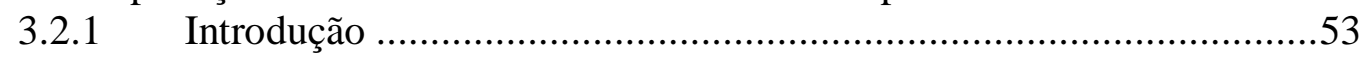

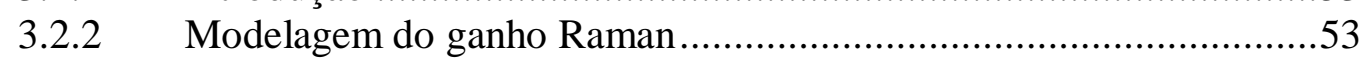

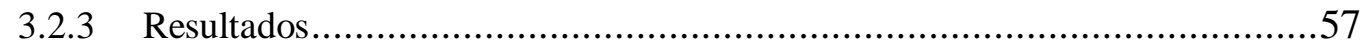

3.2.4 Caso especial: Amplificação Raman em fibras DCF .......................59

3.3 Isolador óptico baseado em fibras microestruturadas ...........................61

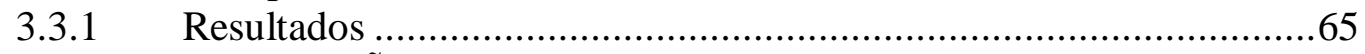

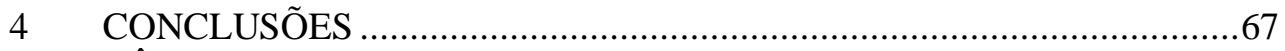

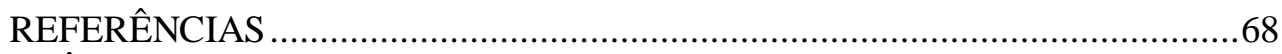

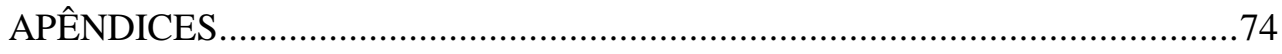

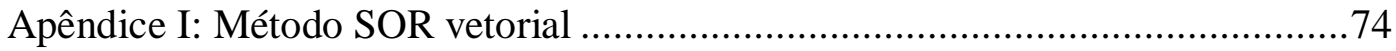


Apêndice II: SOR para meios magneto-ópticos com campo magnético aplicado na

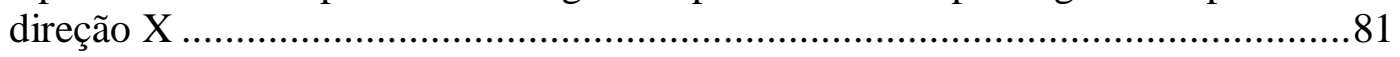

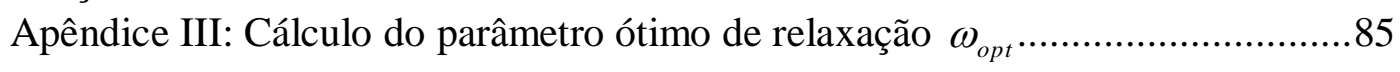
Apêndice IV: Condição de contorno transparente ............................................8 88 


\section{LISTA DE FIGURAS}

Figura 1.1 - Seção transversal de uma fibra de cristal fotônico. [1.6] 3

Figura 1.2- Tipo de fibra microestruturada onde o núcleo tem índice efetivo menor do que a casca. [1.8]

Figura 1.3- Exemplo de guiamento de luz na fibra da Figura 1.2. O núcleo pode ser bem definido pela região com coloração esverdeada. [1.8].

Figura 1.4- Corte transversal da fibra microestruturada com núcleo de ar. [1.12].......5

Figura 1.5- Esquema da seção transversal da fibra e respectiva distribuição radial de índice de refração.

Figura 2.1-Célula tridimensional de Yee. As componentes do campo elétrico e

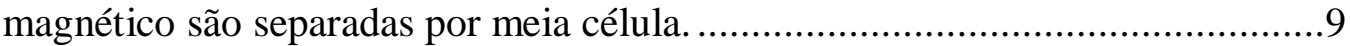

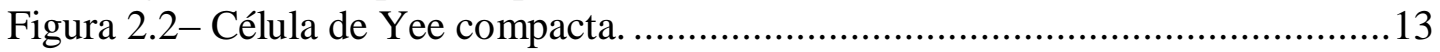

Figura 2.3- Condição de contorno periódica. ..................................................... 13

Figura 2.4- Janela computacional de uma célula de um cristal bidimensional formado por bastões cilíndricos numa estrutura quadrada. Cada região em negro representa um quarto de um bastão.

Figura 2.5- Esquema de supercélula formada a partir do cristal da Figura 2.4

contendo um defeito. As células em cinza representam o cristal fora da janela computacional.

Figura 2.6- Exemplos de decomposição por domínio. a) Tarefa única. b)

Decomposição unidimensional. c) Decomposição bidimensional.....................16

Figura 2.7- Tempo total de computação em função do número de computadores para um número fixo de operações para um algoritmo FDTD rodando em um "cluster" de microcomputadores [2.7].

Figura 2.8- Célula modificada para minimização do custo com comunicação. ........17

Figura 2.9- Exemplo de "cluster" de microcomputadores. .......................................18

Figura 2.10- Exemplo de comportamento do FDTD em "beowulf" formado por computadores DEC Alpha [2.9] utilizando três formas diferentes de comunicação entre os computadores.

Figura 2.11- Tempo de processamento para o método FDTD em função do tamanho do problema para a modelagem de cristais fotônicos obtidos neste trabalho.....20

Figura 2.12- Diagrama de bandas para a propagação no plano para um cristal bidimensional formado por bastões dielétricos em disposição quadrada na polarização TE.

Figura 2.13-Diagrama de bandas para a propagação no plano para um cristal bidimensional formado por bastões dielétricos em disposição quadrada na polarização TM.

Figura 2.14- Diagrama de bandas para propagação fora do plano, $\mathrm{Kz}=0.4 \pi / \mathrm{a}$, para bastões dielétricos no ar.

Figura 2.15- Diagrama de bandas para um cristal formado por furos elípticos de ar em arseneto de gálio com parâmetros: $1_{\mathrm{x}} / 1_{\mathrm{y}}=0,77, \mathrm{a}=0.451_{\mathrm{y}}, \mathrm{b}=0,381_{\mathrm{y}} \ldots \ldots \ldots .26$

Figura 2.16- Distribuição de campo calculada a partir do método FDTD. 
Figura 2.17- Evolução do índice efetivo em função do número de iterações para vários valores de $\omega$ em comparação com o valor ótimo calculado $\omega_{o p t}$ para uma fibra microestruturada com raio dos furos $a=0,7 \mu \mathrm{m}$, espaçamento entre furos $\Lambda=2,3 \mu \mathrm{m}$, e comprimento de onda de operação $\lambda=1,3 \mu \mathrm{m}$, para uma malha com $512 \times 512$ pontos. 32

Figura 2.18- Esquema de guia tipo rib. Os parâmetros W, H e são largura e altura do rib enquanto que D representa a espessura da camada guiante. A camada superior é tomada como sendo composta de ar.

Figura 2.19- Esquema da seção transversal de uma fibra tipo D............................34

Figura 2.20- Diferença absoluta em função do comprimento de onda para uma fibra microestruturada com os seguintes parâmetros: raio dos furos $(a)$ igual a $1,0 \mu \mathrm{m}$ e distância entre furos $(\Lambda)$ de $2,3 \mu \mathrm{m}$.

Figura 2.21- Diferença absoluta do índice efetivo em função do comprimento de onda para a fibra microestruturada com os seguintes parâmetros: raio dos furos (a) igual a $0,4 \mu \mathrm{m}$ e distância entre furos $(\Lambda)$ de $2,71 \mu \mathrm{m}$.

Figura 2.22- Diagrama de dispersão para a fibra microestruturada com $\Lambda=2,3 \mu \mathrm{m}$ e $a=0,25,0,3105$ e $0,5 \mu \mathrm{m}$. O ponto experimental representa o caso a $=0,3105$ para $\lambda=813 \mathrm{~nm}$.

Figura 3.1- Dispersão cromática em função do comprimento de onda para uma fibra microestruturada com período $(\Lambda)$ igual a $2.3 \mu \mathrm{m}$ e raio $(a)$ igual a $0.315 \mu \mathrm{m}$. A linha sólida refere-se ao processo MCVD, enquanto a linha tracejada é referente ao processo SPCVD e a linha pontilhada, por sua vez, refere-se ao processo PCVD.

Figura 3.2- Dispersão cromática em função do comprimento de onda para a mesma fibra da Figura 3.1 utilizando vidro fabricado pelo processo PCVD. Linha sólida: Sílica não dopada. Linha tracejada: 4,5 mol.\%. Linha pontilhada: 11,6 mol.\%.

Figura 3.3- Dispersão cromática em função do comprimento de onda para a mesma fibra da Figura 3.1 utilizando vidro fabricado pelo processo SPCVD. Linha sólida: sílica não dopada. Linha tracejada: Al 4,9 wt\%.

Figura 3.4- Características de dispersão em função do comprimento de onda tendo o raio dos furos $a$ e sua separação $\Lambda$ como parâmetro.

Figura 3.5- Influência de flutuações pseudo-aleatórias nos parâmetros geométricos $a$ e $\Lambda$ em função do comprimento de onda. Linha sólida: Média aritmética. Linhas pontilhadas: Média adicionada e subtraída do desvio padrão. ..........................45

Figura 3.6 - Perdas ópticas em função do número de anéis. .................................51

Figura 3.7 - Influencia de variações geométrica sobre o parâmetro de dispersão. ....52

Figura 3.8- Espectro do coeficiente de eficiência de ganho Raman........................54

Figura 3.9 - Área efetiva em função da distância entre furos para quatro valores de preenchimento de ar.

Figura 3.10 - Coeficiente de ganho Raman $\gamma$ em função da distância entre furos para quatro valores de preenchimento de ar........................................................59

Figura 3.11 - Ganho Raman para uma fibra microestruturada projetada para compensação de dispersão.

Figura 3.12- Seção transversal do isolador baseado em fibras microestruturadas....62

Figura 3.13 - Funcionamento do isolador. Existirão comprimentos de acoplamentos diferentes para cada direção de propagação. 
Figura 3.14 - Funcionamento do circulador. 63

Figura 3.15 - Utilização do dispositivo como sensor de campo magnético...............64

Figura 3.16 - Comprimento de acoplamento em função do parâmetro d/ $\Lambda$ para o acoplador isotrópico, supondo $\Lambda=3 \mu \mathrm{m}$ 65

Figura 3.17 - Comprimento do isolador para o caso de $2 \mathrm{a} / \Lambda=0,55$ e $\Lambda=3,0 \mu \mathrm{m}$. .....66 


\section{LISTA DE TABELAS}

Tabela 2.1 - Definição dos pontos de simetria para os cristais estudados.

Tabela 2.2- Resultados obtidos através do método FDTD em comparação com resultados publicados em [2.16]. (Valores calculados no ponto de simetria $X$ para polarização TM).

Tabela 2.3- Resultados obtidos para a frequiência normalizada através do método FDTD considerando-se um cristal formado por cilindros dielétricos com $\varepsilon_{\mathrm{r}}=8,9$, em disposição quadrada no ar e com relação entre raio e separação $r / a=0,2 \mathrm{e}$ constante de propagação fora do plano $k z=0,4 \pi / \mathrm{a}$ em comparação com os resultados derivados de [2.17].

Tabela 2.4- Constante de propagação normalizada $B=\left(n_{\text {eff }}^{2}-n_{\text {sub }}^{2}\right) /\left(n_{n u c}^{2}-n_{\text {sub }}^{2}\right)$ para modos TE em guias rib calculadas por diversas formulações e desvio do SOR em relação ao método $\mathrm{SV}$-IBPM.

Tabela 2.5- Resultados obtidos pelo SOR e V-BPM para fibras tipo D e três valores do parâmetro D.

Tabela 3.1 - Casos de projeto para fibra compensadora de dispersão. O duplo asterisco em alguns dos itens da tabela abaixo significa que o raio dos furos obedece a um limite máximo tal que a razão entre o raio dos furos e o espaçamento entre eles não excede 0,85 .

Tabela 3.2-Casos de projeto para compensação em banda larga. 


\section{RESUMO}

Este trabalho tem por objetivo a modelagem numérica das fibras microestruturadas e a proposição de dispositivos inovadores com base nos modelos numéricos construídos. Primeiramente, são implementados dois formalismos distintos: o FDTD (do inglês Finite Diference Time Domain) para a geração dos diagramas de bandas dos cristais fotônicos e o SOR (do inglês Successive Over Relaxation) para a análise modal das fibras. A partir destes modelos, são propostas três aplicações distintas que utilizam as propriedades inovadoras das fibras microestruturadas, a saber: compensador de dispersão a fibra com capacidade de compensar um enlace óptico com cerca de vinte vezes seu comprimento, amplificador Raman com alto ganho óptico e isolador óptico a fibra microestruturada. 


\section{ABSTRACT}

The goal of this work is the numerical modeling of microstructured optical fibers and the proposition of novel applications using the model developed. First, two distinct formalisms are implemented, the Finite Difference Time Domain Method (FDTD) to generate the photonic crystal band diagrams and the Successive Over Relaxation method (SOR) to carry out modal analysis on the microstructured optical fibers. By means of these models, three applications are investigated: high performance dispersion compensation fiber, high gain Raman amplifier and microstructured optical fiber isolator. 


\section{INTRODUÇÃO}

Desde o surgimento dos cristais fotônicos, uma grande variedade de aplicações tem sido proposta na literatura, dentre as quais destacam-se as fibras de cristal fotônico, conhecidas por PCFs (do inglês Photonic Crystal Fiber) ou, simplesmente, fibras microestruturadas. Esta classe de fibras apresenta características peculiares como guiamento monomodo em uma larga faixa de comprimentos de onda, alta não-linearidade e uma grande maneabilidade de suas características de dispersão cromática.

O objetivo deste trabalho é desenvolver modelos numéricos para a previsão do comportamento destas fibras e, a partir destes modelos, propor novos dispositivos e aplicações para estas fibras.

\subsection{Cristais fotônicos}

Os cristais fotônicos são estruturas periódicas cuja periodicidade é da ordem do comprimento de onda da luz. Estas estruturas periódicas são denominadas cristais em analogia aos cristais naturais, que possuem periodicidades de ordem atômica. Os mesmos conceitos utilizados no estudo dos cristais naturais, como zona de Brillouin e relação de dispersão, podem também ser utilizados no estudo de cristais fotônicos artificiais. Da mesma forma que existem bandas de energia proibidas para elétrons em cristais naturais, existem também bandas de energia proibida para os fótons em cristais fotônicos, onde as frequiências de propagação para estes fótons não são permitidas. Na região de banda proibida, modos de propagação, emissão espontânea e flutuações quânticas inexistem. A característica de supressão de emissão espontânea foi a motivação das primeiras pesquisas em cristais fotônicos. Desde então, muito esforço foi empregado no desenvolvimento de técnicas de fabricação e, atualmente, os cristais fotônicos são utilizados numa grande gama de aplicações tanto em óptica integrada quanto em fibras ópticas.

Algumas das aplicações inovadoras em óptica integrada podem ser ressaltadas, como lasers com baixa intensidade de bombeio [1.1], guias de onda com curvatura acentuada e baixas perdas [1.2], filtros ópticos [1.3], multiplexadores e demultiplexadores ópticos $[1.4,1.5]$, dentre outras. 
No entanto, a aplicação de maior interesse neste trabalho é a fibra óptica formada pelo cristal fotônico, também chamada de fibra de cristal fotônico, ou, simplesmente, fibra microestruturada.

\subsection{Fibras microestruturadas}

O surgimento, em 1996, das fibras microestruturadas, produziu um grande impacto na comunidade científica, dando origem a edições especiais em periódicos de renome, diversos artigos em revistas tais como Science e Nature, seções especiais em congressos, etc. Uma coleção bastante completa de referências pode ser encontrada em http://home.earthlink.net/ jpdowling/pbgbib.html. As propriedades inovadoras destas fibras e um breve histórico são apresentados a seguir.

Nas fibras microestruturadas, um cristal fotônico bidimensional é formado por uma distribuição periódica de furos de ar que percorrem longitudinalmente a fibra. Nesta estrutura, um defeito pode ser criado através da eliminação de um furo de ar, quebrando assim, a periodicidade dos furos. Da mesma forma, pode-se criar um defeito através da retirada de sílica de uma determinada região, violando também a periodicidade da estrutura. Estes defeitos têm a propriedade de criar níveis permitidos de propagação dentro da banda proibida criada pelo cristal. Este defeito, portanto, será capaz de guiar a luz, constituindo-se, assim, no núcleo da fibra.

A primeira fibra cristalina foi fabricada em 1996 [1.6], sendo formada por um núcleo de sílica e a casca composta por furos de ar em disposição triangular (veja Figura 1.1). Este tipo de fibra pode também ser compreendida como sendo formada por um núcleo com índice de refração igual ao da sílica e por uma casca, cujo índice efetivo será uma média entre os índices da sílica e do ar, média esta que deve ser ponderada pela intensidade de campo em cada região [1.7]. Desta forma, o guiamento poderia ser explicado por reflexão interna total. Por este motivo, alguns autores chamam este tipo de fibra como TIR-PCF do inglês "Total Internal Reflection - Photonic Crystal Fiber".

Outro tipo de fibra fabricado é mostrado na Figura 1.2 [1.8]. Nesta fibra os furos de ar têm uma disposição hexagonal, sendo o núcleo formado pela inclusão de um furo de ar extra no centro da fibra. Neste caso, o guiamento de luz (mostrado na Figura 1.3) dá-se num núcleo cujo índice efetivo é menor do que o índice da casca. O modelo do índice efetivo, portanto, não pode ser usado para explicar o funcionamento da fibra por reflexão interna total. Alguns autores chamam este tipo de fibra de PBG-PCF do inglês "Photonic Band $\boldsymbol{G}$ ap 
- Photonic Crystal Fibers". Neste trabalho, ambas as fibras são chamadas de fibras microestruturadas, diferenciando-se apenas pela denominação núcleo sólido e núcleo de ar.

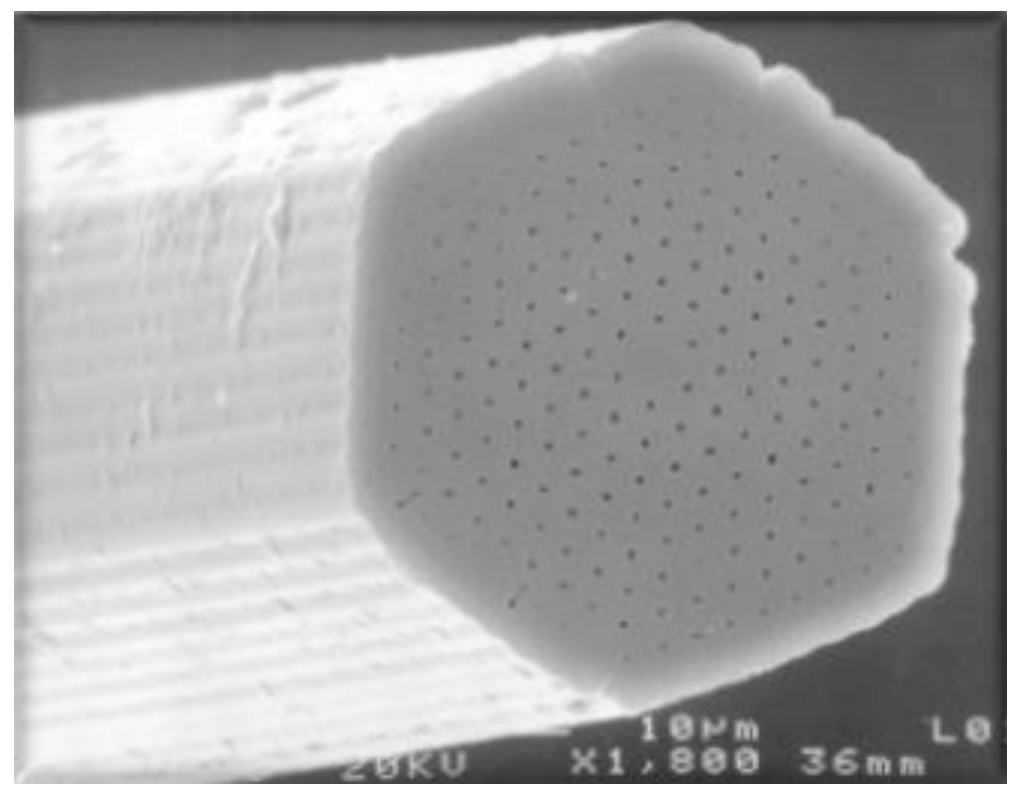

Figura 1.1 - Seção transversal de uma fibra de cristal fotônico. [1.6]

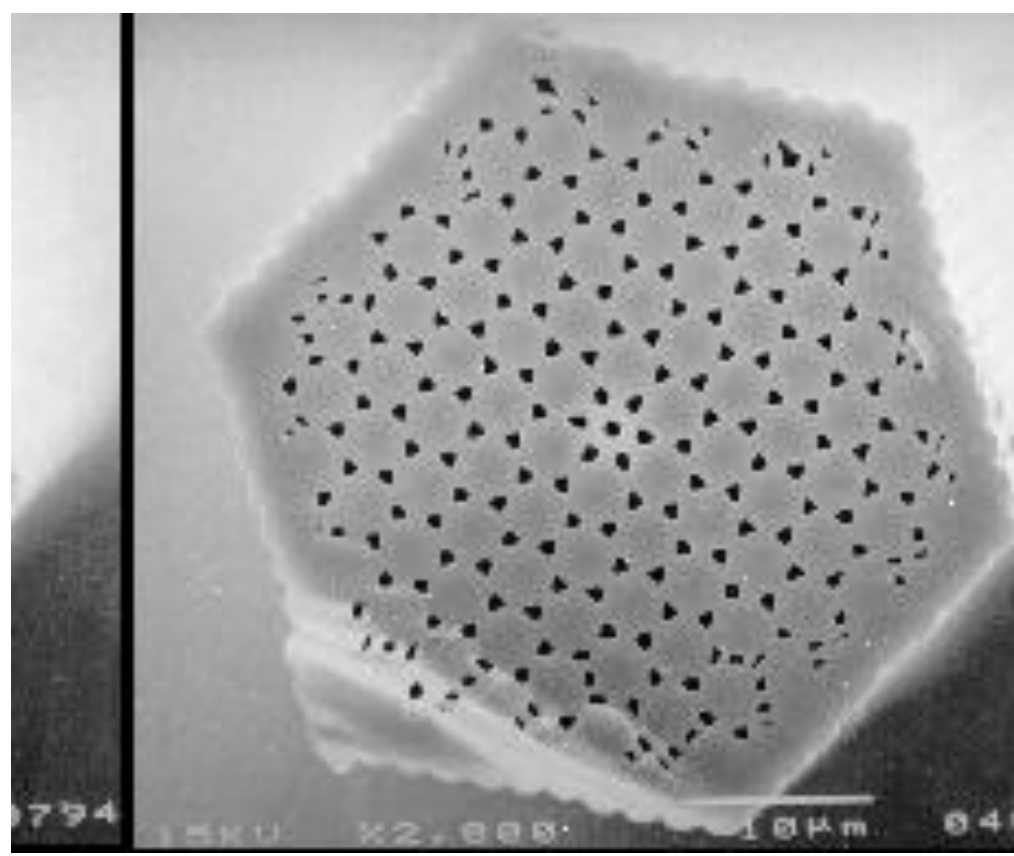

Figura 1.2- Tipo de fibra microestruturada onde o núcleo tem índice efetivo menor do que a casca. [1.8] 


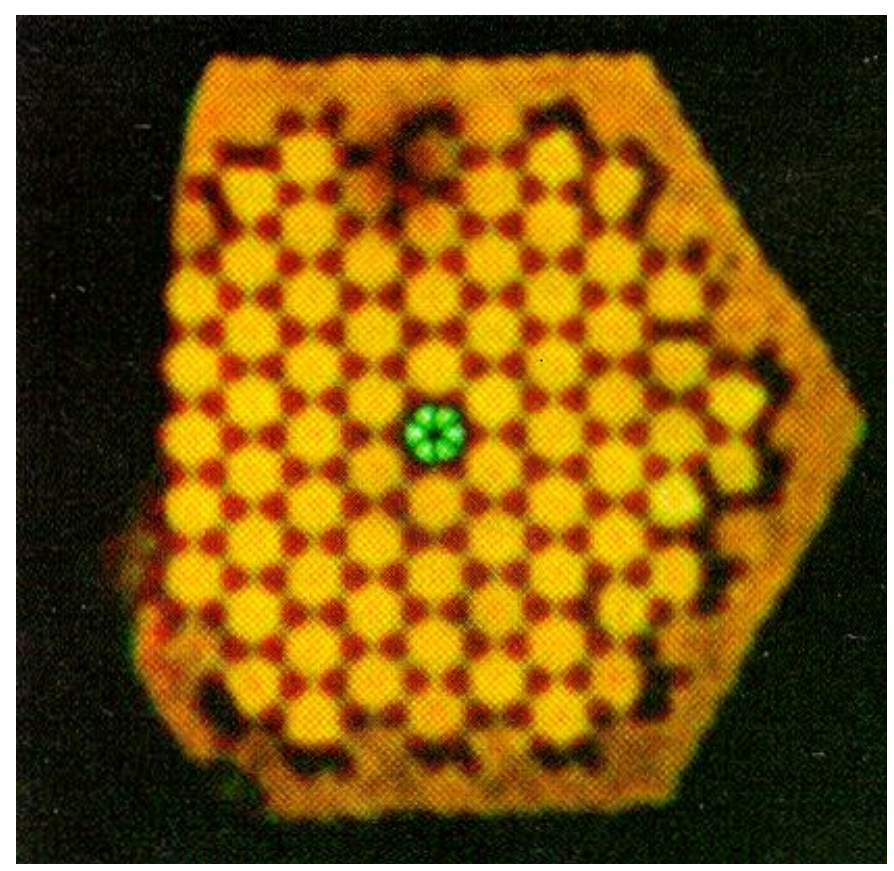

Figura 1.3- Exemplo de guiamento de luz na fibra da Figura 1.2. O núcleo pode ser bem definido pela região com coloração esverdeada. [1.8].

A fibra microestruturada com núcleo sólido pode apresentar-se como monomodo em uma ampla faixa de atuação [1.9], pelo menos de 458 a $1550 \mathrm{~nm}$. Numa fibra convencional, com índice degrau, raio $\mathrm{r}$, índice do núcleo $n_{n}$, índice da casca $n_{c} \mathrm{e}$ comprimento de onda $\lambda$, o número de modos guiados é dado pelo número $V$ :

$$
V=\frac{2 \pi r}{\lambda} \sqrt{n_{n}^{2}-n_{c}^{2}}
$$

parâmetro que deve ser menor do que 2,405 para que a fibra seja monomodo. Deve-se notar, portanto, que uma fibra projetada para operação monomodo torna-se sempre multimodo para um comprimento de onda suficientemente curto. Conforme mencionado, no caso da fibra microestruturadas de núcleo sólido (TIR-PCF), o índice da casca pode ser entendido como uma média entre os índices de refração do ar e da sílica. A partir deste modelo, pode-se explicar o guiamento monomodo em larga faixa de comprimentos de onda através do seguinte fenômeno: para comprimentos de onda mais curtos, o campo mostra-se bem confinado nas áreas de sílica, enquanto que para comprimentos de onda mais longos a luz interage mais com os furos de ar. Desta forma, o índice efetivo da casca aumenta com a diminuição do comprimento de onda, diminuindo o numerador da Equação (1.1) e mantendo 
o número $\mathrm{V}$ abaixo de 2,405 para uma faixa ampla de freqüências. Outra aplicação interessante é a fabricação de fibras monomodo cujo núcleo tenha uma área muito elevada [1.10], podendo assim guiar grandes potências sem excitar efeitos não-lineares indesejados.

Além disso, outra propriedade interessante das fibras cristalinas é a maneabilidade da dispersão óptica resultante. De fato, é possível obter uma dispersão extremamente baixa para comprimentos de onda menores que $1,27 \mu \mathrm{m}$ bem como altos coeficientes de dispersão na faixa de $1,55 \mu \mathrm{m}$, úteis para compensação de dispersão em enlaces de fibra convencional [1.11].

As fibras microestruturadas de núcleo sólido podem ainda ser fabricadas sem uma periodicidade bem definida. Tais fibras são denominadas fibras vazadas, do inglês, "Holey Fibers". Todavia, desde o início das pesquisas em fibras microestruturadas buscava-se efetivamente uma estrutura que fosse capaz de guiar luz numa região composta apenas por ar. Neste caso, seriam evitados o efeito dispersivo e a absorção óptica presentes na sílica. Tal objetivo foi alcançado em 1999 pelo grupo de J. C. Knight [1.12]. Eles fabricaram fibras a partir de capilares de sílica obtendo um alto fator de preenchimento de ar numa estrutura do tipo triangular. O núcleo é formado pela ausência dos sete capilares centrais, ou seja, por uma região de ar. A Figura 1.4 mostra um corte transversal da estrutura fabricada.

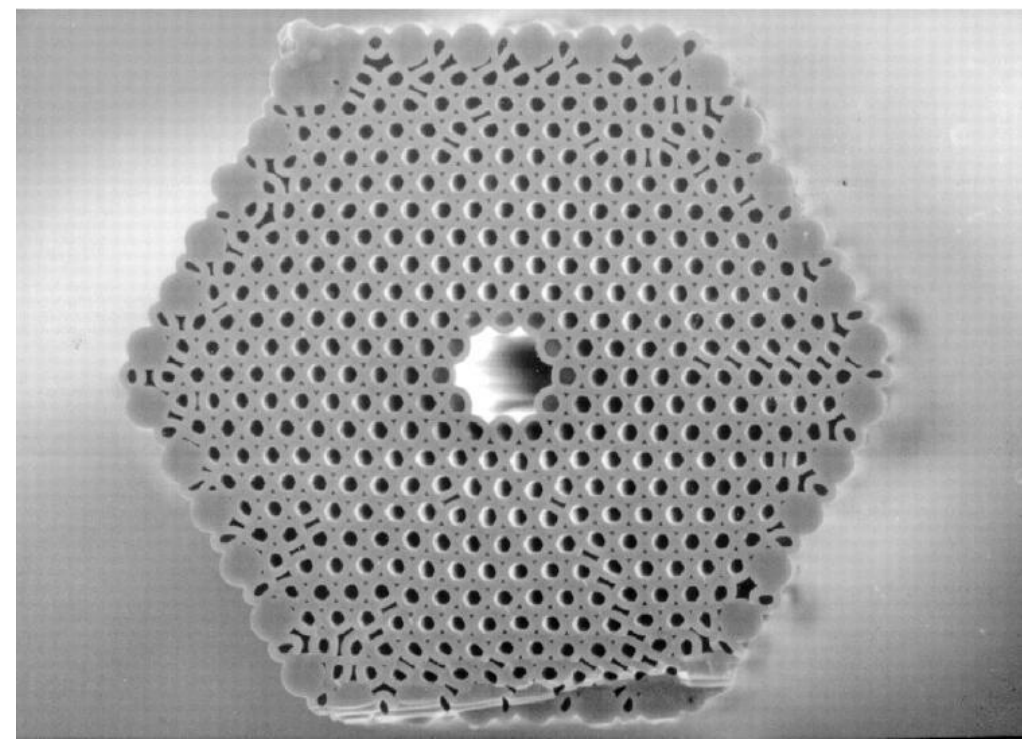

Figura 1.4- Corte transversal da fibra microestruturada com núcleo de ar. [1.12]

Outros pesquisadores [1.13] fabricaram fibras com núcleo de ar a partir de capilares de telúrio e poliestireno, formando uma estrutura circular conforme mostra a Figura 
3.5. Esta fibra pode ser projetada para suportar um único modo guiado puramente TE ou TM, em semelhança com guias metálicos circulares [1.14].

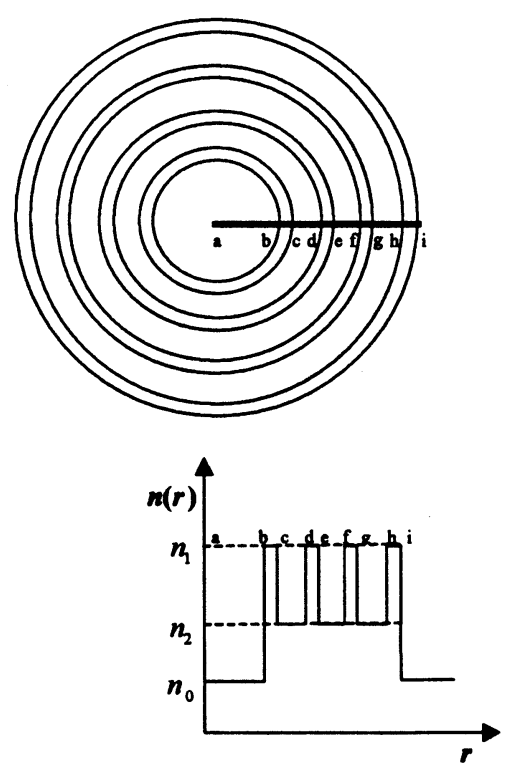

Figura 1.5- Esquema da seção transversal da fibra e respectiva distribuição radial de índice de refração.

Também foram fabricadas fibras microestruturadas cujo núcleo incorpora uma região fotossensitiva de germânio [1.15]. Nesta região uma rede de Bragg convencional foi fabricada dando origem a um filtro óptico. Uma estrutura similar foi investigada em [1.16] para fabricação de lasers em fibra. No intuito de permitir uma maior flexibilidade no projeto do índice da casca, uma estrutura com simetria cilíndrica foi proposta em [1.17].

O Capítulo 2 descreve o ferramental matemático utilizado na modelagem dos cristais fotônicos e das fibras microestruturadas. Além disso, é realizada a aferição dos métodos através da comparação dos resultados obtidos com outros encontrados na literatura. Adicionalmente, são apresentados os principais diagramas de banda gerados. No Capítulo 3 são discutidas três aplicações utilizando as fibras microestruturadas, enquanto no Capítulo 4 são realizadas as conclusões do trabalho e as propostas para trabalhos futuros. 


\section{MODELAGEM}

Neste capítulo são apresentados os métodos numéricos implementados para a modelagem dos cristais fotônicos e das fibras microestruturadas. Na seção 2.1 os principais métodos utilizados para a modelagem dos cristais fotônicos e das fibras microestruturadas são sucintamente discutidos. Na seção 2.2 o método FDTD é apresentado de forma detalhada. Este método é utilizado para o cálculo do diagrama de bandas de cristais fotônicos bidimensionais, que são a base das fibras microestruturadas empregando núcleo de ar. Diversos diagramas gerados pelo método FDTD são mostrados na seção 2.3. O método SOR, desenvolvido para a modelagem das fibras microestruturadas com núcleo sólido é apresentado na seção 2.4 e os principais resultados gerados para sua aferição são discutidos na seção 2.5 .

\subsection{Métodos de modelagem}

Devido ao grande interesse despertado pelas fibras microestruturadas, diversos métodos estão sendo utilizados na literatura, alguns já usuais e de caráter geral, como, por exemplo, diferenças finitas no domínio do tempo (FDTD) e elementos finitos, e outros, mais específicos, como o método de ondas planas. Os principais métodos utilizados na modelagem dos cristais fotônicos e das fibras microestruturadas são apresentados a seguir:

\section{Método do índice efetivo}

Este método consiste em aproximar a fibra microestruturada por uma fibra de índice degrau [2.1]. O índice efetivo da casca é estimado resolvendo-se a equação de onda escalar para uma célula da estrutura da casca. Esta célula é escolhida tendo seu centro num furo de ar. O índice adotado para a casca será o índice do modo fundamental encontrado. A aproximação serve apenas para uma análise qualitativa dos fenômenos envolvidos.

\section{Método de ondas planas}


Este método é um dos mais utilizados na modelagem de estruturas de cristais fotônicos e está intimamente relacionado com o método utilizado para calcular o diagrama de bandas eletrônico em semicondutores [2.2]. Ele consiste em descrever o campo magnético $H$ como uma onda plana multiplicada por uma função de Bloch $U$ com a periodicidade do cristal.

Em duas dimensões, pode-se descrever o campo $H$ como um somatório de ondas planas e inserí-lo na equação vetorial de Maxwell. Posteriormente, aplica-se a transformada de Fourier na função que descreve a distribuição dielétrica da estrutura, recaindo em um problema de autovalor e autovetor. Através deste método pode-se calcular o diagrama de bandas para um cristal fotônico bidimensional (propagação no plano), caso em que as soluções podem ser divididas em TE e TM. No caso da fibra, que é um problema tridimensional, passa a ser considerada também a componente de propagação longitudinal $\mathrm{k}_{\mathrm{z}}$, também conhecida como constante de propagação $\beta$, nas fibras convencionais.

\section{Método modal}

Este método consiste em descrever a estrutura cristalina, bem como a distribuição de campo, através de funções de Hermite-Gauss, enquanto o defeito é descrito através de funções co-seno. Este método também recai num problema de autovalores, onde os termos da matriz envolvida podem ser calculados analiticamente [2.3].

\section{Método vetorial biortonormal}

O método biortonormal assemelha-se ao método modal descrito anteriormente, mas utiliza-se um procedimento similar ao método dos gradientes conjugados para solucionar o problema de autovalores gerado [2.4]. Este método é considerado muito preciso e eficiente, sendo inclusive utilizado para comparar os resultados fornecidos por um método analítico para o cálculo do modo fundamental da casca [2.5].

\subsection{O Método FDTD}

O método FDTD baseia-se num algoritmo originalmente proposto por Yee [2.6]. Este algoritmo realiza a discretização das equações de Maxwell no espaço e no tempo segundo uma célula tridimensional, onde os campos elétrico e magnético são devidamente 
posicionados na malha computacional. A Figura 2.1 mostra a célula original de Yee, onde o posicionamento das componentes de campo elétrico e magnético é separado por uma distância de meia célula.

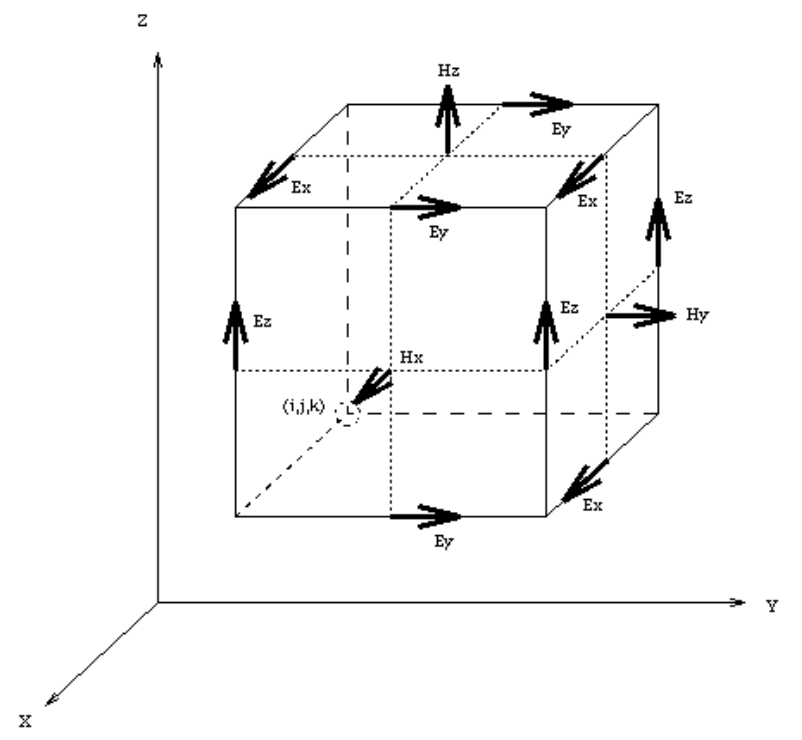

Figura 2.1- Célula tridimensional de Yee. As componentes do campo elétrico e magnético são separadas por meia célula.

Parte-se das equações de Maxwell dependentes do tempo para materiais isotrópicos e regiões livres de carga:

$$
\begin{aligned}
& \frac{\partial H}{\partial t}=-\frac{1}{\mu(r)} \nabla \times E \\
& \frac{\partial E}{\partial t}=\frac{1}{\varepsilon(r)} \nabla \times H-\frac{\sigma(r)}{\varepsilon(r)} E
\end{aligned}
$$

onde $\varepsilon(r), \mu(r)$ e $\sigma(r)$ são a permissividade elétrica, a permeabilidade magnética e a condutividade elétrica do meio, respectivamente. Estas equações podem ser discretizadas no espaço e no tempo pela chamada técnica da célula de Yee [2.6]. As fórmulas a seguir são resultado da discretização no tempo e no espaço das Equações (2.1) e formam o núcleo do método FDTD. A evolução temporal tridimensional de uma dada distribuição de campo num meio isotrópico e livre de cargas pode ser descrita pelas fórmulas mencionadas acima, dando origem ao método FDTD tridimensional [2.7]. 


$$
\begin{aligned}
& \left.H_{x}\right|_{i, j, k} ^{n+1 / 2}=\left.H_{x}\right|_{i, j, k} ^{n-1 / 2}+\frac{\Delta t}{\mu_{i . j . k}}\left(\frac{\left.E_{y}\right|_{i, j, k+1 / 2} ^{n}-\left.E_{y}\right|_{i, j, k-1 / 2} ^{n}}{\Delta z}-\frac{\left.E_{z}\right|_{i, j+1 / 2, k} ^{n}-\left.E_{z}\right|_{i, j-1 / 2, k} ^{n}}{\Delta y}\right) \\
& \left.H_{y}\right|_{i, j, k} ^{n+1 / 2}=\left.H_{y}\right|_{i, j, k} ^{n-1 / 2}+\frac{\Delta t}{\mu_{i . j . k}}\left(\frac{\left.E_{z}\right|_{i+1 / 2, j, k} ^{n}-\left.E_{z}\right|_{i-1 / 2, j, k} ^{n}}{\Delta x}-\frac{\left.E_{x}\right|_{i, j, k+1 / 2} ^{n}-\left.E_{x}\right|_{i, j, k-1 / 2} ^{n}}{\Delta z}\right) \\
& \left.H_{z}\right|_{i, j, k} ^{n+1 / 2}=\left.H_{z}\right|_{i, j, k} ^{n-1 / 2}+\frac{\Delta t}{\mu_{i . j . k}}\left(\frac{\left.E_{x}\right|_{i, j+1 / 2, k} ^{n}-\left.E_{x}\right|_{i, j-1 / 2, k} ^{n}}{\Delta y}-\frac{\left.E_{y}\right|_{i+1 / 2, j, k} ^{n}-\left.E_{y}\right|_{i-1 / 2, j, k} ^{n}}{\Delta x}\right) \\
& \left.E_{x}\right|_{i, j, k} ^{n+1}=\left.\frac{\varepsilon_{i, j, k}-\sigma_{i, j, k} \Delta t / 2}{\varepsilon_{i, j, k}+\sigma_{i, j, k} \Delta t / 2} E_{x}\right|_{i, j, k} ^{n} \\
& +\frac{\Delta t}{\varepsilon_{i, j, k}+\sigma_{i, j, k} \Delta t / 2}\left(\frac{\left.H_{z}\right|_{i, j+1 / 2, k} ^{n+1 / 2}-\left.H_{z}\right|_{i, j-1 / 2, k} ^{n+1 / 2}}{\Delta y}-\frac{\left.H_{y}\right|_{i, j, k+1 / 2} ^{n+1 / 2}-\left.H_{y}\right|_{i, j, k-1 / 2} ^{n+1 / 2}}{\Delta z}\right) \\
& \left.E_{y}\right|_{i, j, k} ^{n+1}=\left.\frac{\varepsilon_{i, j, k}-\sigma_{i, j, k} \Delta t / 2}{\varepsilon_{i, j, k}+\sigma_{i, j, k} \Delta t / 2} E_{y}\right|_{i, j, k} ^{n} \\
& +\frac{\Delta t}{\varepsilon_{i, j, k}+\sigma_{i, j, k} \Delta t / 2}\left(\frac{\left.H_{x}\right|_{i, j, k+1 / 2} ^{n+1 / 2}-\left.H_{x}\right|_{i, j, k-1 / 2} ^{n+1 / 2}}{\Delta z}-\frac{\left.H_{y}\right|_{i+1 / 2, j, k} ^{n+1 / 2}-\left.H_{y}\right|_{i-1 / 2, j, k} ^{n+1 / 2}}{\Delta x}\right) \\
& \left.E_{z}\right|_{i, j, k} ^{n+1}=\left.\frac{\varepsilon_{i, j, k}-\sigma_{i, j, k} \Delta t / 2}{\varepsilon_{i, j, k}+\sigma_{i, j, k} \Delta t / 2} E_{z}\right|_{i, j, k} ^{n} \\
& +\frac{\Delta t}{\varepsilon_{i, j, k}+\sigma_{i, j, k} \Delta t / 2}\left(\frac{\left.H_{y}\right|_{i+1 / 2, j, k} ^{n+1 / 2}-\left.H_{y}\right|_{i-1 / 2, j, k} ^{n+1 / 2}}{\Delta x}-\frac{\left.H_{x}\right|_{i, j+1 / 2, k} ^{n+1 / 2}-\left.H_{x}\right|_{i, j-1 / 2, k} ^{n+1 / 2}}{\Delta y}\right)
\end{aligned}
$$

onde o índice $n$ indica o passo temporal, os subscritos $i, j, k$ indicam a posição de um ponto na malha nas direções $\mathrm{x}, \mathrm{y}$ e $\mathrm{z}$, respectivamente, $\Delta \mathrm{t}$ é o incremento de tempo e $\Delta \mathrm{x}, \Delta \mathrm{y}$ e $\Delta \mathrm{z}$ são os incrementos espaciais entre dois pontos contíguos da malha nas direções $\mathrm{x}$, y e z, respectivamente. 
Para um determinado campo que se propaga numa direção que não esteja contida no plano X-Y, cada componente tem a forma:

$$
\Phi(x, y, z)=\varphi(x, y) e^{i k_{z} z}
$$

onde $\Phi$ denota uma componente qualquer de campo. Desta forma, os campos definidos em pontos vizinhos num determinado plano $\mathrm{X}-\mathrm{Y}$ satisfazem as seguintes relações:

$$
\left.E_{p}\right|_{i, j, k \pm 1} ^{n}=\left.E_{p}\right|_{i, j, k} ^{n} e^{i k_{z} \Delta z},\left.H_{p}\right|_{i, j, k \pm 1} ^{n}=\left.H_{p}\right|_{i, j, k} ^{n} e^{i k_{z} \Delta z}, p=x, y
$$

Então, as Equações 2.2 a 2.7 podem ser reescritas como [2.8]:

$$
\begin{aligned}
& \left.E_{z}\right|_{i, j} ^{n+1}=\left.\frac{\varepsilon_{i, j}-\sigma_{i, j} \Delta t / 2}{\varepsilon_{i, j}+\sigma_{i, j} \Delta t / 2} E_{z}\right|_{i, j} ^{n} \\
& +\frac{\Delta t}{\varepsilon_{i, j}+\sigma_{i, j} \Delta t / 2}\left(\frac{\left.H_{y}\right|_{i+1 / 2, j} ^{n+1 / 2}-\left.H_{y}\right|_{i-1 / 2, j} ^{n+1 / 2}}{\Delta x}-\frac{\left.H_{x}\right|_{i, j+1 / 2} ^{n+1 / 2}-\left.H_{x}\right|_{i, j-1 / 2} ^{n+1 / 2}}{\Delta y}\right) \\
& \left.H_{x}\right|_{i, j} ^{n+1 / 2}=\left.H_{x}\right|_{i, j} ^{n-1 / 2}-\frac{\Delta t}{\mu_{i . j}}\left(\frac{\left.E_{z}\right|_{i, j+1 / 2} ^{n}-\left.E_{z}\right|_{i, j-1 / 2} ^{n}}{\Delta y}-\left.i k_{z} E_{y}\right|_{i, j} ^{n}\right) \\
& \left.H_{y}\right|_{i, j} ^{n+1 / 2}=\left.H_{y}\right|_{i, j} ^{n-1 / 2}+\frac{\Delta t}{\mu_{i . j}}\left(\frac{\left.E_{z}\right|_{i+1 / 2, j} ^{n}-\left.E_{z}\right|_{i-1 / 2, j} ^{n}}{\Delta x}-\left.i k_{z} E_{x}\right|_{i, j} ^{n}\right) \\
& \left.H_{z}\right|_{i, j} ^{n+1 / 2}=\left.H_{z}\right|_{i, j} ^{n-1 / 2}+\frac{\Delta t}{\mu_{i, j}}\left(\frac{\left.E_{x}\right|_{i, j+1 / 2} ^{n}-\left.E_{x}\right|_{i, j-1 / 2} ^{n}}{\Delta y}-\frac{\left.E_{y}\right|_{i+1 / 2, j} ^{n}-\left.E_{y}\right|_{i-1 / 2, j} ^{n}}{\Delta x}\right) \\
& \left.E_{x}\right|_{i, j} ^{n+1}=\left.\frac{\varepsilon_{i, j}-\sigma_{i, j} \Delta t / 2}{\varepsilon_{i, j}+\sigma_{i, j} \Delta t / 2} E_{x}\right|_{i, j} ^{n} \\
& +\frac{\Delta t}{\varepsilon_{i, j}+\sigma_{i, j} \Delta t / 2}\left(\frac{\left.H_{z}\right|_{i, j+1 / 2} ^{n+1 / 2}-\left.H_{z}\right|_{i, j-1 / 2} ^{n+1 / 2}}{\Delta y}-\left.i k_{z} H_{y}\right|_{i, j} ^{n+1 / 2}\right)
\end{aligned}
$$




$$
\begin{aligned}
& \left.E_{y}\right|_{i, j, k} ^{n+1}=\left.\frac{\varepsilon_{i, j}-\sigma_{i, j} \Delta t / 2}{\varepsilon_{i, j}+\sigma_{i, j} \Delta t / 2} E_{y}\right|_{i, j} ^{n} \\
& -\frac{\Delta t}{\varepsilon_{i, j}+\sigma_{i, j} \Delta t / 2}\left(\frac{\left.H_{y}\right|_{i+1 / 2, j} ^{n+1 / 2}-\left.H_{y}\right|_{i-1 / 2, j} ^{n+1 / 2}}{\Delta x}-\left.i k_{z} H_{x}\right|_{i, j} ^{n+1 / 2}\right)
\end{aligned}
$$

Pode-se notar pelas Equações 2.9 a 2.14 que é necessária apenas uma malha bidimensional para a solução de um problema originalmente tridimensional. Este fato reduz significantemente o tempo de processamento e a memória computacional requerida no cálculo de estruturas tridimensionais.

Após a substituição da Equação (2.8), a célula de Yee original transforma-se na célula de Yee compacta, mostrada na Figura 2.2. Esta célula pode ser tomada como uma projeção bidimensional da célula original. Adicionalmente, a condição de estabilidade para este método é dada por [2.8]:

$$
\Delta t \leq \frac{1}{c \sqrt{\Delta x^{-2}+\Delta y^{-2}+\left(k_{z} / 2\right)^{2}}}
$$

onde $\Delta t$ é o passo no tempo, $c$ é a velocidade da luz, $\Delta x$ e $\Delta y$ são as distâncias entre dois pontos consecutivos da malha na direção $\mathrm{x}$ e $\mathrm{y}$, respectivamente, e $k_{z}$ é a constante de propagação na direção $z$.

A condição de contorno que surge naturalmente no caso de cristais fotônicos é a condição de contorno periódica. Esta condição é facilmente implementada através de equações que relacionam as amplitudes e fases dos campos nas extremidades da janela computacional, conforme ilustra a Figura 2.3. 


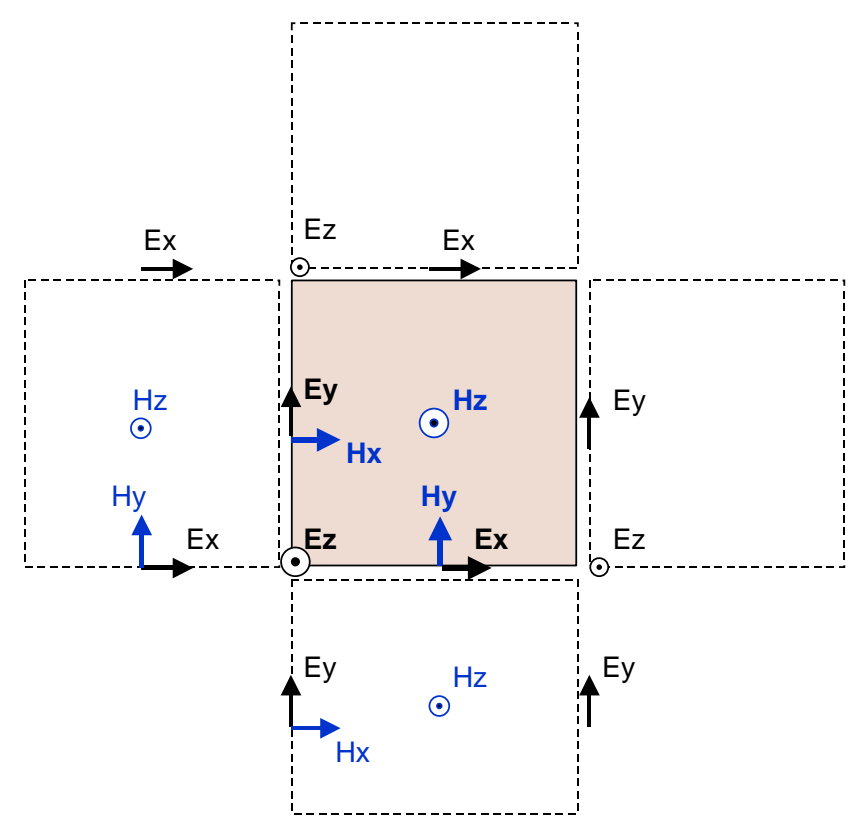

Figura 2.2-Célula de Yee compacta.

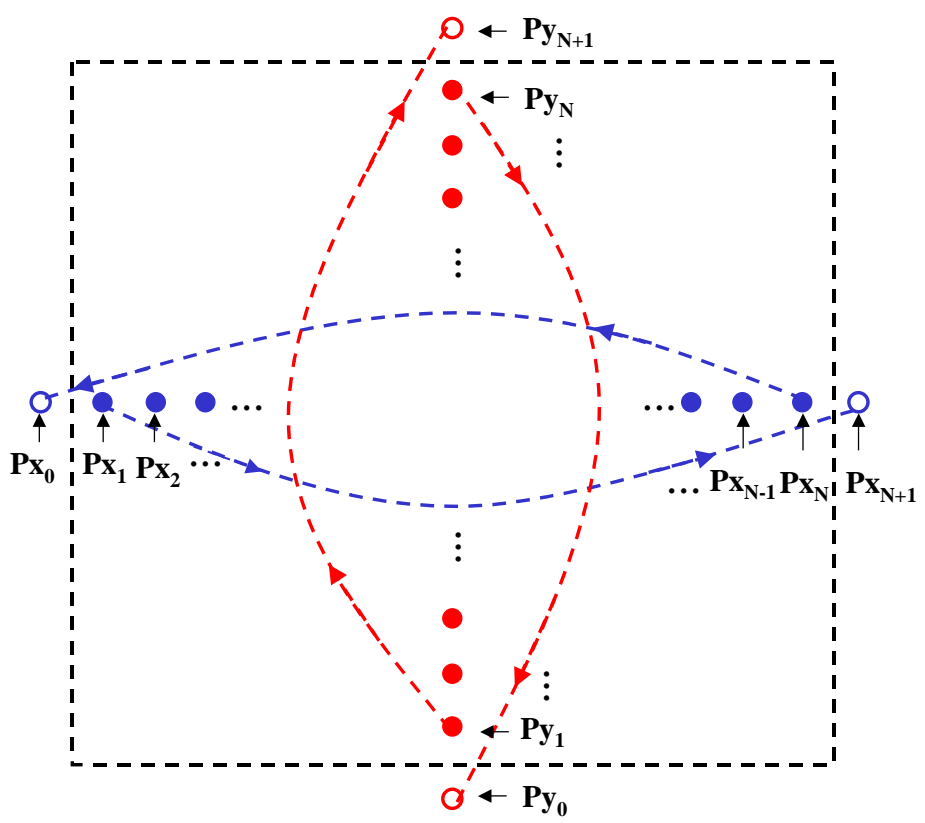

Figura 2.3- Condição de contorno periódica. 
Esta condição de contorno pode ser descrita matematicamente pelas equações:

$$
\begin{aligned}
& \Phi\left(P x_{0}\right)=\Phi\left(P x_{N}\right) \cdot \exp \left(j \cdot k_{x} \cdot L_{x}\right) \\
& \Phi\left(P x_{N}\right)=\Phi\left(P x_{0}\right) \cdot \exp \left(j \cdot k_{x} \cdot L_{x}\right) \\
& \Phi\left(P y_{0}\right)=\Phi\left(P y_{N}\right) \cdot \exp \left(j \cdot k_{y} \cdot L_{y}\right) \\
& \Phi\left(P y_{N}\right)=\Phi\left(P y_{0}\right) \cdot \exp \left(j \cdot k_{y} \cdot L_{y}\right)
\end{aligned}
$$

onde $\Phi$ é o valor complexo do campo, $k_{x}$ e $k_{y}$ são as constantes de propagação nas direções x e y, respectivamente e $L_{x}$ e $L_{y}$ são as dimensões da célula unitária nas direções x e y, respectivamente. $\mathrm{O}$ termo exponencial é responsável pela devida correção de fase no campo. Desta forma, a condição de contorno modifica-se para cada ponto de simetria. A Figura 2.4 exemplifica a célula unitária de uma estrutura formada por bastões cilíndricos dispostos num arranjo quadrado.

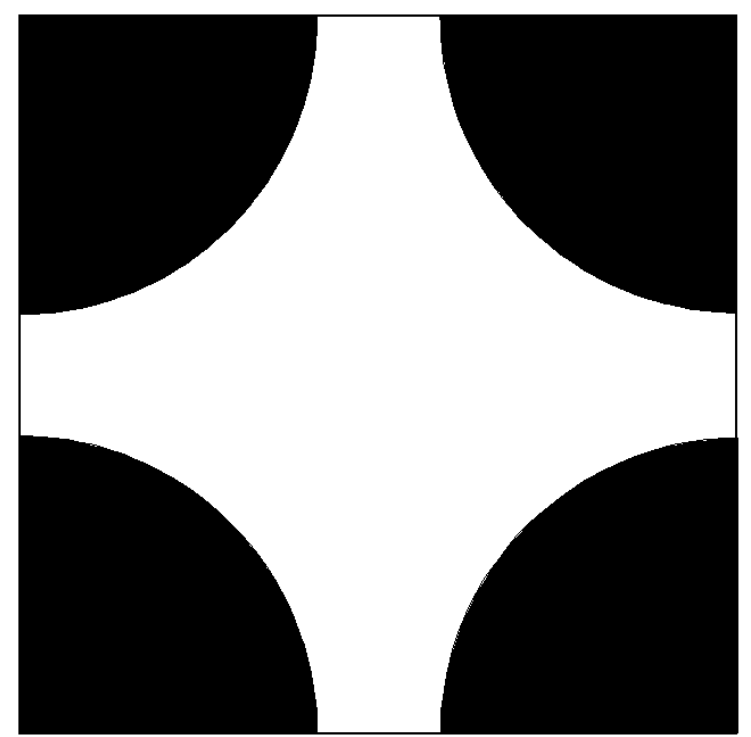

Figura 2.4- Janela computacional de uma célula de um cristal bidimensional formado por bastões cilíndricos numa estrutura quadrada. Cada região em negro representa um quarto de um bastão.

No entanto, para o caso do cálculo do diagrama de bandas de um cristal contendo um defeito, é utilizada a técnica da supercélula. Esta técnica consiste em considerar uma estrutura que contenha o defeito, mas que não seja formada pela célula unitária e sim por uma célula maior, conforme exemplifica a Figura 2.5. 


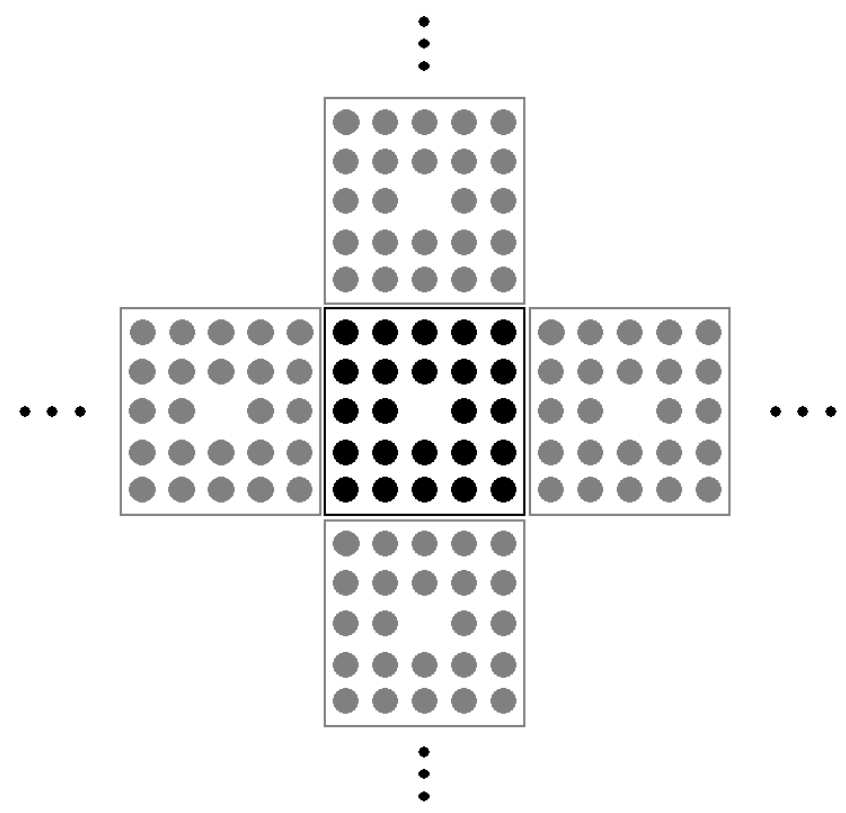

Figura 2.5- Esquema de supercélula formada a partir do cristal da Figura 2.4 contendo um defeito. As células em cinza representam o cristal fora da janela computacional.

Como pode ser observado na Figura 2.5, o espaço é considerado como sendo preenchido por seções idênticas à contida na janela computacional, o que corresponde ao cristal real a menos dos defeitos indesejáveis existentes fora da janela computacional. Devido à inclusão destes defeitos, a supercélula deve conter tantos elementos quantos forem necessários para que a influência dos defeitos presentes fora da janela seja desprezível sobre o cálculo do diagrama de bandas. Explicando de outra forma, pode-se dizer que a supercélula deve ser formada por um número suficiente de células primárias de forma que os defeitos da estrutura estejam desacoplados. Deve-se salientar ainda, que a presença do defeito não altera o diagrama de bandas, apenas insere um nível extra que pode ser localizado dentro da banda proibida.

Apesar do método FDTD ser um método de ordem $\mathrm{N}$, devido à complexidade das estruturas de interesse torna-se necessário um alto esforço computacional. Uma das saídas para este problema é a utilização de técnicas de computação paralela, que são discutidas na seção a seguir.

\subsubsection{Paralelização do algoritmo FDTD}

Vários grupos de pesquisa vêm buscando desenvolver algoritmos paralelos eficientes para implementação do método FDTD. Nestes algoritmos a decomposição, ou 
seja, a divisão do trabalho computacional, é do tipo decomposição por domínio. Esta decomposição por domínio pode ser unidimensional, ou bidimensional, conforme ilustrado na Figura 2.6.

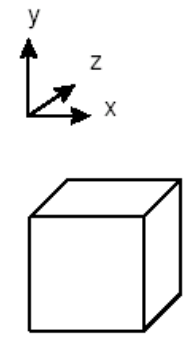

(a)

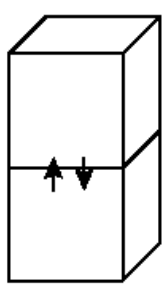

(b)

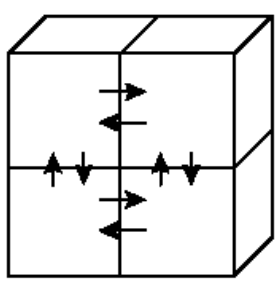

(c)

Figura 2.6- Exemplos de decomposição por domínio. a) Tarefa única. b) Decomposição unidimensional. c) Decomposição bidimensional.

No caso unidimensional, o número de comunicações estabelecidas entre os processos é menor enquanto que a quantidade de dados comunicados a cada vez é maior. Este tipo de decomposição é vantajoso quando o "overhead" de comunicação é alto. Isto vale para o caso específico de "clusters" pois gasta-se um tempo considerável para o envio de pacotes de dados em redes do tipo TCP/IP. A Figura 2.7 ilustra como o tempo adicional que se despende com a comunicação, aqui chamado de "custo de comunicação" afeta o desempenho de algoritmos paralelos [2.9].

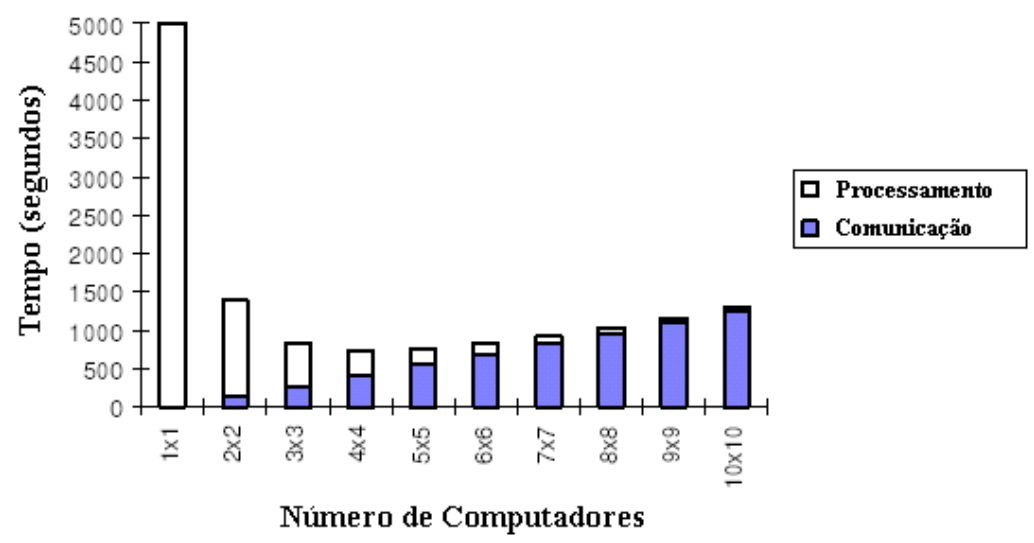

Figura 2.7- Tempo total de computação em função do número de computadores para um número fixo de operações para um algoritmo FDTD rodando em um "cluster" de microcomputadores [2.7]. 
Pode-se notar que, após um determinado ponto, o tempo total de processamento passa a aumentar com o aumento do número de computadores. Devido a este fato, o tempo de comunicação deve ser cuidadosamente estimado (e minimizado) na montagem de um sistema para processamento paralelo.

Após cuidadosa pesquisa bibliográfica [2.10-2.15], optou-se pela abordagem proposta em [2.14], onde a decomposição é por domínio, unidimensional, utilizando uma célula modificada de forma a minimizar o custo gerado pelas comunicações entre os processos. A Figura 2.8 mostra esquematicamente a célula tridimensional modificada.

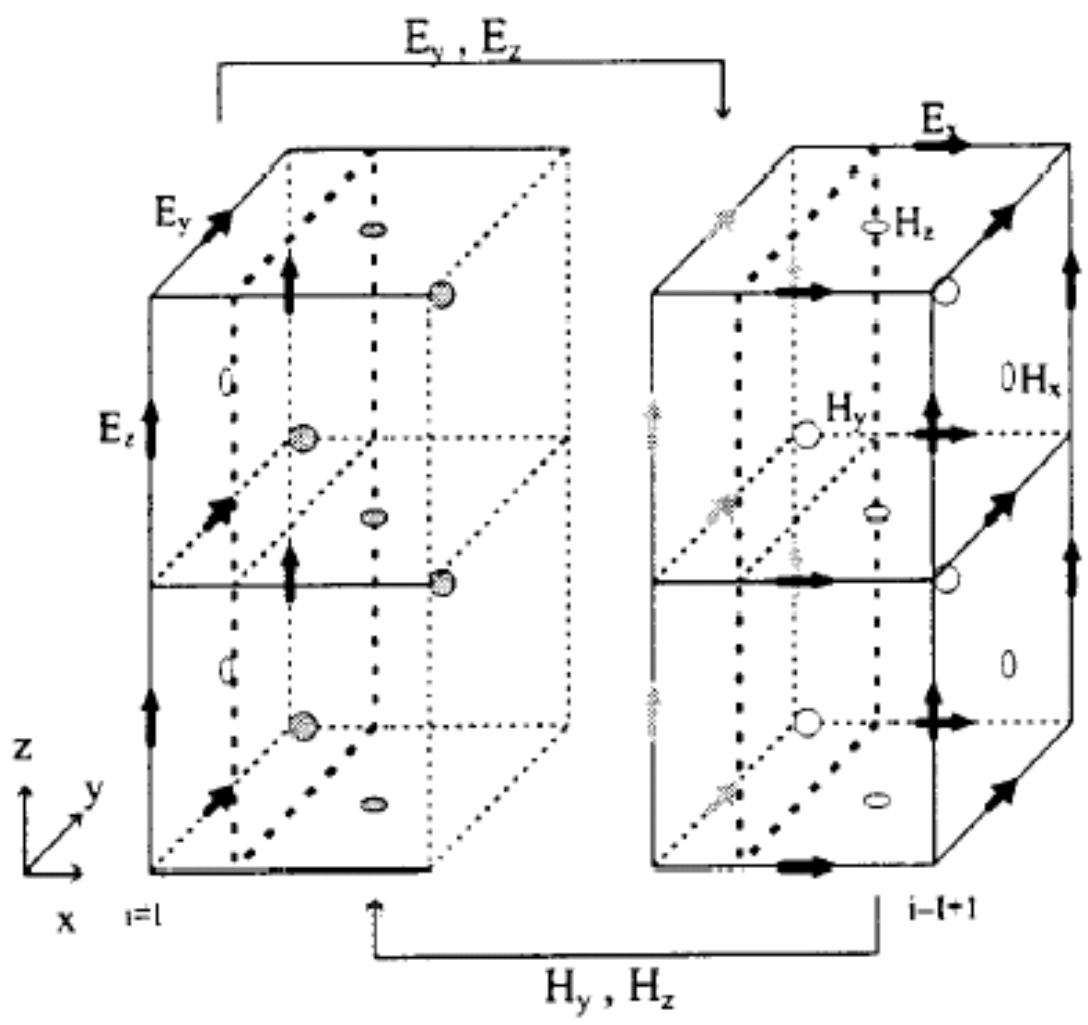

Figura 2.8-Célula modificada para minimização do custo com comunicação.

Analisando a célula da Figura 2.8 verifica-se que apenas duas componentes de campo necessitam ser passadas para a célula vizinha a cada etapa do método FDTD. Diferentemente, a utilização da célula original necessitaria que quatro componentes fossem comunicadas a cada etapa. Desta forma, o custo de comunicação é minimizado. 
Para a implementação de códigos com paralelismo necessita-se, em geral, de máquinas específicas. No entanto, estas máquinas costumam ter um custo extremamente alto. $\mathrm{Na}$ busca de alternativas mais acessíveis para tais máquinas, encontrou-se uma saída que se tornou amplamente utilizada atualmente. Trata-se da utilização de "clusters" de computadores, ou seja, computadores pessoais ligados em rede para a execução paralela de tarefas. A Figura 2.9 exemplifica este tipo de arranjo.

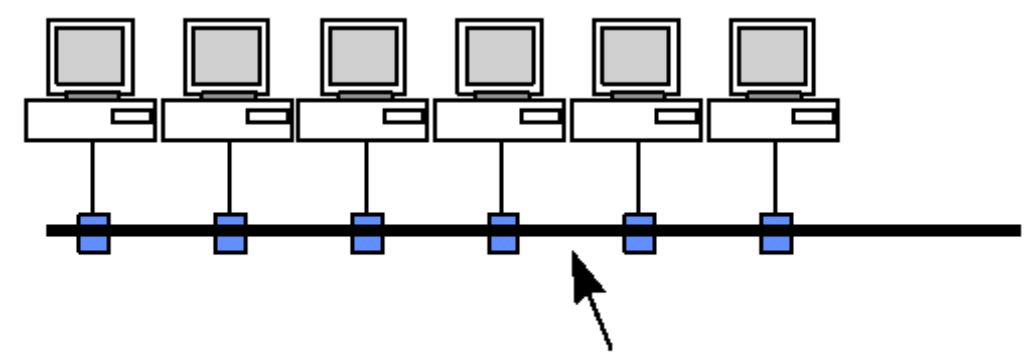

Rede de $100 \mathrm{Mbps}$

Figura 2.9- Exemplo de "cluster" de microcomputadores.

Um grande problema, neste tipo de configuração, é o balanceamento de carga, ou seja, a correta distribuição de tarefas para cada máquina. Este problema acontece por dois motivos: estes "clusters" são geralmente compostos por tipos diferentes de máquinas com capacidade computacional distinta e a utilização destas máquinas pelos usuários ocorre de forma não previsível. Isso torna a programação para este tipo de ambiente uma tarefa extremamente complexa. Como alternativa, são montadas máquinas dedicadas, compostas por CPUs de microcomputadores onde apenas uma das máquinas é dotada dos periféricos (monitor, mouse, teclado). Assim, originaram-se as primeiras configurações, chamadas de "Beowulf". Um exemplo de desempenho do FDTD em "beowulfs", retirado de [2.9], é mostrado na Figura 2.10, que compara o desempenho de um código FDTD paralelo utilizando procedimento comunicação do tipo tabuleiro de xadrez (red-black), envio e recebimento simultâneo (SENDRECV) e envio simples não bloqueador (ISEND).

Na Figura 2.10 observa-se um comportamento inusitado, pois o aumento de performance é superlinear em relação ao aumento no número de computadores. Este comportamento deve-se ao fato de que com a divisão dos dados entre as tarefas, cada computador individualmente recebe matrizes e vetores menores. Esta diminuição na quantidade de dados, por sua vez, estabelece uma melhoria considerável de eficiência no gerenciamento da memória cache do computador, dando origem ao comportamento superlinear. 


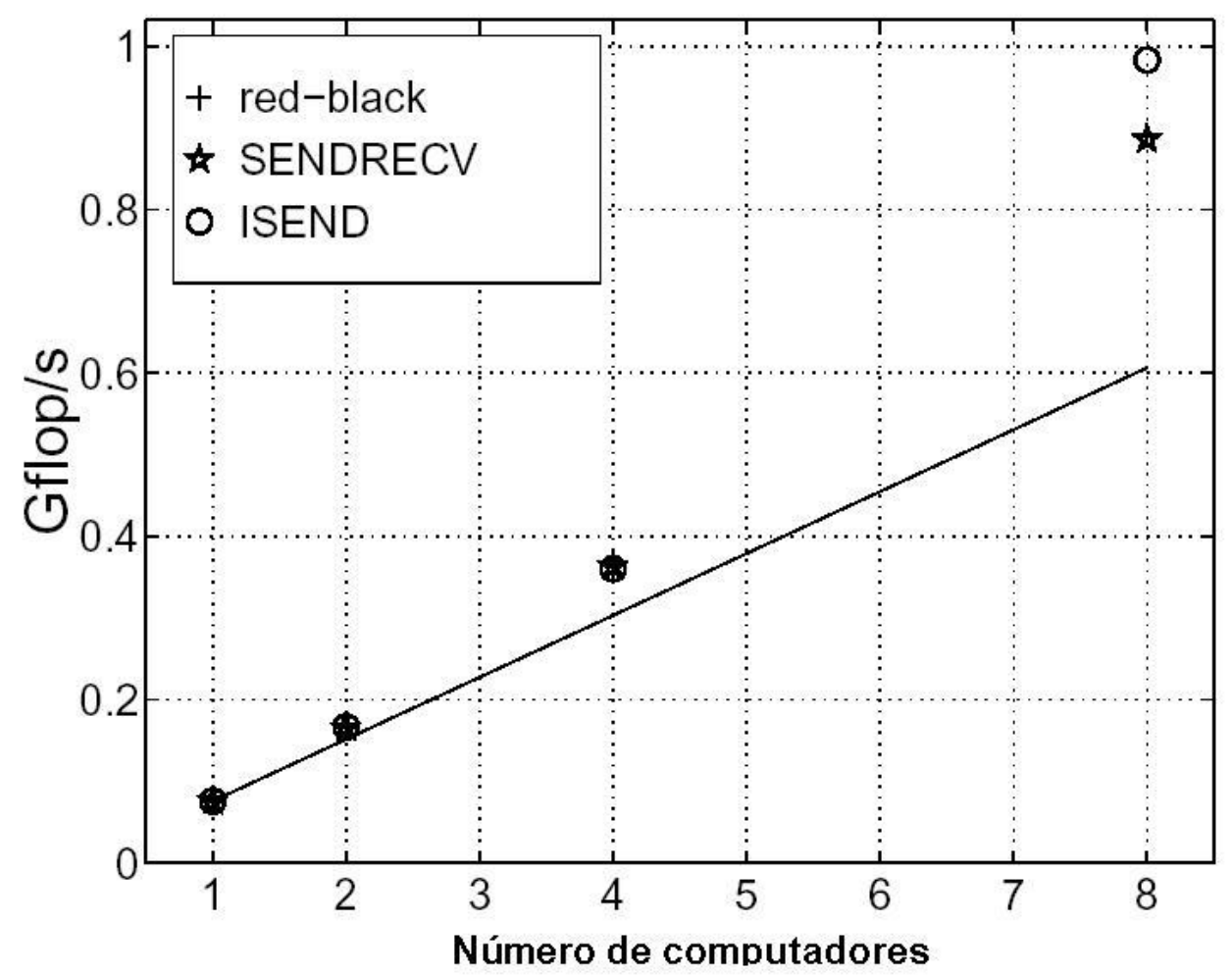

Figura 2.10- Exemplo de comportamento do FDTD em "beowulf" formado por computadores DEC Alpha [2.9] utilizando três formas diferentes de comunicação entre os computadores.

Visando testar a viabilidade de implementação de uma versão paralela do método FDTD utilizando biblioteca de passagem de mensagem MPI sobre ambiente Windows 2000, neste trabalho foi desenvolvida uma versão paralela inicial seguindo o procedimento da referência [2.15]. Esta versão foi testada utilizando dois computadores ligados diretamente por cabo UTP com placas de rede Ethernet de 100Mbps. Os resultados, ainda que preliminares, indicam a viabilidade da aplicação de beowulfs na modelagem de dispositivos de cristal fotônico usando FDTD. A Figura 2.11 mostra o tempo de processamento do programa FDTD paralelo, usado no cálculo de diagramas de banda para cristais bidimensionais, em função do tamanho do problema para um e dois processadores. 


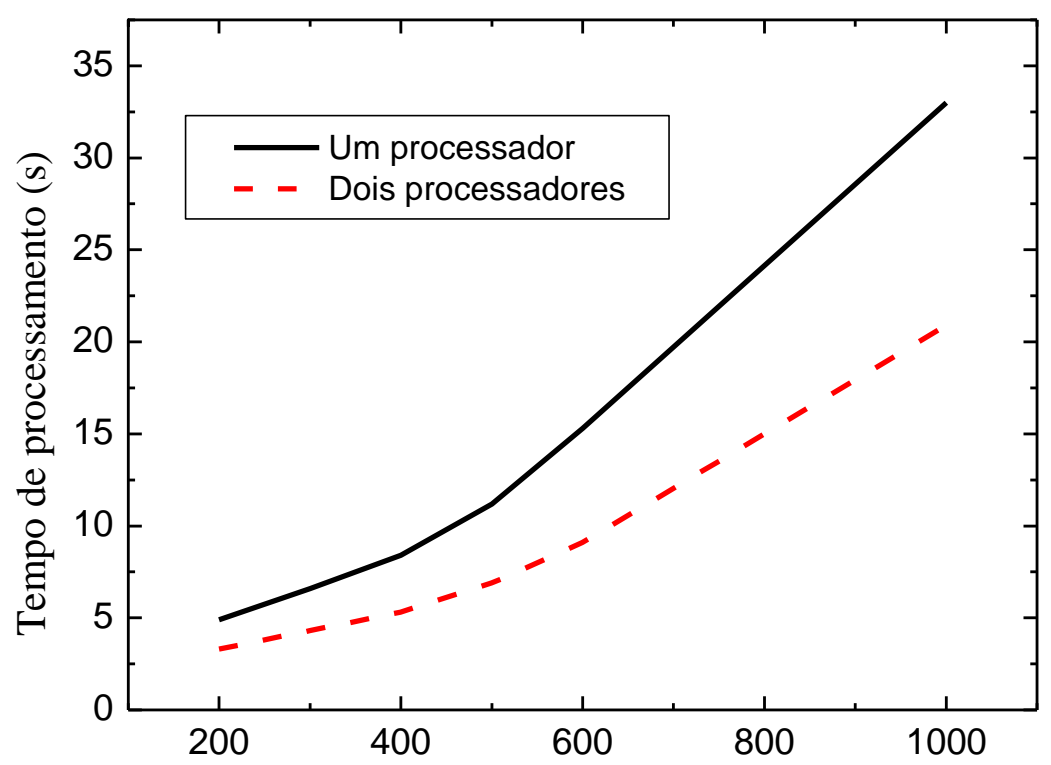

Número de pontos de discretização em uma dimensão

Figura 2.11- Tempo de processamento para o método FDTD em função do tamanho do problema para a modelagem de cristais fotônicos obtidos neste trabalho.

Pode-se verificar que a eficiência do algoritmo paralelo aumenta com o tamanho do problema, para problemas tridimensionais é prevista uma eficiência ainda maior.

\subsection{Aferição do método FDTD}

No intuito de aferir numericamente a exatidão do programa, foram gerados alguns resultados numéricos para serem cotejados com resultados publicados na literatura.

\subsubsection{Resultados numéricos para propagação no plano}

Primeiramente, devem ser definidos os pontos de simetria para as estruturas utilizadas. A Tabela 2.1 mostra os valores para as componentes do vetor k para cada ponto, onde $a$ é a constante de rede. 
Tabela 2.1 - Definição dos pontos de simetria para os cristais estudados.

\begin{tabular}{|c|c|c|}
\hline Pontos de simetria & $\mathrm{kx}(\mathrm{rad} / \mathrm{m})$ & $\mathrm{ky}(\mathrm{rad} / \mathrm{m})$ \\
\hline$\Gamma$ & 0 & 0 \\
\hline $\mathrm{X} / 2$ & $\frac{\pi}{2 a}$ & 0 \\
\hline $\mathrm{X}$ & $\frac{\pi}{a}$ & 0 \\
\hline $\mathrm{X}-\mathrm{M}$ & $\frac{\pi}{a}$ & $\frac{\pi}{2 a}$ \\
\hline $\mathrm{M}$ & $\frac{\pi}{a}$ & $\frac{\pi}{a}$ \\
\hline $\mathrm{M} / 2$ & $\frac{\pi}{2 a}$ & $\frac{\pi}{2 a}$ \\
\hline
\end{tabular}

Na Ref. [2.16], encontram-se resultados para o método de ondas planas PWM e para o método proposto pelo autor, chamado de MG (do inglês, Mult Grid). A estrutura analisada no artigo é formada por cilindros dielétricos com $\varepsilon_{\mathrm{r}}$ igual a 13 , dispostos no ar $\left(\varepsilon_{\mathrm{r}}=1\right)$ numa rede quadrada. A razão entre raio dos cilindros $r$ e sua separação $a$ é dada por $r / a=0,45$. Como pode ser observado na Tabela 2.2 , houve boa concordância entre os valores obtidos com o método FDTD e os publicados em [2.16].

Tabela 2.2- Resultados obtidos através do método FDTD em comparação com resultados publicados em [2.16]. (Valores calculados no ponto de simetria $X$ para polarização TM).

\begin{tabular}{cccc}
\hline Bandas & PWM & MG & FDTD \\
\hline 1 & 0,15163 & 0,15071 & 0,1507 \\
2 & 0,19066 & 0,18778 & 0,1878 \\
3 & 0,31962 & 0,31851 & 0,3169 \\
4 & 0,36678 & 0,36219 & 0,3632 \\
\hline
\end{tabular}

\subsubsection{Resultados numéricos para propagação fora do plano}

Um cristal bidimensional é formado por uma estrutura com periodicidade em duas dimensões. No entanto, a propagação da luz nestes cristais pode dar-se fora do plano de periodicidade do mesmo. A análise deste tipo de propagação, que ocorre fora do plano X-Y, 
pode também ser realizada sem dificuldades através do método FDTD, conforme discutido na Seção 2.2. A Tabela 2.3 mostra os resultados obtidos pelo método FDTD em contraste com resultados retirados de um gráfico apresentado na referência [2.17]. Por isso, estes resultados são mostrados aqui com baixa precisão, ou seja, apenas duas casas decimais.

Pode-se observar que os valores apresentados na Tabela 2.3 para o método FDTD apresentam excelente concordância com os valores retirados da Ref. [2.17] para todas os pontos de simetria no espaço $k$. Conclui-se, portanto que o método é, em princípio, tão adequado para o cálculo do diagrama de bandas de cristais fotônicos quanto aquele.

Tabela 2.3- Resultados obtidos para a freqüência normalizada através do método FDTD considerando-se um cristal formado por cilindros dielétricos com $\varepsilon_{\mathrm{r}}=8,9$, em disposição quadrada no ar e com relação entre raio e separação $r / a=0,2$ e constante de propagação fora do plano $k z=0,4 \pi / a$ em comparação com os resultados derivados de [2.17].

\begin{tabular}{|c|c|c|c|c|c|c|}
\hline & \multicolumn{2}{|c|}{ X/2 } & \multicolumn{2}{c|}{ X } & \multicolumn{2}{c|}{ X-M } \\
\hline $\begin{array}{c}\text { Ban } \\
\text { das }\end{array}$ & $\begin{array}{r}\mathrm{P} \\
\mathrm{WM}\end{array}$ & $\begin{array}{c}\mathrm{FD} \\
\mathrm{TD}\end{array}$ & $\begin{array}{r}\mathrm{P} \\
\mathrm{WM}\end{array}$ & $\begin{array}{c}\mathrm{FD} \\
\mathrm{TD}\end{array}$ & $\begin{array}{r}\mathrm{P} \\
\mathrm{WM}\end{array}$ & $\begin{array}{c}\mathrm{FD} \\
\mathrm{TD}\end{array}$ \\
\hline \multirow{2}{*}{1} & 0,2 & 0,2 & 0,3 & 0,3 & 0,3 & 0,3 \\
& 4 & 48 & 4 & 35 & 5 & 47 \\
\hline \multirow{2}{*}{2} & 0,2 & 0,2 & 0,4 & 0,4 & 0,5 & 0,4 \\
& 8 & 83 & 4 & 43 & 0 & 91 \\
\hline \multirow{2}{*}{3} & 0,5 & 0,5 & 0,4 & 0,4 & 0,5 & 0,5 \\
& 4 & 31 & 7 & 63 & 0 & 02 \\
\hline \multirow{2}{*}{4} & 0,6 & 0,6 & 0,5 & 0,4 & 0,5 & 0,5 \\
& 2 & 10 & 0 & 98 & 3 & 33 \\
\hline \multirow{2}{*}{5} & 0,6 & 0,6 & 0,6 & 0,6 & 0,6 & 0,6 \\
& 6 & 47 & 6 & 58 & 2 & 16 \\
\hline \multirow{2}{*}{6} & 0,7 & 0,7 & 0,7 & 0,7 & 0,6 & 0,6 \\
& 0 & 00 & 25 & 21 & 8 & 83 \\
\hline 7 & 0,7 & 0,7 & 0,8 & 0,7 & 0,7 & 0,7 \\
& 6 & 57 & 0 & 89 & 7 & 62 \\
\hline
\end{tabular}

\begin{tabular}{|r|r|r|r|}
\hline \multicolumn{2}{|c|}{ M } & \multicolumn{2}{c|}{ M/2 } \\
\hline PM & FD & P & FD \\
TD & WM & TD \\
\hline 0,3 & 0,3 & 0,3 & 0,2 \\
75 & 73 & 0 & 89 \\
\hline
\end{tabular}




\begin{tabular}{|c|c|c|c|}
\hline 0,5 & 0,5 & 0,3 & 0,3 \\
5 & 47 & 6 & 60 \\
\hline 0,5 & 0,5 & 0,5 & 0,5 \\
5 & 47 & 4 & 28 \\
\hline 0,5 & 0,5 & 0,6 & 0,5 \\
7 & 75 & 0 & 93 \\
\hline 0,6 & 0,6 & 0,6 & 0,6 \\
5 & 47 & 3 & 30 \\
\hline 0,7 & 0,7 & 0,7 & 0,6 \\
2 & 08 & 0 & 96 \\
\hline 0,7 & 0,7 & 0,7 & 0,7 \\
2 & 19 & 5 & 43 \\
\hline
\end{tabular}

\subsection{Diagramas de banda gerados pelo método FDTD}

Diversos diagramas de banda para cristais bidimensionais foram gerados empregando o método FDTD. A intenção é gerar um conjunto de diagramas que possam ser usados no dimensionamento dos cristais visando sua aplicação tanto em óptica integrada quanto em fibras microestruturadas.

O primeiro cristal analisado foi o composto por bastões de dielétrico $\left(\varepsilon_{\mathrm{r}}=8.9\right) \mathrm{com}$ raio $r=0.2 a$, dispostos numa matriz quadrada no ar [2.18]. Primeiramente, foi gerado o diagrama de bandas para o caso de propagação no plano $\left(\mathrm{k}_{\mathrm{z}}=0\right)$. Neste caso, duas polarizações distintas podem ser obtidas: TE e TM. Na polarização TE o campo magnético é perpendicular ao plano definido pelo eixo $\mathrm{z}$, enquanto na polarização TM o campo elétrico é perpendicular ao plano formado pelo eixo z. As Figuras 2.12 e 2.13 mostram os diagramas de bandas para as polarizações TE e TM, respectivamente. 


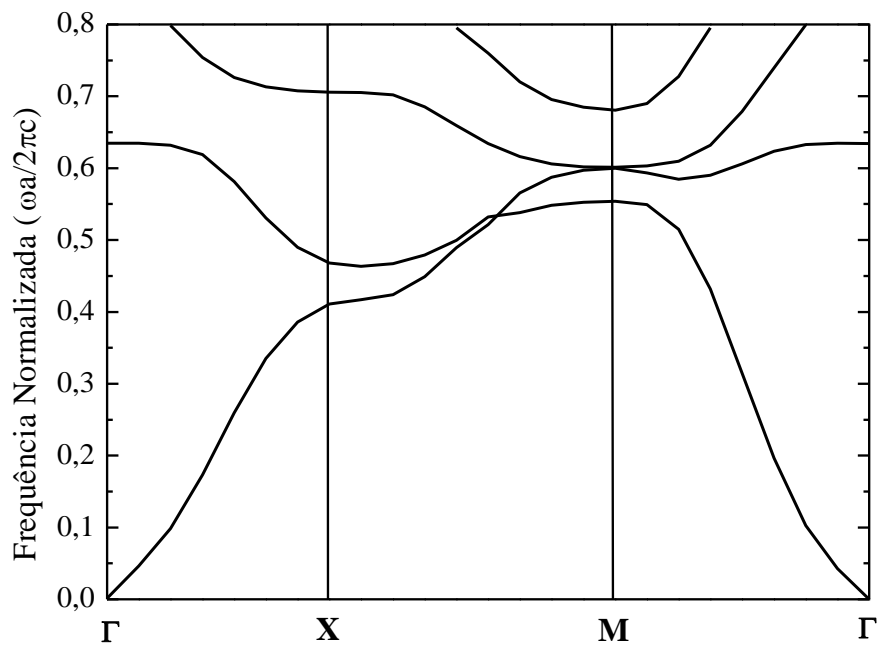

Figura 2.12- Diagrama de bandas para a propagação no plano para um cristal bidimensional formado por bastões dielétricos em disposição quadrada na polarização TE.

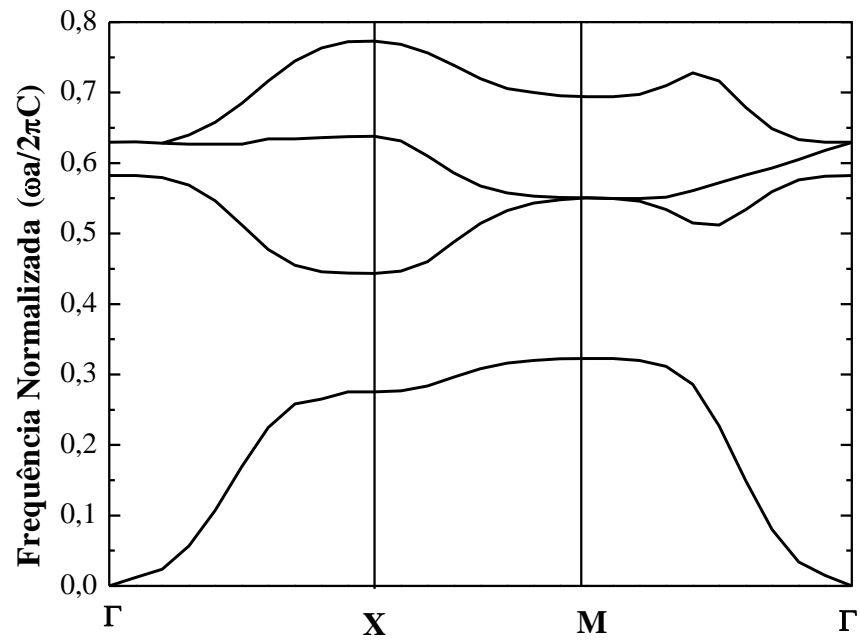

Figura 2.13-Diagrama de bandas para a propagação no plano para um cristal bidimensional formado por bastões dielétricos em disposição quadrada na polarização TM.

Como pode ser observado, o diagrama de bandas para a polarização TM exibe uma banda proibida em torno de 0,35 (freqüência normalizada), enquanto para a polarização TE não existe banda proibida alguma. Este tipo de cristal é dito ter uma banda proibida nãocompleta. O diagrama de bandas fora do plano $\left(\mathrm{k}_{\mathrm{z}}=0,4 \pi / \mathrm{a}\right)$ para este tipo de cristal é 
mostrado na Figura 2.14. Como pode ser observado, mesmo para propagação fora do plano, não existe banda proibida para este tipo de estrutura.

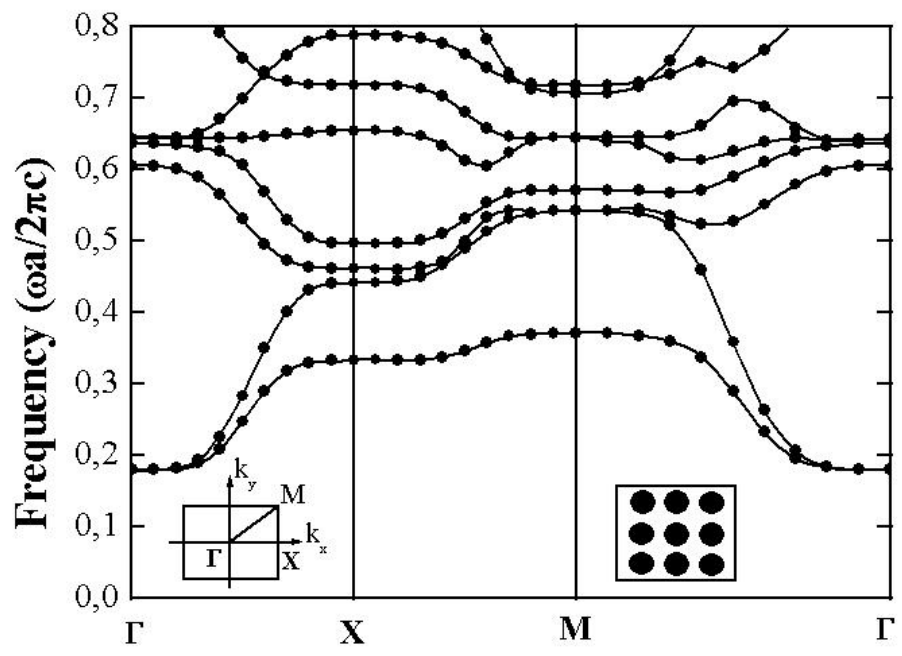

Figura 2.14- Diagrama de bandas para propagação fora do plano, $\mathrm{Kz}=0.4 \pi / \mathrm{a}$, para bastões dielétricos no ar.

Outro tipo de estrutura que pode apresentar interesse na aplicação em fibras microestruturadas é formado por furos de ar elípticos, dispostos numa matriz retangular sobre uma base de material semicondutor ou dielétrico. Para esta estrutura são definidos os parâmetros $1_{x}$ e $1_{y}$, que são os períodos da rede nas direções x e y respectivamente. Também são definidas as constantes $b$, que representa o raio dos furos na direção x e $a$, representando o raio na direção y. Este tipo de cristal foi proposto em [2.19] por apresentar uma banda proibida significativa. A Figura 2.15 mostra o diagrama de bandas para um cristal formado por furos elípticos de ar em arseneto de gálio, seguindo a proposta da referência [2.19].

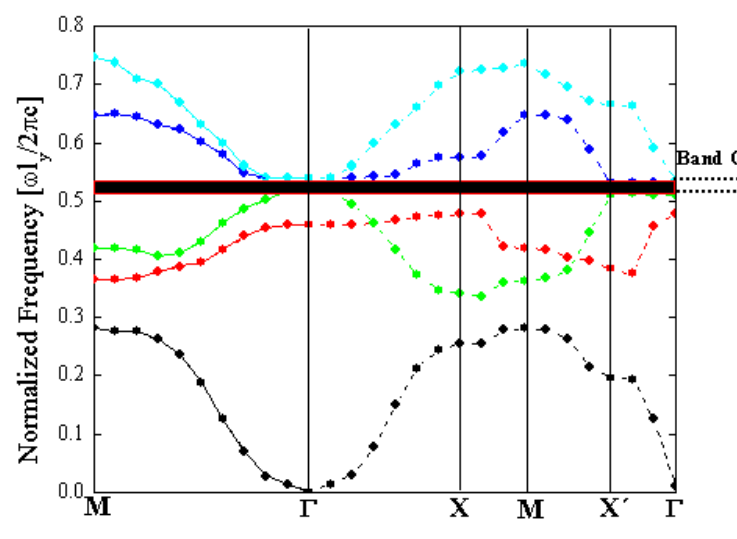

TM

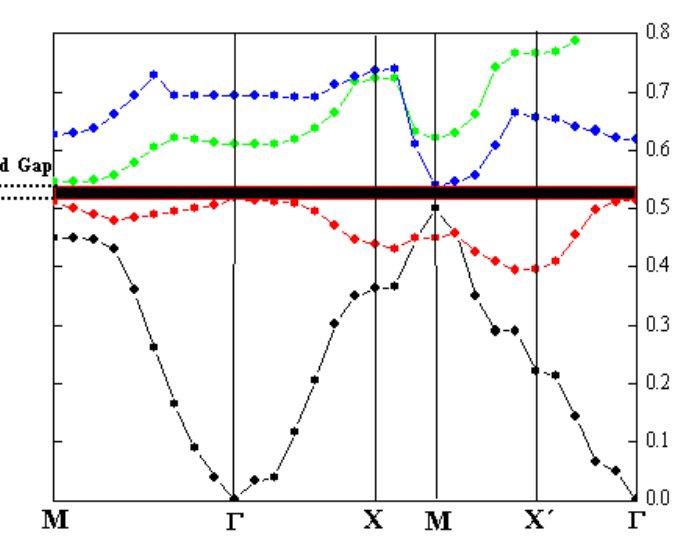

TE 
Figura 2.15- Diagrama de bandas para um cristal formado por furos elípticos de ar em arseneto de gálio com parâmetros: $1_{\mathrm{x}} / 1_{\mathrm{y}}=0,77, \mathrm{a}=0.451_{\mathrm{y}}, \mathrm{b}=0,381_{\mathrm{y}}$.

Como pode ser observado na Figura 2.15, este tipo de cristal pode ser promissor para aplicação em fibras microestruturadas por fornecer uma banda proibida relativamente larga.

\subsection{Análise de Guias de Onda}

Para análise de guias de onda, a única alteração necessária no algoritmo é a adequação das condições de contorno, isto é, de periódica para transparente. A condição de contorno transparente [2.20] é implementada através das equações:

$$
\begin{aligned}
& \Phi\left(P x_{0}\right)=\Phi\left(P x_{N}\right) \cdot \exp \left(j \cdot k b_{i x} \cdot \Delta x\right) \\
& \Phi\left(P x_{N}\right)=\Phi\left(P x_{0}\right) \cdot \exp \left(-j \cdot k b_{f x} \cdot \Delta x\right) \\
& \Phi\left(P y_{0}\right)=\Phi\left(P y_{N}\right) \cdot \exp \left(j \cdot k b_{i y} \cdot \Delta y\right) \\
& \Phi\left(P y_{N}\right)=\Phi\left(P y_{0}\right) \cdot \exp \left(-j \cdot k b_{f y} \cdot \Delta y\right)
\end{aligned}
$$

onde as constantes $k b$ são dadas por:

$$
\begin{aligned}
& k b_{i x}=-j \cdot \Delta x \cdot \log \left(\frac{\Phi\left(P x_{1}\right)}{\Phi\left(P x_{2}\right)}\right) \\
& k b_{f x}=j \cdot \Delta x \cdot \log \left(\frac{\Phi\left(P x_{N}\right)}{\Phi\left(P x_{N-1}\right)}\right) \\
& k b_{i y}=-j \cdot \Delta y \cdot \log \left(\frac{\Phi\left(P y_{1}\right)}{\Phi\left(P y_{2}\right)}\right) \\
& k b_{f y}=j \cdot \Delta y \cdot \log \left(\frac{\Phi\left(P y_{N}\right)}{\Phi\left(P y_{N-1}\right)}\right)
\end{aligned}
$$

Através da substituição da condição de contorno periódica, dada pelas Equações (2.16), pela condição de contorno transparente, dada por (2.17), as fibras microestruturadas 
podem também ser analisadas como guias de onda. Isso demonstra a versatilidade do método.

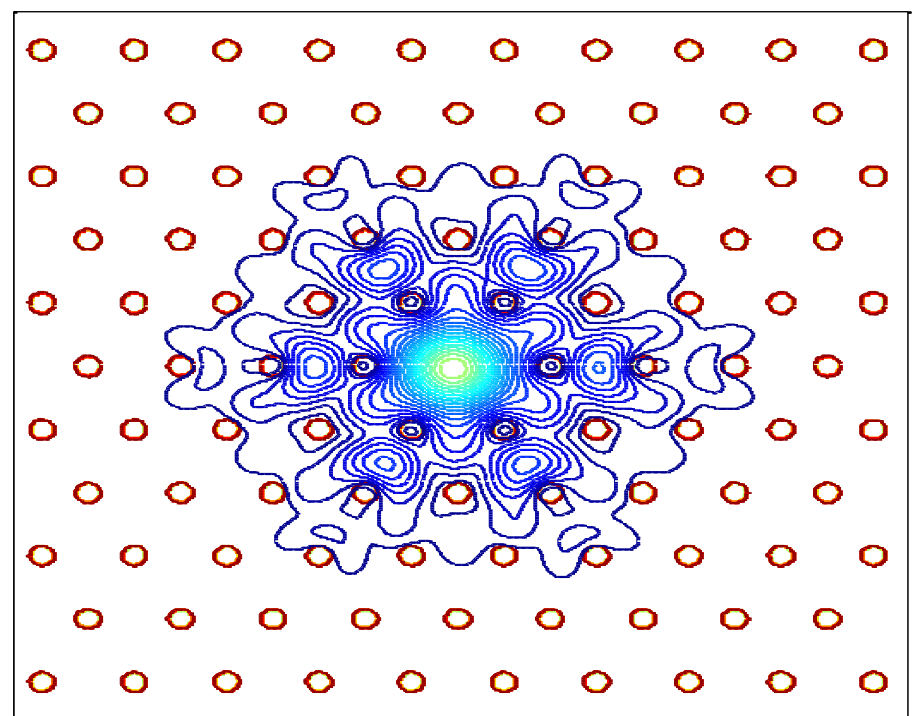

Figura 2.16- Distribuição de campo calculada a partir do método FDTD.

A Figura 2.16 mostra a distribuição de campo para a componente $H_{x}$, para uma fibra microestruturada com pitch de $2,3 \mu \mathrm{m}$, raio dos furos de $0,3 \mu \mathrm{m}$ e comprimento de onda de operação $\lambda$ igual a $1,0 \mu \mathrm{m}$.

Pode-se concluir, através dos resultados mostrados, que o método FDTD é um método versátil e eficiente para a síntese (cálculo do diagrama de bandas) e pode também ser utilizado na análise (solução do guia de onda) de fibras de cristal fotônico.

\subsection{O Método SOR (do inglês, Successive Over Relaxation)}

Os métodos numéricos geralmente utilizados na modelagem das características de dispersão das fibras microestruturadas são métodos vetoriais, uma vez que encontra-se freqüentemente na literatura a afirmação de que, para modelar com precisão fibras com uma grande fração de ar, é necessário o emprego de tais métodos, pois a aproximação escalar não gera bons resultados. No entanto nenhum esforço foi observado na literatura para modelar as fibras microestruturadas através de uma aproximação semivetorial. Neste intuito, foi proposto um formalismo semivetorial baseado no método SOR (do inglês Successive Over Relaxation). A aproximação semivetorial considera as propriedades de polarização do campo 
eletromagnético através de um cálculo cuidadoso da derivada dos campos normal e tangencial nas interfaces dielétricas. Todavia, nesta aproximação, as componentes de campo ortogonais (direção x e y) são consideradas desacopladas. Em outras palavras, os modos são considerados linearmente polarizados. Embora esta consideração possa não ser estritamente válida para todos os casos de interesse, é demonstrado que a aproximação não afeta consideravelmente a precisão dos resultados obtidos. Foram desenvolvidas três versões para o método SOR considerando as aproximações escalar, semivetorial e vetorial completa, sendo que as versões escalar e vetorial completa estão descritas no Apêndice I. Uma versão vetorial completa considerando a presença de material magneto-óptico foi ainda implementada, visando sua utilização na modelagem do isolador óptico a fibra descrito no Capítulo 3. Esta versão encontra-se descrita no Apêndice II. Nesta seção será descrita detalhadamente a versão semivetorial do método SOR.

A derivação do formalismo semivetorial inicia-se com a equação semivetorial de Helmholtz, escrita aqui em termos do campo magnético polarizado na direção x [2.21]:

$$
-\beta^{2} H^{x}+\frac{d^{2}}{d x^{2}} H^{x}+n^{2} \frac{d}{d y}\left(\frac{1}{n^{2}} \frac{d}{d y} H^{x}\right)+\kappa^{2} n^{2} H^{x}=0
$$

onde $n$ descreve o perfil de índice de refração, $\kappa$ é o número de onda e $\beta$ é a constante de propagação. A expansão da Equação (2.19) em diferenças finitas pode ser obtida pela representação do perfil de índice de refração, $n$, em um esquema de cinco pontos, com as derivadas transversais do campo descritas como [2.21]:

$$
\begin{aligned}
& \frac{d^{2}}{d x^{2}} H^{x}=\frac{H_{i+1, j}^{x}-2 H_{i, j}^{x}+H_{i-1, j}^{x}}{h^{2}} \\
& n^{2} \frac{d}{d y}\left(\frac{1}{n^{2}} \frac{d}{d y} H^{x}\right)=\frac{a_{i, j} H_{i, j+1}^{x}-2 b_{i, j} H_{i, j}^{x}+c_{i, j} H_{i, j-1}^{x}}{h^{2}}
\end{aligned}
$$

sendo $h$ a distância entre dois pontos adjacentes da malha e os coeficientes $a, b$ e $c$ são relacionados com o perfil de índice da seguinte forma:

$$
a_{i, j}=\frac{2 n_{i, j}^{2}}{n^{2}{ }_{i, j+1}+n^{2}{ }_{i, j}}, c_{i, j}=\frac{2 n_{i, j}^{2}}{n^{2}{ }_{i, j-1}+n^{2}{ }_{i, j}} \text { e } b_{i, j}=\left(a_{i, j}+c_{i, j}\right) / 2
$$


Vale mencionar que em uma aproximação escalar, a derivada parcial na direção y pode ser tratada como uma derivada de segunda ordem convencional e portanto $a_{i, j}=b_{i, j}=c_{i, j}=1$.

Substituindo (2.20) e (2.21) em (2.19) e isolando o termo central $H_{i, j}^{x}$, resulta:

$$
H_{i, j}^{x \text { int }}=\frac{\frac{1}{h^{2}}\left(H_{i+1, j}^{x}+H_{i-1, j}^{x}+a_{i, j} H_{i, j+1}^{x}+c_{i, j} H_{i, j-1}^{x}\right)}{\left(\beta^{2}-\kappa^{2} n^{2}+\frac{2}{h^{2}}+\frac{2 b_{i, j}}{h^{2}}\right)}
$$

O parâmetro $\beta$, constante de propagação longitudinal, pode ser calculada a cada iteração pela relação variacional semivetorial [2.22]:

$$
\begin{aligned}
& \beta^{2}=\frac{k^{2} \int n^{2}\left|H^{x}\right|^{2} d x d y-\int\left|\frac{d}{d x} H^{x}\right|^{2} d x d y+P}{\int\left|H^{x}\right|^{2} d x d y} \\
& P=\int n^{2} \frac{d}{d y}\left(\frac{1}{n^{2}} \frac{d}{d y}\left(H^{x}\right)\right) \cdot H^{x *} d x d y
\end{aligned}
$$

onde $H^{x^{*}}$ representa o complexo conjugado do campo magnético polarizado na direção $\mathrm{x}$. O primeiro e o segundo termos no numerador da Equação (2.24) são os usuais na aproximação escalar enquanto o termo $P$ pode ser considerado como uma correção semivetorial [2.22].

A Equação (2.23) pode então ser utilizada para gerar um esquema iterativo para aproximar a distribuição $H^{x}$. No presente caso, o esquema iterativo é construído em termos do método da sobre-relaxação sucessiva, SOR. Este método corrige o campo de uma forma sobre estimada a cada iteração, conforme a seguinte Equação [2.23]:

$$
H_{i, j}^{x^{\text {new }}}=\omega H_{i, j}^{x \text { int }}+(1-\omega) H_{i, j}^{x^{\text {old }}}
$$


onde $\omega$ é conhecido por parâmetro de sobrerelaxação, $H_{i, j}^{x}$ old é o campo inicial no princípio de cada iteração, $H_{i, j}^{x^{i n t}}$ é o campo intermediário calculado segundo a equação (2.23) e $H_{i, j}^{x^{n e w}}$ é o campo corrigido no final de cada iteração. O campo $H_{i, j}^{x^{n e w}}$ torna-se o campo $H_{i, j}^{x^{\text {old }}}$ na próxima iteração. A escolha adequada do parâmetro de sobrerelaxação $\omega$ dita a taxa de convergência do método. Esta escolha de $\omega$ resulta num parâmetro ótimo, $\omega_{\mathrm{opt}}$, que pode ser relacionado com o maior autovalor $\bar{\mu}$ da matriz de Jacobi correspondente segundo [2.23]:

$$
\omega_{o p t}=2 \times\left[1+\left(1-\bar{\mu}^{2}\right)^{1 / 2}\right]^{-1}
$$

O maior autovalor $\bar{\mu}$ pode ser estimado iterativamente por [2.23]:

$$
\bar{\mu}^{2} \cong \frac{\left\|e_{k}\right\|}{\left\|e_{k-1}\right\|}
$$

onde $\left\|e_{k}\right\|$ é a norma euclidiana do resíduo a cada iteração $k$, sendo dada por [2.23]:

$$
\left\|e_{k}\right\|=\sqrt{\sum_{i, j}\left|H_{i, j}^{x \text { int }}-H_{i, j}^{x o l d}\right|^{2}}
$$

esta técnica consome um tempo computacional considerável para o cálculo das normas. Outra forma, menos dispendiosa de se estimar o maior autovalor $\bar{\mu}$ utiliza a equação:

$$
\bar{\mu}=4 \times\left(4 / h^{2}+\beta^{2}-\kappa^{2} n^{2}\right)^{-1}
$$

que encontra-se deduzida no Apêndice III. A condição de contorno adotada foi a condição de contorno transparente, que encontra-se detalhada no Apêndice IV.

$\mathrm{O}$ algoritmo pode ser resumido da seguinte forma: primeiramente, uma distribuição de campo inicial, uma gaussiana por exemplo, é definida como o campo inicial $H^{x}$. O próximo passo é o cálculo da constante de propagação $\beta$ pelas equações (2.24) e (2.25). O 
campo intermediário $H^{x i n t}$ pode ser calculado então pela equação (2.23). A distribuição de campo corrigida $H_{i, j}^{x}$ new é finalmente obtida pela equação (2.26). Este processo é repetido a cada iteração até que o critério de convergência, definido em termos da variação do índice de refração efetivo entre duas iterações consecutivas, seja atingido. Ao final do processo, tanto a distribuição de campo, quanto a constante de propagação são obtidas simultaneamente.

\subsection{Resultados do método SOR}

A Seção 2.7.1 descreve o cálculo do parâmetro de sobrerelaxação ótimo. Na Seção 2.7.2 alguns resultados obtidos com o SOR são cotejados com resultados da literatura para algumas estruturas padrão. Na Seção 2.7.3 é realizada uma comparação entre alguns resultados obtidos com o SOR e outros métodos. A Figura 2.7.4 apresenta os resultados gerados pelo SOR especificamente para o estudo das características de dispersão das fibras microestruturadas.

\subsubsection{Cálculo do parâmetro de aceleração ótimo $\left(\omega_{\text {opt }}\right)$}

Na Ref. [2.23] o parâmetro ótimo de aceleração para o método SOR $\left(\omega_{\text {opt }}\right)$ é calculado analiticamente para a equação escalar de Helmholtz em meios homogêneos. Para o caso da equação semivetorial de Helmholtz em meios não-homogêneos não existe uma forma analítica para o cálculo do parâmetro ótimo. Busca-se, portanto, uma aproximação satisfatória para o mesmo. Desta forma, através do formalismo da Ref. [2.24], com algumas aproximações adicionais, pôde-se chegar a uma expressão analítica para $\omega_{\text {opt }}$. Verificou-se, através de diversas simulações, que esta aproximação é muito eficiente para todas as estruturas estudadas. A dedução realizada está descrita no Apêndice 3.

Como exemplo, a Figura 2.17 mostra a evolução do índice efetivo em função do número de iterações para diversos valores de $\omega$ em comparação com o valor calculado para $\omega_{\text {opt }}$ para uma dada estrutura de fibra microestruturada. Deve-se observar que, para valores acima do calculado como $\omega_{o p t}$, o comportamento da curva torna-se oscilatório, enquanto que, para valores abaixo de $\omega_{o p t}$ o comportamento é assintótico. De fato, este comportamento é previsto para o método SOR [2.23] confirmando, portanto, o valor calculado como uma boa aproximação para o valor ótimo. 


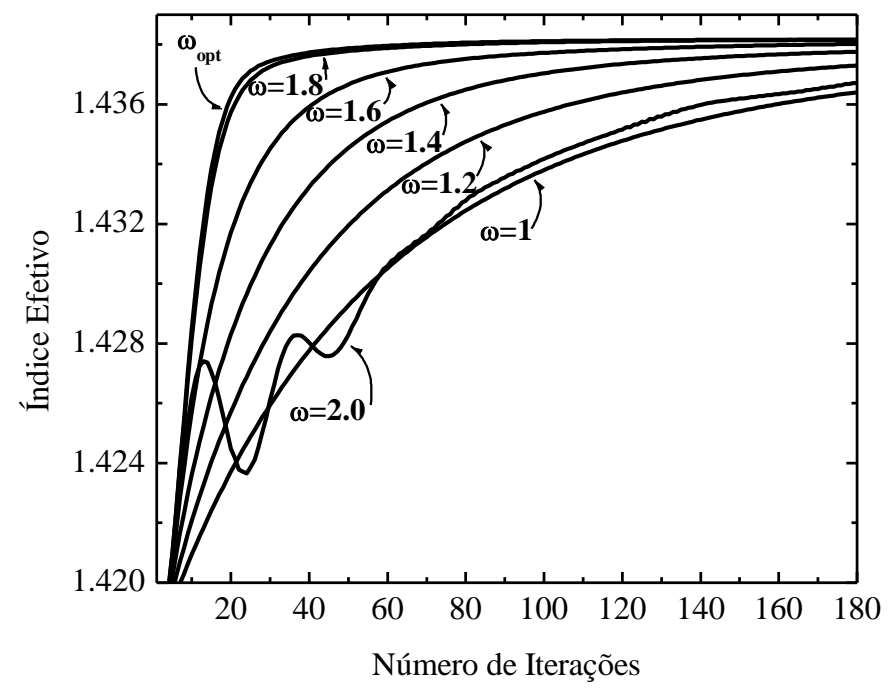

Figura 2.17- Evolução do índice efetivo em função do número de iterações para vários valores de $\omega$ em comparação com o valor ótimo calculado $\omega_{\text {opt }}$ para uma fibra microestruturada com raio dos furos $a=0,7 \mu \mathrm{m}$, espaçamento entre furos $\Lambda=2,3 \mu \mathrm{m}$, e comprimento de onda de operação $\lambda=1,3 \mu \mathrm{m}$, para uma malha com $512 \times 512$ pontos.

Uma vez de posse de uma boa aproximação para $\omega_{o p t}$, procedemos de forma a aferir os resultados obtidos com o método SOR comparando-os com resultados publicados na literatura para algumas estruturas padrão. A seguir são mostrados alguns resultados desta aferição.

\subsubsection{Guias ópticos padrão}

Os guias de onda tipo rib são guias tridimensionais de uso freqüente em óptica integrada. A Figura 2.18 detalha este tipo de estrutura. Estes guias são muito utilizados também como estruturas de teste para comparar o desempenho de métodos de solução de guias de onda tridimensionais. 


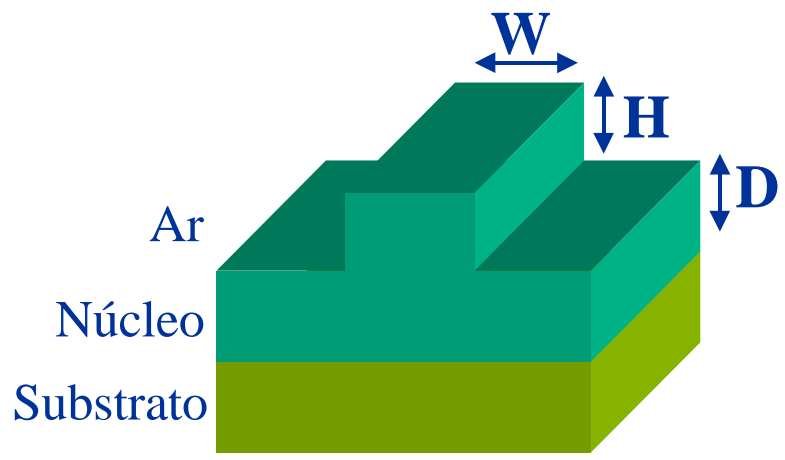

Figura 2.18- Esquema de guia tipo rib. Os parâmetros W, H e são largura e altura do rib enquanto que D representa a espessura da camada guiante. A camada superior é tomada como sendo composta de ar.

Uma estrutura considerada padrão e muito utilizada na literatura para aferição de métodos numéricos foi publicada em [2.24] e analisada através de diversos métodos em comparação com o método Modal de Ressonância Transversa, MTRM (do inglês, Modal Transverse Ressonance Method). Este método é considerado referência por se tratar de um método vetorial bastante robusto. Os parâmetros utilizados são: $\mathrm{W}=3,0 \mu \mathrm{m},(\mathrm{D}+\mathrm{H})=1,0 \mu \mathrm{m}$, índice do núcleo $\mathrm{n}_{\text {nuc }}=3,44$ e índice do substrato $\mathrm{n}_{\text {sub }}=3,4$, comprimento de onda $\lambda=1,15 \mu \mathrm{m}$. A Tabela 2.4 mostra os valores obtidos através do SOR e os valores publicados para os métodos MTRM [2.24] e IBPM [2.25] (do inglês, Imaginary-distance Beam Propagation Method) para vários valores de $\mathrm{H}$ mantendo-se a altura $(\mathrm{D}+\mathrm{H})$ fixa. $\mathrm{O}$ método IBPM foi incluído pois o MTRM é um método completamente vetorial. Para que seja realizada uma comparação adequada entre os métodos de interesse é desejável a comparação com outro método também semivetorial.

Tabela 2.4- Constante de propagação normalizada $B=\left(n_{\text {eff }}^{2}-n_{\text {sub }}^{2}\right) /\left(n_{n u c}^{2}-n_{\text {sub }}^{2}\right)$ para modos TE em guias rib calculadas por diversas formulações e desvio do SOR em relação ao método SV-IBPM.

\begin{tabular}{|c|c|c|c|c|}
\hline $\mathrm{H}(\mu \mathrm{m})$ & $\begin{array}{c}\mathrm{B} \\
(\mathrm{MTRM})\end{array}$ & $\begin{array}{c}\mathrm{B} \\
(\mathrm{SV}-\mathrm{IBPM})\end{array}$ & $\begin{array}{c}\mathrm{B} \\
(\mathrm{SV}-\mathrm{SOR})\end{array}$ & $\begin{array}{c}\text { Desvio } \\
(\text { SVIBPM-SVSOR })\end{array}$ \\
\hline 0.1 & 0,3019 & 0,3018 & 0,301869 & $6,910^{-5}$ \\
\hline 0.5 & 0,3270 & 0,3267 & 0,326810 & $1,110^{-4}$ \\
\hline 0.9 & 0,3883 & 0,3884 & 0,387966 & $6,3410^{-4}$ \\
\hline
\end{tabular}

Como podemos observar na Tabela 2.4, o desvio entre o método SOR semivetorial e o método BPM com distância imaginária é bastante pequeno $\left(<7 \times 10^{-4}\right)$ para todos os 
parâmetros $H$ investigados. Vale ressaltar que, na Ref. [2.24], o autor considera que um método confiável deve resultar em valores de B que sejam exatos até a terceira casa decimal.

As fibras ópticas tipo D são fibras birrefringentes muito utilizadas como fibras de polarização mantida em diversos sistemas ópticos [2.27]. A Figura 2.19 mostra esquematicamente a seção transversal deste tipo de fibra. Nesta fibra, o efeito de polarização é tão importante que a validade da aproximação por modos linearmente polarizados (aproximação semivetorial) é contestada por alguns autores [2.27]. Desta forma, este tipo de guia torna-se propício para o estudo da influência das componentes vetoriais e semivetoriais na formulação utilizada.

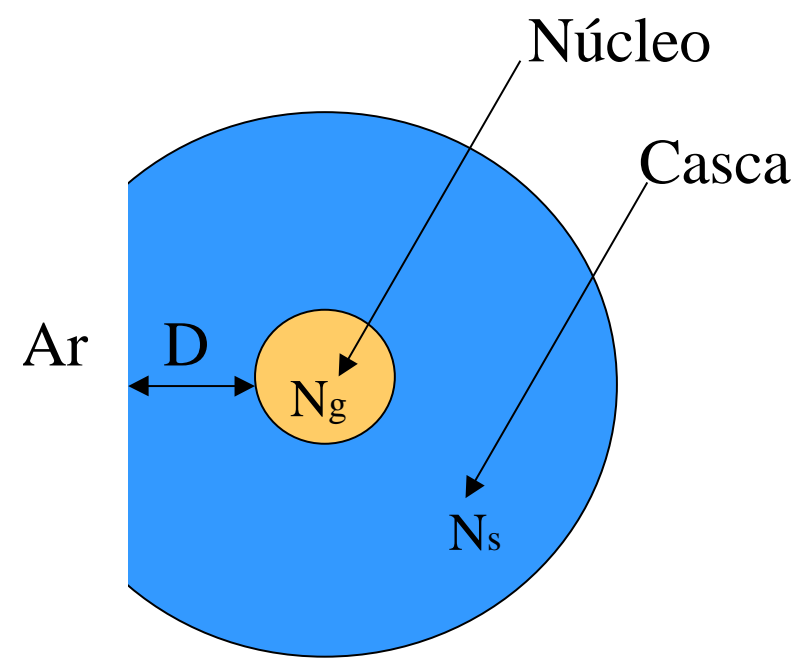

Figura 2.19- Esquema da seção transversal de uma fibra tipo D.

A Tabela 2.5 mostra o índice de refração obtido pelo método SOR em comparação com valores publicados para o método VBPM [2.28] (do inglês, Vector Beam Propagation Method).

Tabela 2.5- Resultados obtidos pelo SOR e V-BPM para fibras tipo D e três valores do parâmetro D.

\begin{tabular}{|c|c|c|c|}
\hline \multirow{2}{*}{$\mathrm{D}(\mu \mathrm{m})$} & \multicolumn{2}{|c|}{ Neff } & \multirow{2}{*}{ Diferença } \\
\cline { 2 - 4 } & VBPM $^{\mathrm{x}}$ & SOR & \\
\hline 0,0 & 1,4575065 & 1,4575157 & $9,210^{-6}$ \\
\hline
\end{tabular}




\begin{tabular}{|c|c|c|c|}
\hline 0,5 & 1,4576882 & 1,4576930 & $4,810^{-6}$ \\
\hline 1,0 & 1,4577763 & 1,4577785 & $2,210^{-6}$ \\
\hline
\end{tabular}

Na Tabela 2.5 observa-se que a diferença entre os valores obtidos pelos métodos SOR semivetorial e BPM vetorial para a constante de propagação é suficientemente pequena mesmo quando o parâmetro D utilizado é igual a zero, caso em que as componentes vetoriais são mais significativas. Desta forma, pode-se afirmar que o método SOR semivetorial fornece bons resultados mesmo para guias birrefringentes, cujos modos contêm componentes minoritárias de campo, ou seja, modos que não são exatamente LP (linearmente polarizados), como é o caso da fibra tipo D aqui estudada.

\subsubsection{Fibras microestruturadas}

Nesta seção os resultados da simulação de fibras microestruturadas através do método SOR são cotejados com resultados gentilmente enviados por investigadores de dois grupos de pesquisa: Juan José Miret da Universidade de Valência, Espanha e Ambre Peyrilloux da empresa IRCOM situada em Limoges, França. Ambos resultados dizem respeito a fibras microestruturadas com núcleo sólido, ou seja, onde o defeito é criado pela ausência de um furo de ar. A Figura 2.20 mostra o erro absoluto no índice efetivo calculado entre os resultados publicados em [2.29], que foram obtidos através de um software que utiliza o método de elementos finitos desenvolvido pela empresa IRCOM, e os resultados obtidos pelo método SOR implementado.

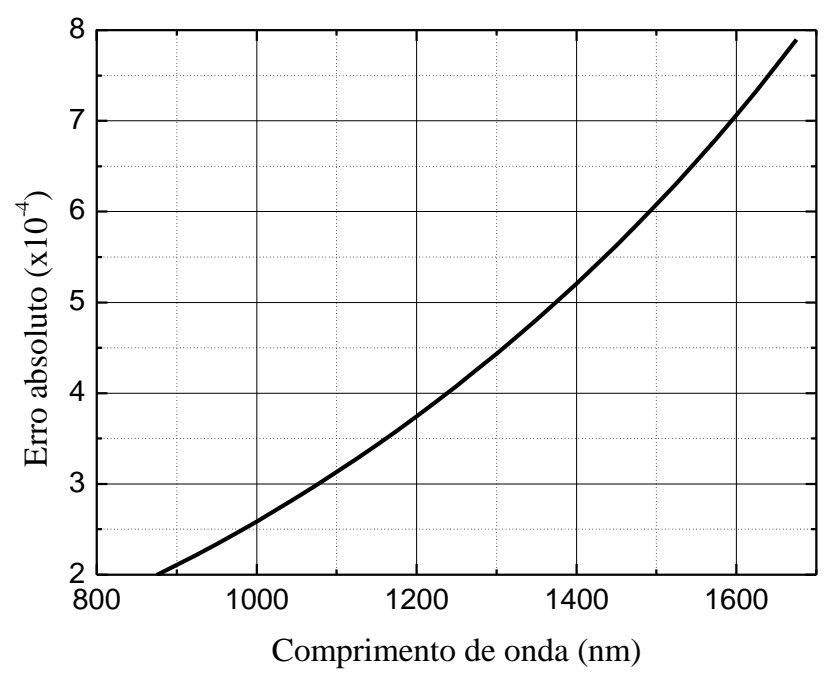


Figura 2.20- Diferença absoluta em função do comprimento de onda para uma fibra microestruturada com os seguintes parâmetros: raio dos furos $(a)$ igual a 1,0 $\mu \mathrm{m}$ e distância entre furos $(\Lambda)$ de $2,3 \mu \mathrm{m}$.

A Figura 2.21 compara os dados enviados por Juan José Miret, os quais foram obtidos através do método biortonormal [2.30], com aqueles gerados pelo método SOR.

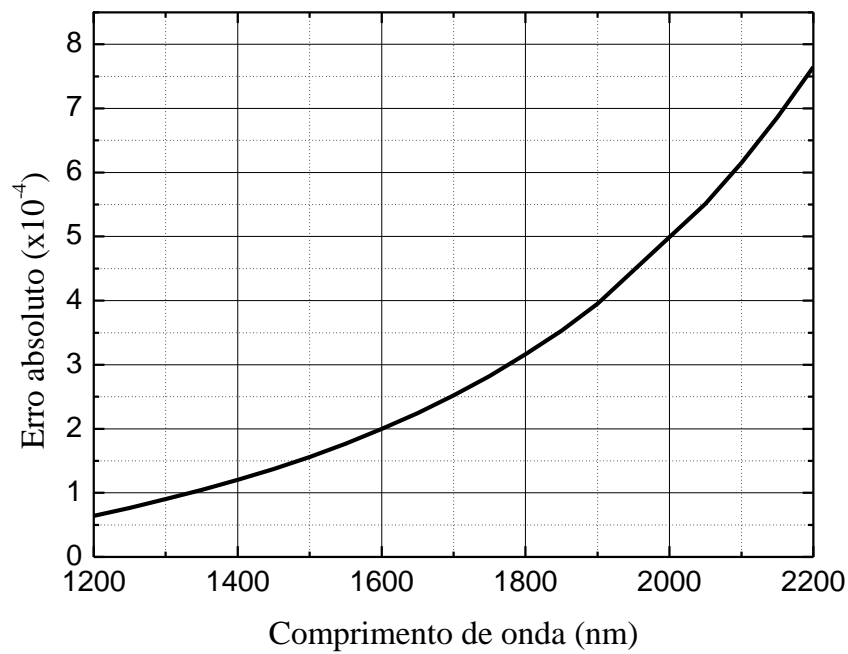

Figura 2.21- Diferença absoluta do índice efetivo em função do comprimento de onda para a fibra microestruturada com os seguintes parâmetros: raio dos furos (a) igual a $0,4 \mu \mathrm{m}$ e distância entre furos $(\Lambda)$ de $2,71 \mu \mathrm{m}$.

Pode-se concluir pela observação das Figuras 2.20 e 2.21 que o método SOR semivetorial resulta em valores com boa concordância se comparado com valores obtidos através de métodos vetoriais. Outra observação importante é que o erro apresenta um aumento proporcional ao comprimento de onda. Este comportamento é esperado, pois o aumento do comprimento de onda, causa uma diminuição no confinamento. Desta forma, a luz interage mais com as interfaces sílica-ar causando um maior acoplamento entre as componentes ortogonais de campo. Neste acoplamento é justamente onde diferem o formalismo vetorial e o semivetorial, pois este acoplamento é desprezado no formalismo semivetorial. No entanto, o erro foi menor do que $8 \times 10^{-4}$ mesmo para o pior caso avaliado.

Os resultados apresentados demonstraram a eficiência do método SOR na análise do modo fundamental de guias de onda tradicionais bem como em fibras microestruturadas. Desta forma, conclui-se que guias monomodo podem ser modelados adequadamente através da técnica SOR e do formalismo semivetorial. 


\subsubsection{Cálculo de dispersão}

As curvas de dispersão cromática podem ser facilmente obtidas através do método SOR de acordo com a equação:

$$
D_{G}=-\frac{\lambda}{c} \frac{d^{2} n_{e f f}}{d \lambda^{2}}
$$

onde $c$ é a velocidade da luz no vácuo, $n_{\text {eff }}$ é o índice de refração efetivo do modo fundamental na fibra, obtido pelo método SOR e $\lambda$ é o comprimento de onda.

O controle das características de dispersão das fibras microestruturadas é particularmente importante quando da sua utilização em sistemas de telecomunicações. Para aferição da eficácia do formalismo SOR, foram geradas as curvas de dispersão mostradas na Figura 2.22 em comparação com os resultados publicados em [2.29] os quais por sua vez foram obtidos através do método dos elementos finitos. Também é mostrada a dispersão de uma fibra comercial fabricada pela Corning, a SMF-28, para efeito de comparação. Além disso, é mostrado o resultado experimental obtido em [2.31], em excelente concordância com os resultados teóricos obtidos.

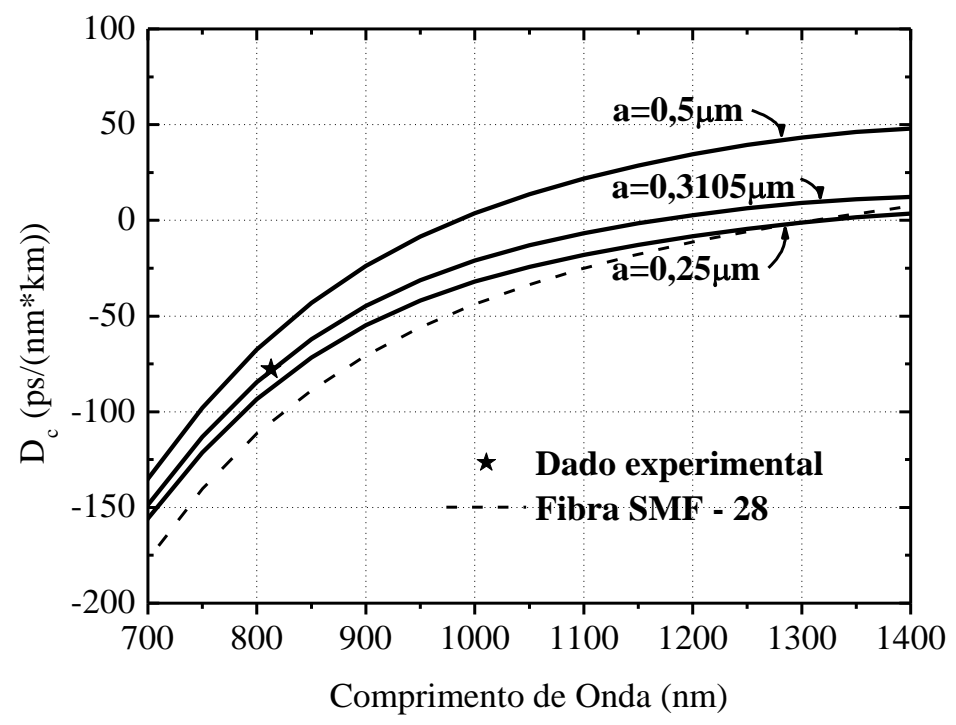


Figura 2.22- Diagrama de dispersão para a fibra microestruturada com $\Lambda=2,3 \mu \mathrm{m}$ e $a=$ $0,25,0,3105$ e $0,5 \mu \mathrm{m}$. O ponto experimental representa o caso a $=0,3105$ para $\lambda=813 \mathrm{~nm}$. 


\section{APLICAÇÕES}

Este capítulo descreve as três aplicações investigadas utilizando os modelos numéricos desenvolvidos. A seção 3.1 descreve o estudo de sensitividade do parâmetro de dispersão em relação a variações nos parâmetros físicos da fibra microestruturada bem como desenvolve o estudo de aplicação das fibras para compensação de dispersão. A seção 3.2 descreve a aplicação das fibras microestruturadas em amplificadores Raman. Na seção 3.3 é apresentado o isolador óptico proposto com o uso das fibras microestruturadas.

\subsection{Aproveitamento das características de dispersão das fibras microestruturadas}

Nesta seção são apresentados estudos referentes ao aproveitamento das características inovadoras de dispersão das fibras microestruturadas. Primeiramente é realizado um estudo detalhado da influência de variações estruturais sobre as características de dispersão de fibras microestruturadas projetadas para baixa dispersão. Posteriormente, é analisada a aplicação das fibras microestruturadas em compensadores de dispersão de alto desempenho.

\subsubsection{Análise de sensitividade em fibras com baixa dispersão}

A importância do cálculo da dispersão cromática advém do fato de que ela é a responsável pelo alargamento de pulso em enlaces de fibra óptica. A dispersão cromática pode ser considerada como o resultado das contribuições dadas pela dispersão de material, $M_{D}$ e dispersão de guia de onda, $M_{G}$. A dispersão material surge da variação do índice de refração do material em função do comprimento de onda da luz. As características de dispersão de um determinado material podem ser alteradas através da dopagem do material e até mesmo pelo processo de fabricação empregado [3.1]. A dispersão de guia de onda, por sua vez, é relacionada com o mecanismo de guiamento e pode ser ajustada pela escolha adequada do perfil de índice de refração da fibra. 
Neste contexto, o uso das fibras microestruturadas torna-se particularmente atraente uma vez que o perfil de índice de refração pode ser modificado tanto pela alteração da distribuição espacial dos furos de ar quanto pela modificação do seu raio. Neste tipo de estrutura, a alteração da distribuição dos furos afeta sobremaneira o confinamento modal. Ademais, variações nestes parâmetros são inerentes ao processo de fabricação e não podem ser evitados [3.2]. Desta forma, duas questões podem ser naturalmente levantadas: Como estas imperfeições estruturais que ocorrem durante o processo de fabricação afetam as propriedades de dispersão destas fibras? Como impurezas materiais (ou a presença de dopantes) podem afetar a dispersão? Para responder a estas questões, foram feitas simulações utilizando o formalismo SOR já desenvolvido, cujos resultados são mostrados a seguir.

A dispersão material afeta principalmente o desempenho de dispositivos projetados para operar no regime de baixa dispersão, condição em que seu efeito sobre a dispersão total torna-se significativo. Por sua vez, a dispersão material é afetada pelo eventual tipo de dopante usado durante a fabricação do vidro e também pelo método de fabricação utilizado [3.1]. Portanto, é de vital importância o estudo da alteração das curvas de dispersão das fibras microestruturadas quando do uso de diferentes vidros dopados no processo de fabricação.

Para realizar este estudo, foram utilizados dados de dispersão material publicados recentemente na literatura para diversos vidros dopados [3.1]. Na referência [3.1], os diferentes índices de refração destes materiais foram medidos em diferentes comprimentos de onda e então os resultados foram calibrados através da seguinte equação de Selmeier:

$$
n^{2}(\lambda)=1+\sum_{i=1}^{3} \frac{a_{i} \lambda^{2}}{\lambda^{2}-b_{i}^{2}}
$$

onde $\lambda$ é o comprimento de onda, $n$ é o índice de refração e $a_{i}$ e $b_{i}$ são os coeficientes de ajuste.

Inicialmente, para demonstrar a influência do processo de fabricação de vidros não dopados no diagrama de dispersão de fibras microestruturadas, a Figura 3.1 mostra as curvas de dispersão cromática para uma mesma fibra a ser fabricada utilizando sílica não dopada fabricada por três processos diferentes [3.1]: MCVD (do inglês, "Modified Chemical Vapor Deposition"), SPCVD (do inglês, "Surface Plasma Chemical Vapor Deposition") e PCVD (do inglês, "Plasma Activated Vapor Deposition"). A diferença nos índices de refração para o mesmo vidro é explicada pela presença de diferentes quantidades de cloro que aparece como contaminante da amostra [3.1]. Cada técnica de fabricação do vidro causa uma 
diferente porcentagem de contaminação. Deve-se salientar, ainda, que a fibra em questão foi projetada para ter baixa dispersão cromática.

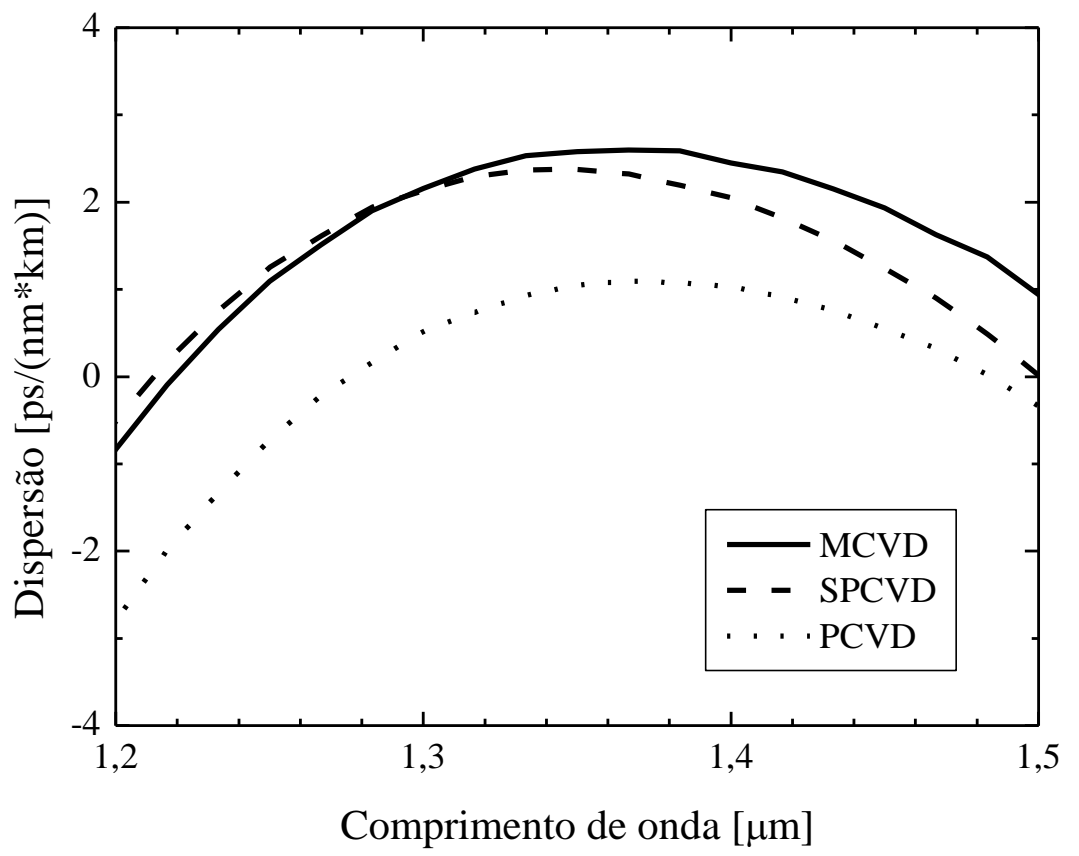

Figura 3.1- Dispersão cromática em função do comprimento de onda para uma fibra microestruturada com período $(\Lambda)$ igual a $2.3 \mu \mathrm{m}$ e raio $(a)$ igual a $0.315 \mu \mathrm{m}$. A linha sólida refere-se ao processo MCVD, enquanto a linha tracejada é referente ao processo SPCVD e a linha pontilhada, por sua vez, refere-se ao processo PCVD.

Como pode ser observado na Figura 3.1, fibras microestruturadas, construídas utilizando sílica fabricada por diferentes processos, geram diagramas de dispersão significativamente diferentes, onde conclui-se que é necessário um controle muito preciso das características dos vidros utilizados na fabricação de fibras microestruturadas com baixa dispersão.

Alumínio e germânio são dois elementos bastante utilizados como dopantes durante o processo de fabricação de fibras ópticas. Portanto, eles serão utilizados para ilustrar como as características de dispersão são afetadas pela presença destes elementos. A Figura 3.2 compara a dispersão cromática de uma fibra microestruturada utilizando sílica não-dopada (fabricada pelo método PCVD) com outras duas que utilizam vidros com diferentes níveis de dopagem de Germânio. 


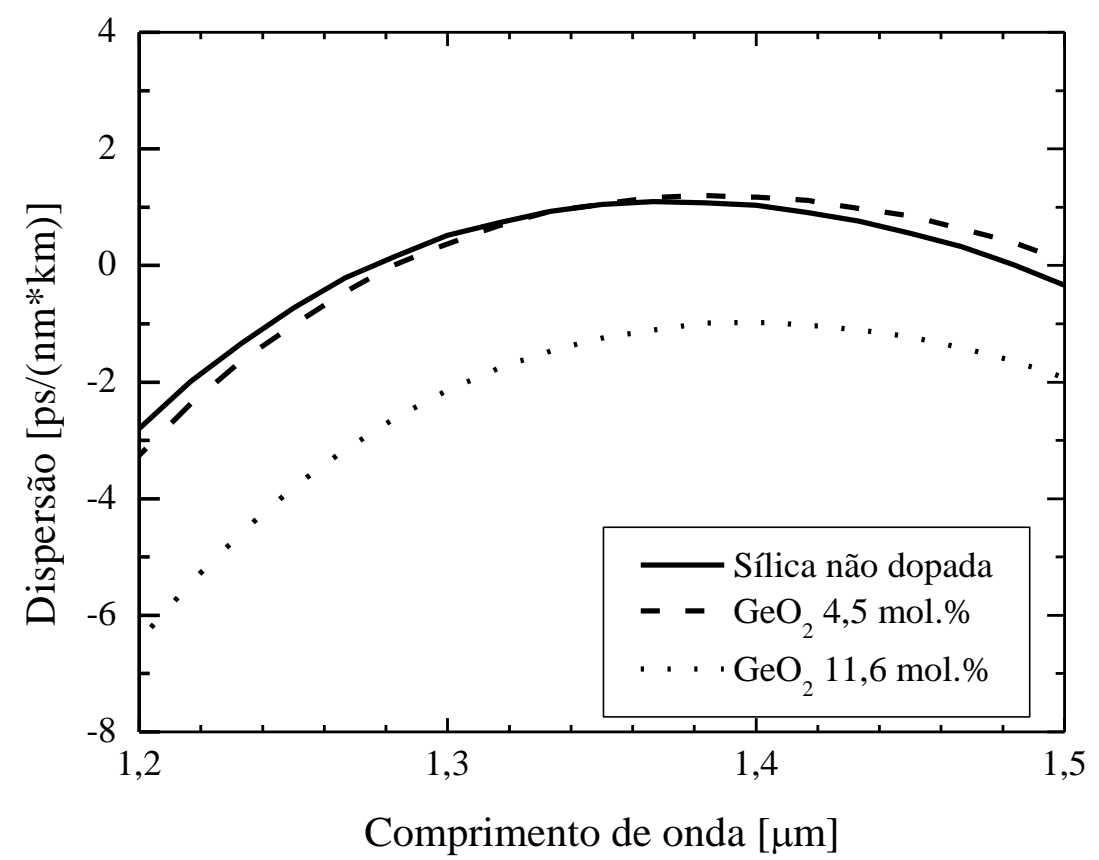

Figura 3.2- Dispersão cromática em função do comprimento de onda para a mesma fibra da Figura 3.1 utilizando vidro fabricado pelo processo PCVD. Linha sólida: Sílica não dopada. Linha tracejada: 4,5 mol.\%. Linha pontilhada: 11,6 mol.\%.

Verifica-se que uma baixa dopagem de germânio altera mais significativamente a inclinação da curva enquanto uma maior dopagem tende a diminuir o valor da dispersão. A Figura 3.3 mostra o diagrama de dispersão para uma fibra microestruturada fabricada com sílica não dopada e sílica dopada com alumínio. Observa-se que a inclusão de alumínio na composição do vidro faz com que a dispersão da fibra em questão diminua e seu pico desloque-se para comprimentos de onda mais longos. 


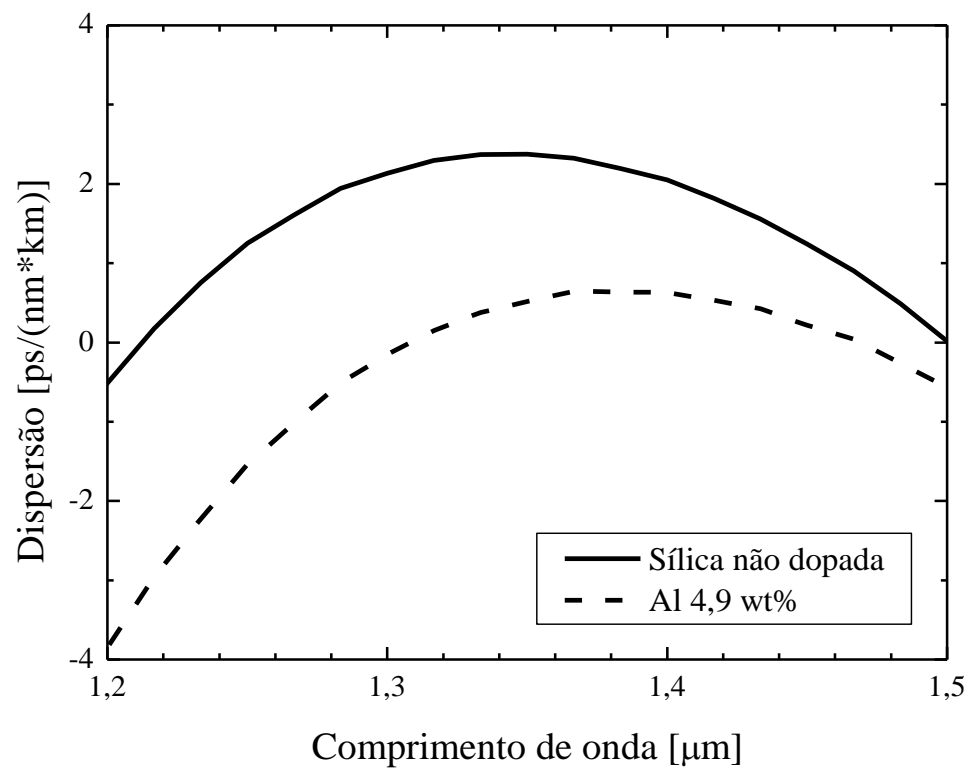

Figura 3.3- Dispersão cromática em função do comprimento de onda para a mesma fibra da Figura 3.1 utilizando vidro fabricado pelo processo SPCVD. Linha sólida: sílica não dopada. Linha tracejada: Al 4,9 wt\%.

Pelos resultados apresentados nas Figuras 3.1, 3.2 e 3.3 pode-se concluir que a dopagem pode ser utilizada para alterar o diagrama de dispersão das fibras microestruturadas visando satisfazer requerimentos de projeto. Da mesma maneira, um controle rigoroso da composição do material deve ser adotado para evitar comportamentos indesejados da curva de dispersão. Esta afirmação é especialmente verdadeira em aplicações que requeiram baixa dispersão total.

Como mencionado anteriormente, outra importante característica das fibras microestruturadas é sua susceptibilidade a imperfeições estruturais causadas durante o processo de fabricação. Os resultados deste estudo serão apresentados na seção seguinte.

\subsubsection{Variações geométricas}

A fabricação das fibras microestruturadas constitui um desafio tecnológico devido a alta precisão requerida quanto aos seus parâmetros geométricos. Para estudar a influência da variação do raio dos furos de ar $(a)$ e da distância entre dois furos consecutivos $(\Lambda)$ sobre as características de dispersão das fibras microestruturadas, foi calculado o diagrama de 
dispersão para uma fibra microestruturada de baixa dispersão. Posteriormente, foram calculados os diagramas de dispersão considerando uma variação de $0,05 \mathrm{~mm}$ no raio dos furos e de 5\% na distância entre eles. A Figura 3.4 mostra as cinco curvas resultantes.

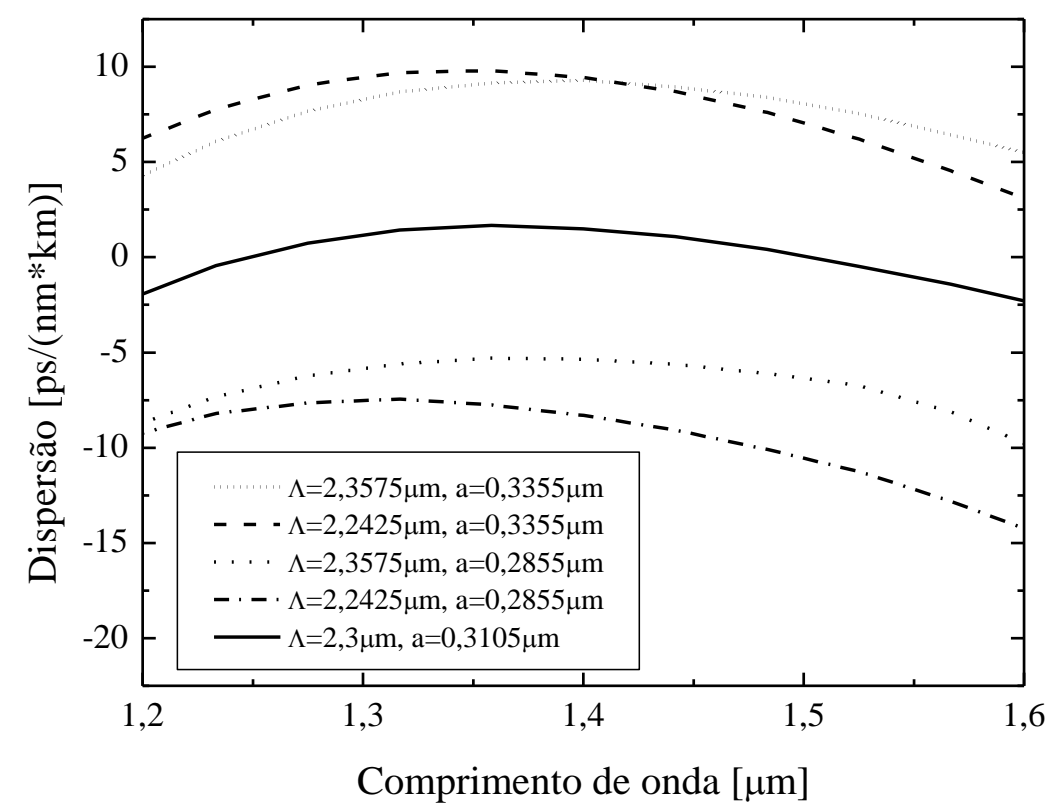

Figura 3.4- Características de dispersão em função do comprimento de onda tendo o raio dos furos $a$ e sua separação $\Lambda$ como parâmetro.

Pode-se verificar, pela análise da Figura 3.4, que pequenas alterações nos parâmetros $a$ e $\Lambda$ alteram de forma significativa a dispersão da fibra. Mais precisamente, pode-se concluir que a variação no raio dos furos afeta substancialmente o valor da dispersão enquanto uma alteração na distância $\Lambda$ altera o pico da curva de dispersão. Este resultado implica que um controle preciso do raio dos furos é necessário durante o processo de fabricação, especialmente em aplicações que requeiram baixa dispersão. Adicionalmente, uma alta precisão no parâmetro $\Lambda$ é necessária se a inclinação da curva de dispersão é de grande importância para uma determinada aplicação.

É também inerente ao processo de fabricação a ocorrência de variações aleatórias nos parâmetros $a$ e $\Lambda$. Torna-se, portanto, necessário quantificar também a influência deste tipo de variação na performance de dispersão das fibras microestruturadas. Isto pode ser feito supondo uma variação aleatória em ambos os parâmetros. Diversas curvas podem então ser geradas, obtendo-se desta forma um feixe de curvas. Deste feixe de curvas, pode-se extrair 
uma curva média e uma curva de desvio padrão. A Figura 3.5 mostra as três curvas geradas através do procedimento descrito. A curva sólida foi obtida através da média aritmética das curvas, enquanto as curvas pontilhadas referem-se à curva média somada e subtraída da curva de desvio padrão. Ou seja, de um ponto de vista probabilístico, as curvas pontilhadas delimitam a região onde podem ser encontradas ao menos cinqüenta por cento das ocorrências. Desta forma pode-se quantificar o efeito das variações aleatórias dos parâmetros geométricos no diagrama de dispersão das fibras microestruturadas.

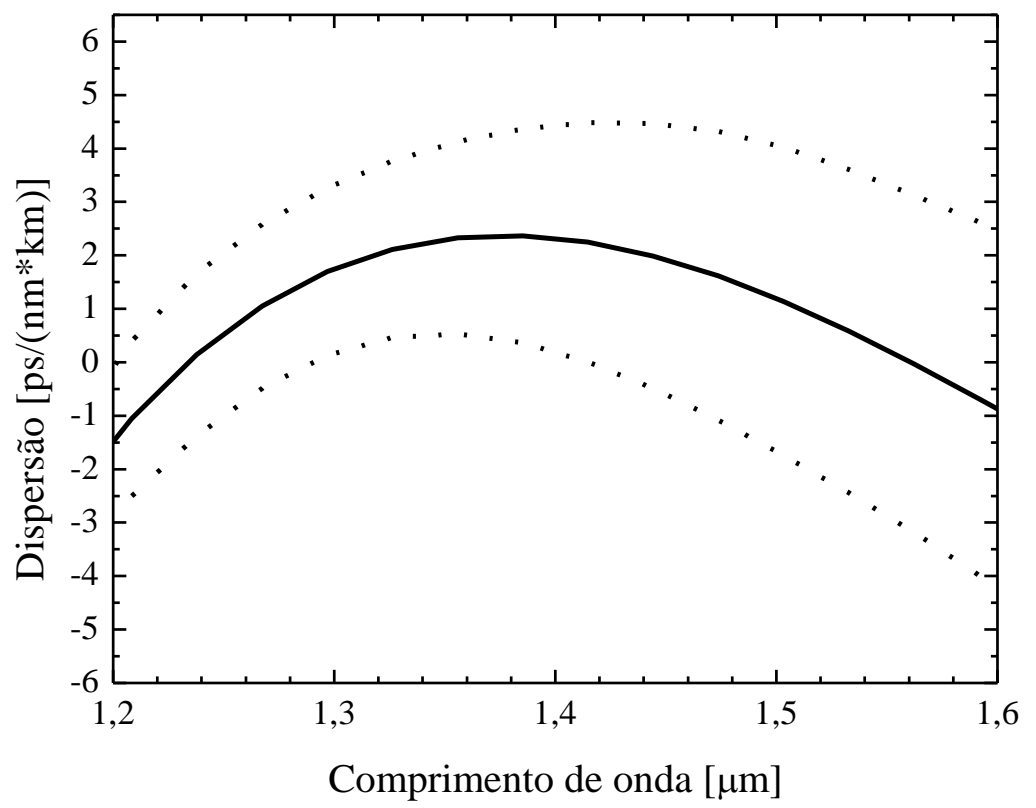

Figura 3.5- Influência de flutuações pseudo-aleatórias nos parâmetros geométricos $a$ e $\Lambda$ em função do comprimento de onda. Linha sólida: Média aritmética. Linhas pontilhadas: Média adicionada e subtraída do desvio padrão.

Pode-se verificar que a aleatoriedade dos furos também influencia significativamente a curva de dispersão. Outra observação importante é o fato de que o desvio padrão torna-se maior para comprimentos de onda mais longos. Este fenômeno se justifica pelo fato de que o confinamento modal diminui para comprimentos de onda mais longos, ou seja, existe uma maior interação da luz com a casca perturbada. Através dos resultados mostrados nesta seção, pode-se concluir que as fibras microestruturadas projetadas para baixa dispersão requerem técnicas de alta precisão na sua fabricação. 


\subsubsection{Compensador de dispersão}

A utilização das fibras ópticas microestruturadas para compensação de dispersão cromática em enlaces de comunicações ópticas foi originalmente proposta pelo grupo da Universidade de Bath [3.3], que realizou um estudo qualitativo, e altamente especulativo, com base na aproximação das fibras microestruturadas por um bastão de sílica disposto no ar. Mais recentemente, em 2003, L. P. Shen [3.4] e outros propuseram um algoritmo para o projeto de fibras compensadoras de dispersão que se baseia em fórmulas de escalonamento e num formalismo vetorial de diferenças finitas. Neste artigo, foi proposta uma estrutura ótima. Todavia, nenhum cálculo foi realizado para estimar as perdas de confinamento para esta estrutura. Finalmente, em outubro de 2003, F. Poli e outros [3.5] publicaram um estudo de caracterização das fibras microestruturadas para compensação de dispersão em banda larga considerando as perdas de confinamento. Com base no método dos elementos finitos, os autores propuseram um esquema de projeto dos parâmetros físicos da fibra e encontraram uma fibra com boas características de compensação de dispersão. Esta fibra apresenta um parâmetro de dispersão cromática $D_{T}$ igual a $-590 \mathrm{ps} /(\mathrm{nm} * \mathrm{~km})$. Além disso, as perdas de confinamento, para um projeto com 9 anéis, estão abaixo das causadas por efeito Rayleigh na sílica. No entanto, a área efetiva não linear do núcleo é de apenas $1 \mu \mathrm{m}^{2}$ o que pode causar efeitos danosos ao sistema, pela alta excitação de efeitos não lineares. Além disso, os furos de ar apresentam diâmetro de 90 por cento do pitch, o que implica numa estrutura muito frágil mecanicamente e de difícil implementação prática.

Nesta seção, revisitamos o procedimento de projeto destas fibras buscando, de um lado, minimizar as perdas ópticas e, de outro, obter uma estrutura fisicamente viável para implementação prática.

\subsubsection{Metodologia de Projeto}

Inicialmente, visando atingir um projeto otimizado em comparação com fibras compensadoras de dispersão DCFs (do inglês, Dispersion Compensation Fibers) comerciais, optou-se por definir uma figura de mérito, dada por:

$$
M_{D}=D_{T} / P_{T}
$$

onde $P_{T}$ é o valor total das perdas $(\mathrm{dB} / \mathrm{km})$ e $D_{T}$ é o coeficiente de dispersão cromática $\left(\mathrm{ps}^{*}(\mathrm{~nm} * \mathrm{~km})^{-1}\right)$. Esta figura de mérito, a ser maximizada, descreve a capacidade de 
compensação de dispersão ponderada pelas perdas ópticas do dispositivo compensador em questão.

Tendo sido definidos os parâmetros de desempenho a serem otimizados, passemos à descrição do procedimento de projeto. No que se segue, o formalismo semivetorial baseado no método SOR para solução das equações de Maxwell nas fibras microestruturadas foi utilizado para o cálculo da dispersão. Para o cálculo das perdas de confinamento foi utilizado um método numérico localmente unidimensional baseado num formalismo escalar SLOD (do inglês, Scalar Locally One-Dimensional) [3.6]. Primeiramente, a análise das curvas de dispersão de guia de onda, estudadas detalhadamente em [3.7], nos revela, que o pico negativo da curva de dispersão ocorre para um comprimento de onda $\left(\lambda_{p}\right)$ que depende, primordialmente, do raio dos furos de ar $(a)$, enquanto o valor de pico ( $\left.D_{p}\right)$ é proporcional ao raio e inversamente proporcional a distância entre furos $(\Lambda)$. A partir desta observação, obtivemos fórmulas empíricas para a determinação aproximada dos valores de $\lambda_{\mathrm{p}}$ e $D_{p}$ :

$$
\begin{gathered}
\lambda_{p} \approx 2 \pi a \\
D_{p} \approx \frac{1000 a}{\Lambda^{2}}
\end{gathered}
$$

Com base nas equações ( 3.3 e 3.4), podemos concluir que, a fim de que o pico de dispersão situe-se em torno de 1,55 $\mu \mathrm{m}$, o raio dos furos de ar deve estar em torno de 0,247 $\mu \mathrm{m}$. O passo seguinte é a análise do compromisso existente entre o valor do pico de dispersão $\mathrm{D}_{\mathrm{p}}$ e o valor da perda de confinamento $\alpha_{\text {conf }}$. O fator de dispersão é inversamente proporcional ao quadrado do valor da distância entre os furos, enquanto que as perdas aumentam consideravelmente com a diminuição do diâmetro do núcleo, que pode ser estimado grosseiramente como sendo $2^{*} \Lambda$. Desta forma, existe um compromisso de projeto entre o valor do pico negativo de dispersão e as perdas ópticas existentes.

Valores de perdas proibitivos, chegando a dezenas de decibéis por metro, são obtidos se valores de pitch da ordem de décimos de micrometros são empregados. Para sanar este problema, pode ser empregada a técnica proposta em [3.8], que consiste em aumentar o diâmetro dos furos de ar conforme aumenta sua distância do núcleo. Esta alteração atua fracamente nas curvas de dispersão, mas diminui significativamente as perdas. Além disto, esta técnica permite maximizar o diâmetro do núcleo, minimizando efeitos não-lineares indesejados. 
O procedimento de projeto pode ser descrito segundo o algoritmo abaixo:

1) Define-se a posição do pico de dispersão e a partir deste valor encontra-se o raio dos furos mais próximos do núcleo.

2) Define-se o pitch necessário para um determinado valor do pico de dispersão.

3) A partir dos valores obtidos em 1 e 2 procede-se ao cálculo da área efetiva não linear.

4) Ajusta-se o pitch para um compromisso satisfatório entre área do núcleo e valor do pico de dispersão.

5) Ajusta-se a variação do raio dos furos e o número dos anéis visando atingir um valor adequado para as perdas de confinamento.

Tabela 3.1 - Casos de projeto para fibra compensadora de dispersão. O duplo asterisco em alguns dos itens da tabela abaixo significa que o raio dos furos obedece a um limite máximo tal que a razão entre o raio dos furos e o espaçamento entre eles não excede 0,85 .

\begin{tabular}{|c|c|c|c|c|c|c|c|c|}
\hline & Pitch & Raio & $\begin{array}{c}\text { Aumento } \\
\text { linear do } \\
\text { raio dos } \\
\text { furos à } \\
\text { partir do } \\
\text { anel central }\end{array}$ & $\begin{array}{c}\text { Número } \\
\text { de Anéis }\end{array}$ & $\begin{array}{c}\text { Perdas } \\
\mathrm{dB} / \mathrm{km}\end{array}$ & $\begin{array}{c}\text { Dispersão } \\
(-) \\
\mathrm{ps} /(\mathrm{nm} . \mathrm{km})\end{array}$ & $\begin{array}{c}\text { Área } \\
\text { Efetiva } \\
\mu \mathrm{m}^{2}\end{array}$ & $\begin{array}{c}\text { Figura de } \\
\text { mérito M }\end{array}$ \\
\hline 1 & 0,9 & 0,21 & 0,12 & 8 & 0,67 & $220 @ 1,45 \mu \mathrm{m}$ & $4,7-5,1$ & 328 \\
\hline 2 & 0,8 & 0,23 & 0,09 & 8 & 1,42 & $390 @ 1,46 \mu \mathrm{m}$ & $3,2-3,5$ & 274 \\
\hline 3 & 0,85 & 0,253 & $0,07 * *$ & 8 & 1,0 & $320 @ 1,63 \mu \mathrm{m}$ & $3,5-3,8$ & 320 \\
\hline 4 & 0,85 & 0,25 & $0,08^{* *}$ & 8 & 0,5 & $860 @ 1,67 \mu \mathrm{m}$ & 2,9 & 1720 \\
\hline 5 & 0,85 & 0,24 & $0,09^{* *}$ & 8 & 0,38 & $350 @ 1,55 \mu \mathrm{m}$ & 3,09 & 921 \\
\hline 6 & 0,85 & 0,235 & $0,09^{* *}$ & 8 & 0,54 & $340 @ 1,53 \mu \mathrm{m}$ & 3,2 & 629 \\
\hline 7 & 0,85 & 0,23 & $0,09^{* *}$ & 8 & 1,1 & $305 @ 1,55 \mu \mathrm{m}$ & 3,3 & 277 \\
\hline
\end{tabular}

A Tabela 3.1 mostra alguns casos de projeto com os respectivos valores de perda, dispersão, área efetiva e figura de mérito $\mathrm{M}$. Este parâmetro de mérito $\mathrm{M}$ para dispositivos compensadores de dispersão convencionais é da ordem de 200 (ps/(nm*dB)) para os módulos compensadores de dispersão fabricados pela Corning e Lucent e disponíveis no CPQD [3.9]. Como pode ser observado na Tabela 3.1, em vários casos, a figura de mérito das fibras PCF supera a das fibras presentes em dispositivos comerciais. 


\subsubsection{Compensação de dispersão em banda larga}

Os resultados acima, embora promissores, não asseguram operação em banda larga. De fato, mesmo tomando uma tolerância de compensação de \pm 5 ps, a fibra apresentada na linha 4 da Tabela 3.1, oferece uma largura de banda em torno de somente 10 $\mathrm{nm}$. Portanto, o projeto específico de uma fibra microestruturada para aplicação como compensadora de dispersão operando, a titulo de exemplo, na região da banda óptica L (1568-1610) requer um procedimento de projeto que satisfaça as características de compensação de dispersão em banda larga, ou seja, a dispersão cromática existente no sistema de comunicações ópticas deve ser compensada em todos os comprimentos de onda dentro da faixa de operação.

Para o estudo de compensação em banda larga, podemos ainda definir dois outros fatores: o fator $\mathrm{R}$, que quantifica a relação entre os coeficientes de dispersão da fibra presente no link óptico e da fibra compensadora, e o fator $\mathrm{K}$, que mede a capacidade de compensação dos efeitos de dispersão sobre uma faixa de comprimentos de onda. Estes fatores são dados por:

$$
R=\frac{D_{c}}{D_{l}}
$$

onde $D_{c}$ e $D_{l}$ são, respectivamente, os coeficientes de dispersão da fibra compensadora e da fibra utilizada no enlace, enquanto:

$$
K=\frac{D_{c}}{S_{c}}=\frac{D_{l}}{S_{l}}[\mathrm{~nm}]
$$

onde $S_{c}$ e $S_{l}$ descrevem a inclinação (slope) das curvas de dispersão para a fibra compensadora e para a fibra utilizada no enlace, respectivamente.

Foram analisados diversos casos visando atingir os requisitos de projeto: maximizar o parâmetro R e adequar o parâmetro K ao sistema em questão. Foi escolhida, como fibra de trabalho, a fibra óptica Corning SMF-28 na execução de um projeto visando compensação em banda larga na banda L, onde o parâmetro K para a fibra SMF-28 vale 356,12 nm. A Tabela 3.2 mostra alguns casos analisados com os respectivos parâmetros de desempenho. 
Tabela 3.2-Casos de projeto para compensação em banda larga.

\begin{tabular}{|c|c|c|c|c|c|c|c|c|}
\hline & $\begin{array}{c}\text { Pitch } \\
\mu \mathrm{m}\end{array}$ & $\begin{array}{c}\text { Raio } \\
\mu \mathrm{m}\end{array}$ & $\begin{array}{c}\text { Aumento } \\
\text { linear } \\
\text { do raio } \\
\text { à partir } \\
\text { do anel } \\
\text { central }\end{array}$ & $\begin{array}{c}\text { Número } \\
\text { De anéis }\end{array}$ & $\begin{array}{c}\text { Perdas } \\
\mathrm{dB} / \mathrm{km}\end{array}$ & $\begin{array}{c}\text { Fator } \\
\mathrm{K} \\
\mathrm{nm}\end{array}$ & $\begin{array}{c}\text { Fator } \\
\mathrm{R}\end{array}$ & $\begin{array}{c}\text { Área } \\
\text { efetiva } \\
\mu \mathrm{m}^{2}\end{array}$ \\
\hline 1 & 0,95 & 0,28 & 0,09 & 8 & 0,2 & 1282 & 16,58 & $\sim 2,0$ \\
\hline 2 & 0,95 & 0,27 & 0,09 & 8 & 0,2 & 1483 & 16,05 & $\sim 2,0$ \\
\hline 3 & 0,9 & 0,29 & 0,09 & 8 & 0,2 & 1000 & 19,7 & $\sim 2,0$ \\
\hline 4 & 0,85 & 0,29 & 0,09 & 8 & 0,2 & 1493 & 24 & $\sim 2,0$ \\
\hline 5 & 0,85 & 0,32 & 0,09 & 8 & 0,2 & 812 & 27 & $\sim 2,0$ \\
\hline 6 & 0,9 & 0,369 & - & 8 & 0,2 & 446 & 30 & $\sim 1,6$ \\
\hline 7 & 0,92 & 0,382 & - & 8 & 0,2 & 395 & 26 & $\sim 1,5$ \\
\hline 8 & 0,94 & 0,395 & - & 8 & 0,2 & 367 & 24 & $\sim 1,55$ \\
\hline 9 & 0,96 & 0,3936 & - & 8 & 0,2 & 341 & 21 & $\sim 1,5$ \\
\hline 10 & 0,96 & 0,375 & - & 8 & 0,2 & 346 & 21,3 & $\sim 1,5$ \\
\hline 11 & 0,955 & 0,37 & - & 8 & 0,2 & 351 & 21 & $\sim 1,65$ \\
\hline 12 & 0,92 & 0,39 & - & 8 & 0,2 & 378 & 26 & $\sim 1,45$ \\
\hline 13 & 0,93 & 0,41 & - & 8 & 0,2 & 345 & 25,7 & $\sim 1,46$ \\
\hline 14 & 0,925 & 0,4 & - & 8 & 0,2 & 351 & 22 & $\sim 1,65$ \\
\hline
\end{tabular}

Os casos 11 e 14 apresentam valores adequados para os parâmetros de mérito, fornecendo um fator de compensação $\mathrm{R}$ superior a 20 , ou seja, com a capacidade de compensar um link óptico com vinte vezes seu comprimento.

\subsubsection{Considerações relativas à implementação prática}

No projeto das fibras microestruturadas, o números de anéis de furos de ar que envolvem o núcleo é determinante na definição das perdas ópticas. A Figura 3.4 mostra a variação das perdas teóricas em função do número de anéis para a fibra microestruturada da Tabela 3.2, linha 14, otimizada para compensação de dispersão. 


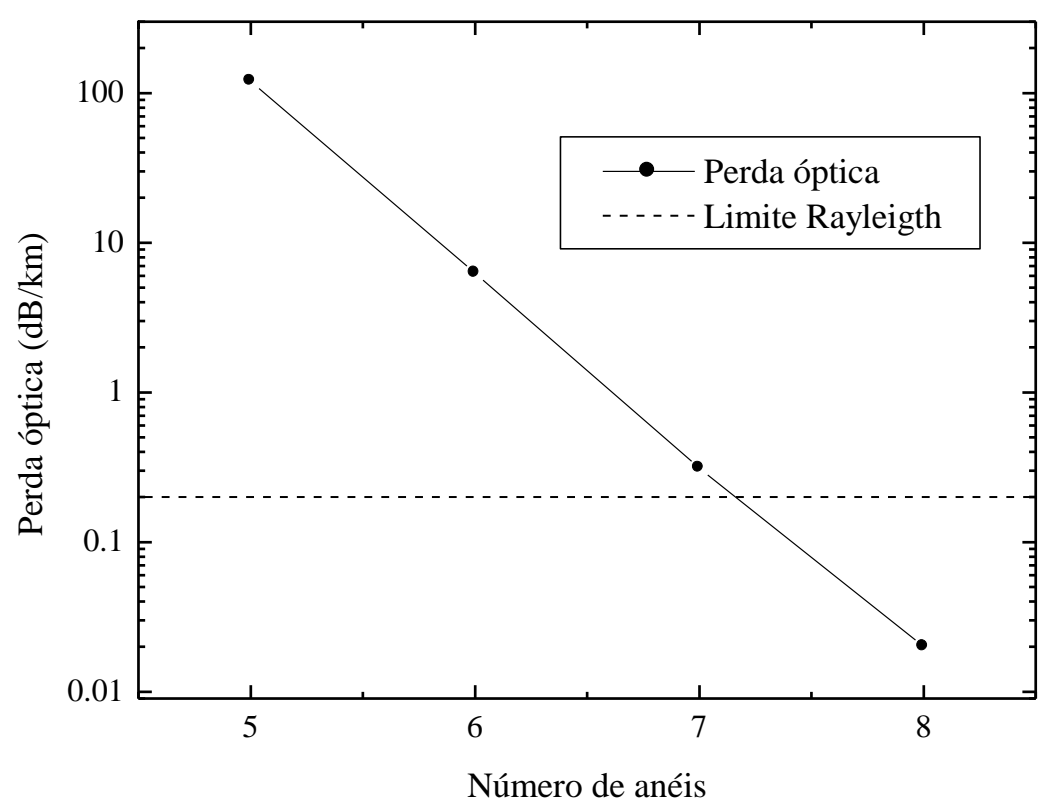

Figura 3.6 - Perdas ópticas em função do número de anéis.

Como pode ser observado na Figura 3.6, são necessários oito anéis para tornar as perdas de confinamento menores do que as perdas por absorção na sílica. No entanto, perdas relativamente baixas, da ordem de $0,3 \mathrm{~dB} / \mathrm{km}$ podem ainda ser obtidas utilizando-se sete anéis. A escolha final do número de anéis deve levar em conta o fator custo, uma vez que uma estrutura com sete anéis utiliza cerca de 168 tubos de sílica na preforma, enquanto que para oito anéis são utilizados cerca de 216 tubos. Além disso, um grande número de anéis, em uma estrutura com baixo fator de preenchimento, pode causar dificuldades quanto à rigidez mecânica da estrutura.

Outro fator que afeta o desempenho das fibras microestruturadas como compensadoras de dispersão é sua sensibilidade com relação a variações nos parâmetros geométricos da estrutura. A Figura 3.7 relaciona a variação percentual no período e no raio da estrutura com a variação correspondente no parâmetro de dispersão. 


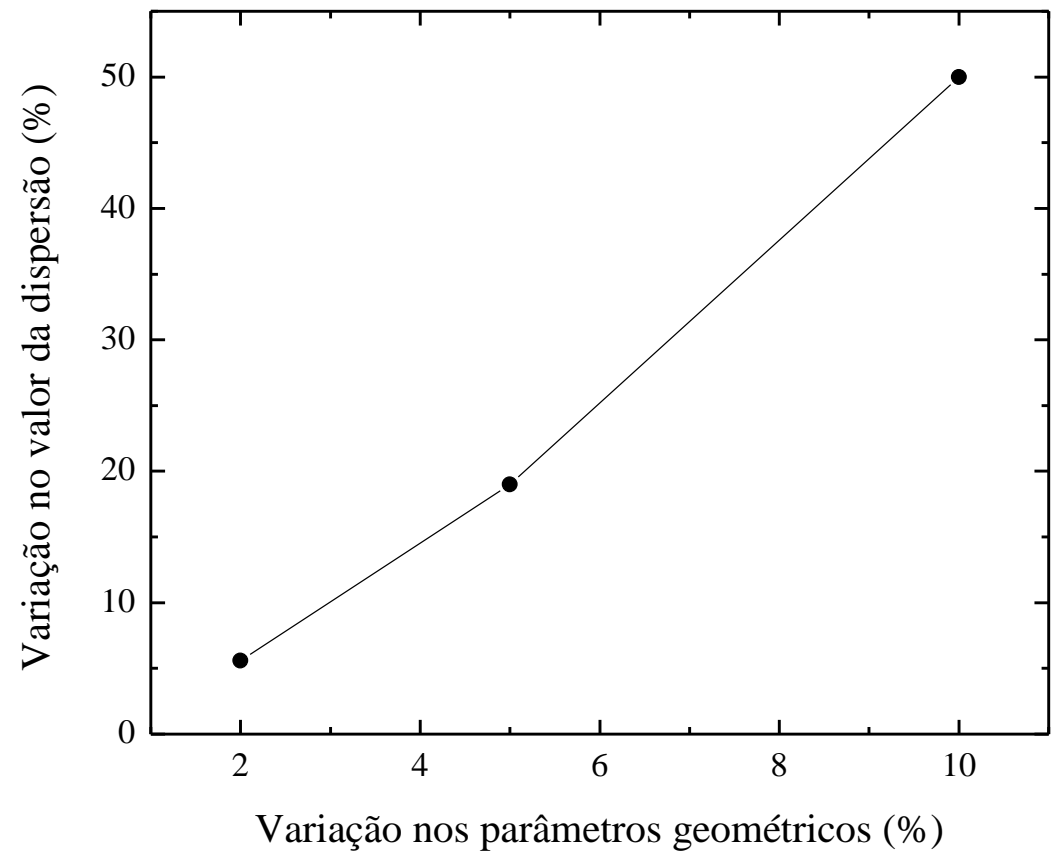

Figura 3.7 - Influencia de variações geométrica sobre o parâmetro de dispersão.

Observa-se que para manter o erro no valor da dispersão abaixo de $10 \%$ é necessária uma precisão em torno de $3 \%$ na geometria. Por outro lado, a ocorrência de uma variação de $10 \%$ na geometria da estrutura acarreta um erro de cerca de 50\% no parâmetro de dispersão. Estes resultados demonstram a precisão requerida na fabricação de fibras para compensação de dispersão.

Vale salientar ainda que a área efetiva não linear para o caso da fibra compensadora de dispersão é da ordem de $1,6 \mu \mathrm{m}^{2}$ (veja a Tabela 3.2, linha 14), o que implica num alto coeficiente não linear, que é estimado em $20 \mathrm{~W}^{-1} \mathrm{~km}^{-1}$. Este alto coeficiente não-linear provavelmente impediria a integração direta da fibra microestruturada atuando como compensadora de dispersão no encapsulamento de um EDFA, conforme a configuração proposta em [3.10]. Todavia, este mesmo coeficiente torna-se extremamente favorável para amplificação Raman, podendo resultar em um dispositivo capaz de compensar dispersão cromática e ao mesmo tempo apresentar ganho óptico. O estudo da aplicação das fibras microestruturadas em amplificação Raman é realizado na seção seguinte. 


\subsection{Aplicação das Fibras microestruturadas em amplificadores Raman}

Nesta seção é descrita a modelagem do ganho Raman em fibras microestruturadas com base no método SOR desenvolvido. Gráficos de desempenho são gerados e a aplicação dos resultados no projeto de amplificadores Raman em sistemas de comunicações ópticas é realizada.

\subsubsection{Introdução}

Os amplificadores Raman apresentam algumas vantagens significativas. Primeiro, o ganho Raman está disponível em toda fibra, tornando sua aplicação altamente flexível. Segundo, o ganho não é ressonante, o que significa que o ganho existe em toda faixa de transparência das fibras ópticas. Uma terceira vantagem dos amplificadores Raman é que o espectro de ganho pode ser modificado ajustando os comprimentos de onda de bombeio. Além disso, os amplificadores Raman apresentam a vantagem de oferecerem ganho em faixa larga, cerca de $5 \mathrm{THz}$. Por estes motivos, os amplificadores Raman a fibra óptica têm sido largamente empregados para melhorar o desempenho de sistemas de comunicações ópticas estando atualmente presentes em diversos dos sistemas de longa distância [3.11].

Não obstante, a utilização de fibras microestruturadas em amplificadores Raman foi implementada pela primeira vez em 2002, tendo sido obtido um ganho líquido de $42 \mathrm{~dB}$ utilizando-se apenas 75 metros de fibra [3.12]. Este experimento indicou, portanto, a viabilidade de implementação de amplificadores Raman em fibras microestruturadas.

Desta forma, torna-se de interesse a realização de um estudo teórico, com a geração de gráficos de projeto, para a otimização dos parâmetros físicos das fibras microestruturadas visando sua aplicação em amplificação Raman. Este estudo é mostrado nas seções seguintes.

\subsubsection{Modelagem do ganho Raman}

O espalhamento Raman é um fenômeno que transfere uma pequena parcela da potência de um feixe óptico para outro feixe de menor freqüência. Este desvio de freqüência é determinado pelos modos vibracionais do meio, num processo conhecido por efeito Raman, descrito através da mecânica quântica como sendo o espalhamento do fóton incidente para um fóton de menor energia por uma molécula que, por sua vez, realiza uma 
transição entre dois dos seus estados vibracionais [3.13]. Desta forma, a luz incidente age como feixe de bombeio para gerar radiação de menor freqüência, chamada de onda "Stokes".

O crescimento inicial da onda Stokes pode ser descrito por:

$$
\frac{d I_{s}}{d z}=g_{R} I_{P} I_{S}
$$

onde $I_{P}$ e $I_{S}$ representam respectivamente as intensidades do feixe de bombeio e do feixe Stokes e $g_{R}$ é o coeficiente de eficiência de ganho Raman $\left[\mathrm{m}^{2} \cdot(\mathrm{W} \cdot \mathrm{m})^{-1}\right]$ (usualmente dado em $\left[\mathrm{m}^{2} /(\mathrm{W} \cdot \mathrm{km})\right]$ ou $\left.[\mathrm{m} / \mathrm{W}]\right)$. A Figura 3.8 mostra o espectro do ganho Raman para uma fibra de sílica [3.14].

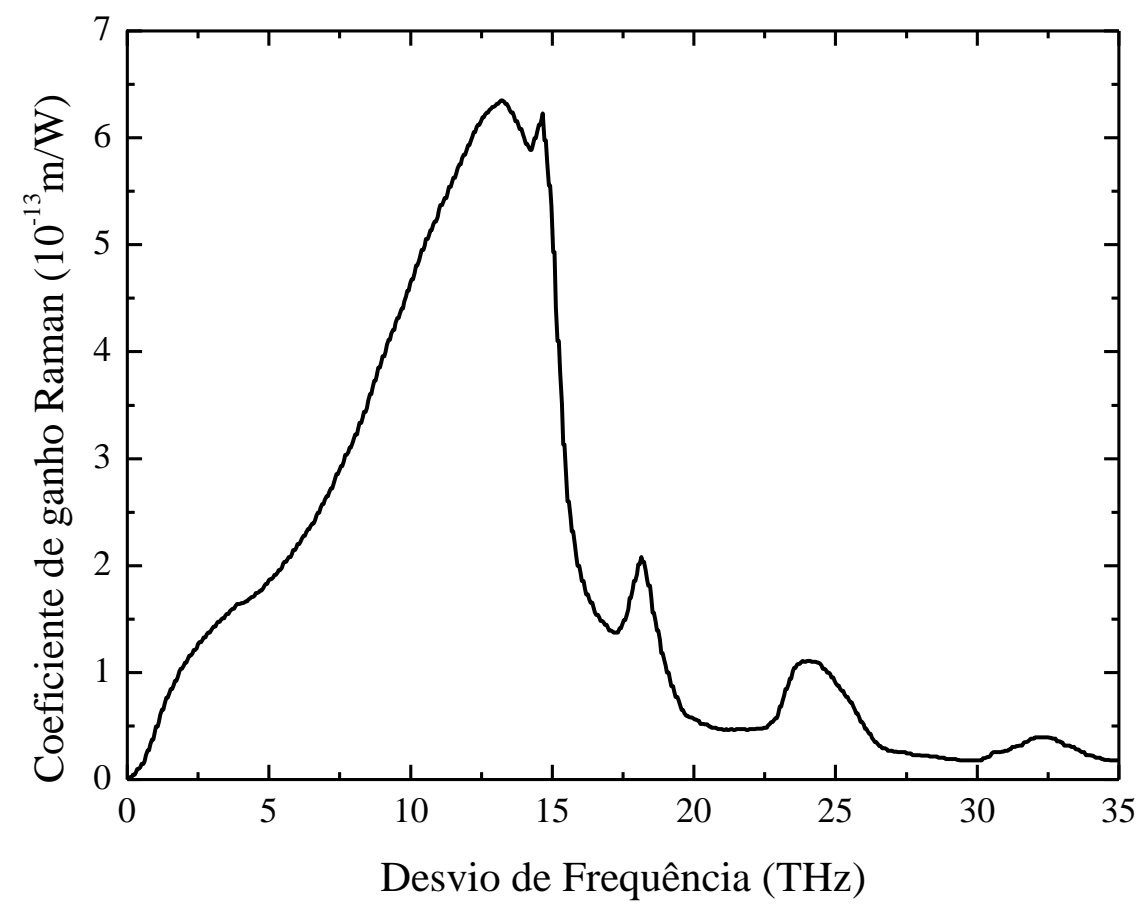

Figura 3.8- Espectro do coeficiente de eficiência de ganho Raman.

Pode-se notar que o efeito Raman em fibras de sílica se estende sobre uma ampla faixa de freqüências (cerca de $40 \mathrm{THz}$ ) com um pico situado em torno da região de $13 \mathrm{THz}$ em relação ao fóton original. Ademais, quando a potência de bombeio excede um determinado valor de limiar, esta componente de frequiência cresce com uma razão 
praticamente exponencial. Então, o efeito Raman passa a gerar uma onda Stokes cuja freqüência é determinada pela posição do pico do ganho Raman. O desvio de freqüência correspondente é conhecido por desvio Raman ou desvio Stokes.

Para o caso de operação contínua (c.w.) a interação entre o feixe de bombeio e o feixe de sinal (Stokes) pode ser descrita pelas seguintes equações [3.13]:

$$
\begin{gathered}
\frac{d I_{s}}{d z}=g_{R} I_{P} I_{S}-\alpha_{S} I_{S} \\
\frac{d I_{P}}{d z}=-\frac{\omega_{P}}{\omega_{S}} I_{P} I_{S}-\alpha_{P} I_{P}
\end{gathered}
$$

onde os coeficientes $\alpha_{S}$ e $\alpha_{P}$ representam as perdas ópticas $\left[\mathrm{m}^{-1}\right]$ para o feixe de sinal e o feixe de bombeio respectivamente. Desprezando inicialmente a depleção do feixe de bombeio, descrita pelo primeiro termo do lado direito da equação (3.9), podemos escrever:

$$
\frac{d I_{s}}{d z}=g_{R} I_{0} \exp \left(-\alpha_{P} z\right) I_{S}-\alpha_{S} I_{S}
$$

onde $I_{0}$ é a intensidade do feixe de bombeio em z=0. A equação (3.10) pode ser resolvida obtendo-se [3.13]:

$$
I_{S}(L)=I_{S}(0) \exp \left\{g_{R} I_{0} L_{e f f}-\alpha_{S} L\right\}
$$

onde $I_{S}(L)$ e $I_{S}(0)$ representam as intensidades do feixe Stokes nas posições $L$ e 0 , respectivamente, e $L_{\text {eff }}$ é o comprimento efetivo da fibra [m], dado por [3.13]:

$$
L_{\text {eff }}=1 / \alpha_{P}\left(1-\exp \left(-\alpha_{P} L\right)\right)
$$

onde $L$ é o comprimento real da fibra em metros. O ganho Raman para pequenos sinais pode ser isolado na equação (3.11) obtendo-se:

$$
G(\Delta v)=\exp \left\{\left(g_{R}(\Delta v) P_{P} L_{e f f} / A_{e f f}\right)-\alpha_{P} L\right\}
$$


onde $P_{P}$ é a potência de bombeio em watts dada por $P_{P}=I_{0} A_{\text {eff }}, g_{R}(\Delta v)$ é o coeficiente de ganho Raman dado em função do desvio de freqüência $\Delta v$ e $A_{e f f}$ é a área efetiva não linear que pode ser calculada segundo [3.15]:

$$
A_{e f}=\frac{1}{\iint_{\text {silica }} I_{S}(x, y) I_{P}(x, y) d x d y}
$$

onde $I_{P}(x, y)$ e $I_{S}(x, y)$ são as intensidades normalizadas $\left(\iint_{S} I(x, y) d x d y=1\right)$ para os lasers de bombeio e de sinal, respectivamente. As intensidades podem ser calculadas dentro da aproximação semivetorial segundo:

$$
I(x, y)=\left|H_{X, Y}\right|
$$

onde $H$ representa a componente de campo magnético para as duas polarizações, X e Y.

Podemos também definir o ganho Raman $\gamma_{R}(\Delta v)$ como sendo [3.15]:

$$
\gamma_{R}(\Delta v)=\frac{g_{R}(\Delta v)}{A_{\text {eff }}}
$$

substituindo a equação (3.16) na equação (3.13), obtêm-se:

$$
G(\Delta v)=\exp \left\{\gamma_{R}(\Delta v) P_{P} L_{e f f}-\alpha_{P} L\right\}
$$

O coeficiente $\gamma_{R}(\Delta v)$ pode ser estimado por [3.15]:

$$
\gamma_{R}(\Delta v)=g_{R}(\Delta v)_{S i} \iint_{\text {silica }} I_{P}(x, y) I_{S}(x, y) d x d y
$$

Pode-se então, estimar o nível de potência necessário para atingir o limiar de ganho Raman, que é definido como a potência de bombeio necessária para que a potência do feixe 
Stokes se iguale à de bombeio na saída, supondo segundo [3.13]:

$$
g_{R} P_{0} L_{\text {eff }} / A_{\text {eff }}=16
$$

para a condição de sinais copropagantes e

$$
g_{R} P_{0} L_{\text {eff }} / A_{\text {eff }}=20
$$

para sinais contrapropagantes.

Como pode ser observado na equação (3.13), para o calculo do ganho Raman é necessário o conhecimento de dois parâmetros: $g_{R}(\Delta v)_{S i}$, que é mostrado na Figura 3.8, sendo um parâmetro físico da sílica e a área efetiva $A_{\text {eff }}$ que pode ser calculada a partir das distribuições de campo para os comprimentos de onda de bombeio e de sinal, pela equação 3.14. Portanto, dentro desta formulação simplificada, o principal parâmetro a ser utilizado na otimização das fibras microestruturadas para amplificação Raman é a área efetiva não linear $A_{\text {eff }}$.

\subsubsection{Resultados}

Os valores de área efetiva não linear para quatro diferentes valores de fator de preenchimento de ar $(f)$, calculado em função da distância entre furos de ar $(\Lambda)$ são mostrados na Figura 3.9. Nestas simulações, os comprimentos de onda de sinal e de bombeio adotados foram $1550 \mathrm{~nm}$ e $1450 \mathrm{~nm}$, respectivamente. O valor do coeficiente de ganho Raman adotado foi $3.34 \times 10^{-11} \mathrm{~m}^{2} /(\mathrm{W} \mathrm{km})[3.15]$. 


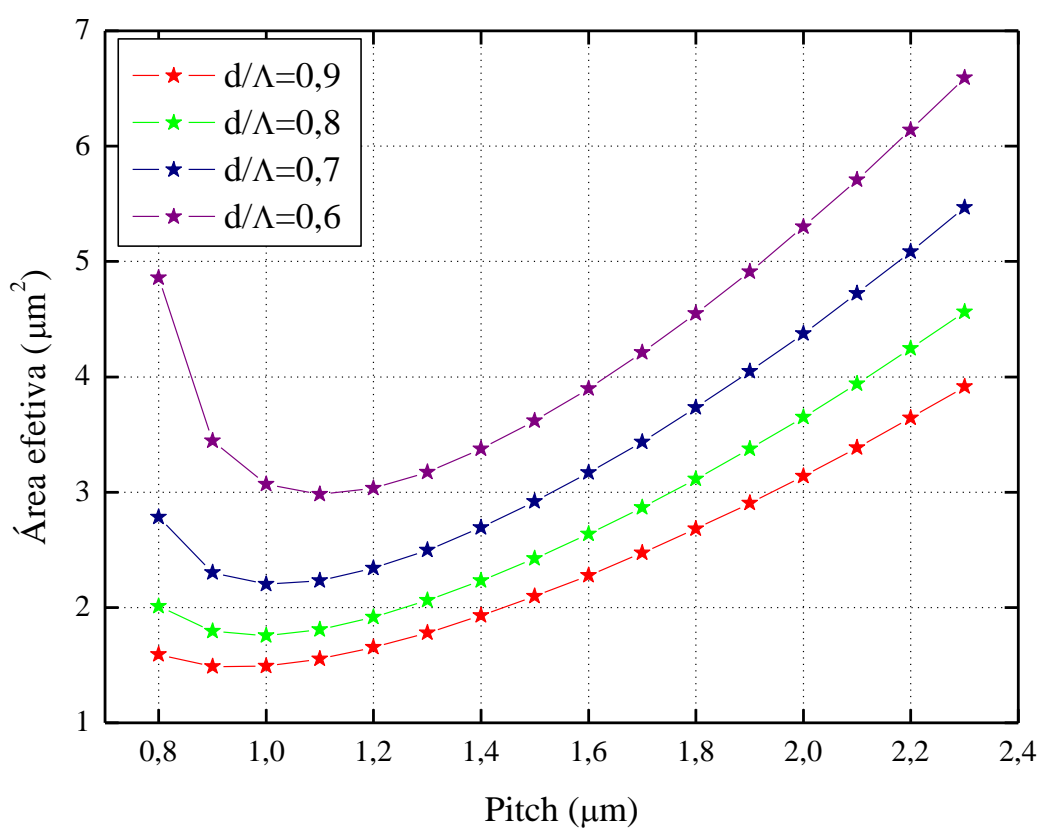

Figura 3.9 - Área efetiva em função da distância entre furos para quatro valores de preenchimento de ar.

Pode-se observar na Figura 3.9 que o valor da área efetiva diminui com o aumento do fator de preenchimento de ar. Isto ocorre porque o aumento de $(f)$ é devido ao aumento no diâmetro dos furos de ar, o que diminui o índice efetivo da casca, aumentando desta forma o confinamento da luz no núcleo. Conseqüentemente, este aumento do confinamento diminui a área efetiva do modo. Por outro lado, pode-se observar que as curvas apresentam mínimos para determinados valores dos parâmetros geométricos da fibra. Este fenômeno pode ser explicado analisando os casos limites, ou seja, valores de $\Lambda$ muito grandes e muito pequenos. No limite para grandes valores de $\Lambda$ o núcleo, cujo diâmetro pode ser aproximado por $2 * \Lambda$, se torna grande aumentando, desta forma, a área efetiva. No caso oposto, o diâmetro do núcleo tende a zero, o que impossibilitaria o guiamento da luz, fazendo com que a área efetiva tenda ao infinito. Os valores de mínimo para a área efetiva estão relacionados ao pico de ganho Raman, conforme mostrado na Figura 3.10. 


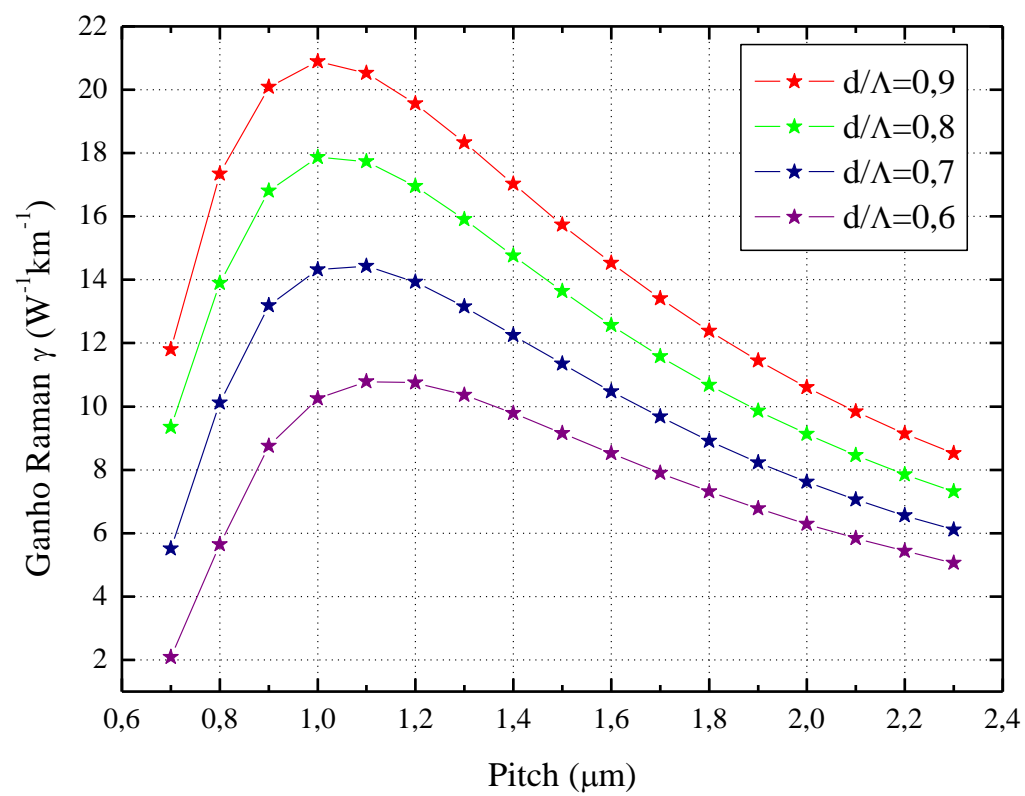

Figura 3.10 - Coeficiente de ganho Raman $\gamma$ em função da distância entre furos para quatro valores de preenchimento de ar.

Analisando a Figura 3.10, conclui-se que para valores fixos de preenchimento de ar, existem valores de separação entre furos que maximizam o ganho Raman. Desta forma, os gráficos gerados podem ser utilizados na otimização das fibras microestruturadas para aplicação em amplificadores Raman.

\subsubsection{Caso especial: Amplificação Raman em fibras DCF}

O interesse neste tipo de aplicação é o aproveitamento da utilização do módulo compensador de dispersão para oferecer também ganho óptico. Este aproveitamento é possível devido à pequena área de núcleo apresentada pelas fibras microestruturadas DCF projetadas para compensação de dispersão em banda larga, o que favorece um acentuado ganho Raman. Em [3.16] foi realizado um estudo sobre a performance de sistemas ópticos utilizando amplificação Raman contrapropagante em enlaces compostos em parte por fibras ópticas comuns e em parte por fibras compensadoras de dispersão. Os resultados de [3.16] indicaram que um enlace óptico de cerca de $150 \mathrm{~km}$ pode ter tanto a dispersão cromática quanto as perdas ópticas compensadas através do uso de amplificação Raman em um estágio, 
atingindo-se até $1000 \mathrm{~km}$ com a utilização de vários estágios. Vislumbra-se, portanto a aplicação eficiente das fibras microestruturadas neste tipo de aplicação, com a vantagem da utilização de um menor comprimento de fibra compensadora com um maior ganho Raman em comparação com as fibras compensadoras comerciais. A título de exemplo, a Figura 3.11 mostra o ganho Raman obtido pela fibra 14 da Tabela 3.2. Pode-se observar que o ganho Raman oferecido pela fibra compensadora de dispersão encontra-se próximo ao pico da curva de ganho, indicando uma alta eficiência na utilização destas fibras DCF em amplificação Raman.

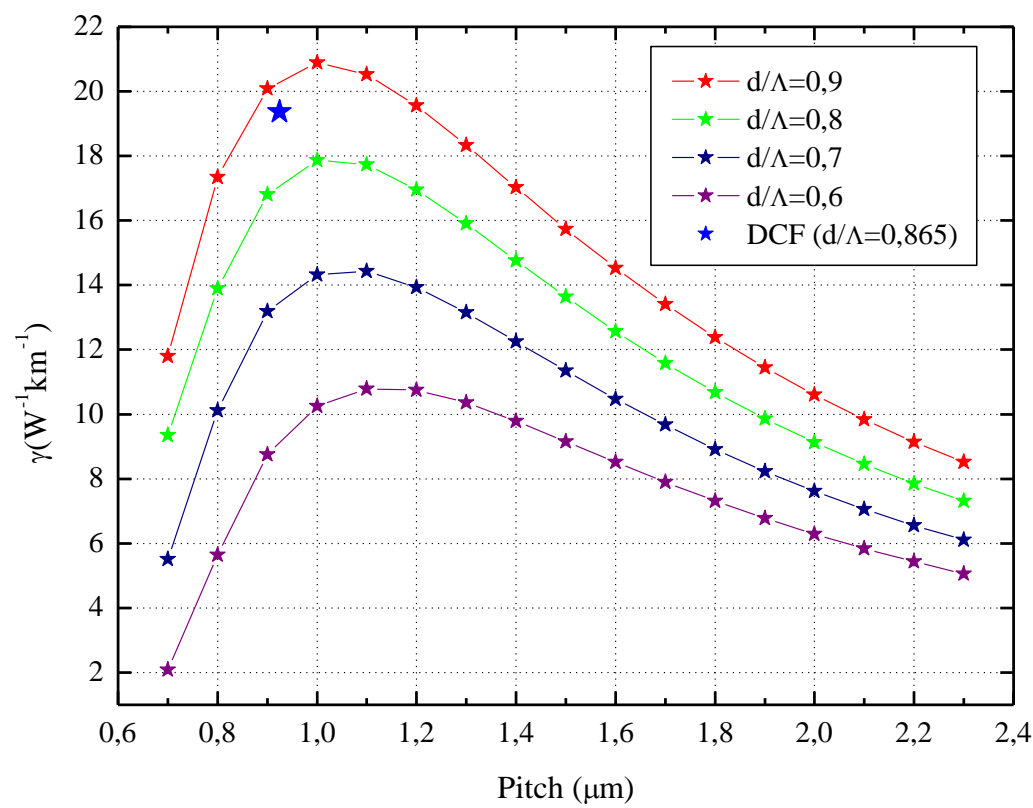

Figura 3.11 - Ganho Raman para uma fibra microestruturada projetada para compensação de dispersão.

Conforme citado na seção 3.1, a área efetiva das fibras microestruturadas pode ser calculada usando o método SOR para o cálculo da distribuição de campo e posteriormente, aplicando-se a equação 3.14. A área efetiva não linear das fibras propostas para uso em compensação de dispersão foram calculadas e situam-se entre 1,5 e 1,7 $\mu \mathrm{m}^{2}$. Estima-se, portanto, o valor do coeficiente de ganho não linear em $20 \mathrm{~W}^{-1} \mathrm{~km}^{-1}$, enquanto o valor do parâmetro R situa-se em torno de 20 e as perdas ópticas são da ordem de $0,2 \mathrm{db} / \mathrm{km}$. Propõese, portanto, a utilização das fibras microestruturadas para compensar perdas e dispersão cromática em enlaces ópticos. Supondo um enlace de 100 km, utilizando fibras SMF-28, é necessário o uso de $5 \mathrm{~km}$ de fibras microestruturadas para compensação de dispersão em banda larga. Utilizando a equação 3.20 para encontrar a potência de limiar para esta fibra, 
supondo perdas de $0,5 \mathrm{db} / \mathrm{km}$ chega-se a $280 \mathrm{~mW}$. Igualando-se o ganho Raman (equação 3.13) às perdas ópticas do enlace $(20 \mathrm{~dB})$, obtém-se a potência necessária ao laser de bombeio para compensar as perdas ópticas sofridas, resultando em $35 \mathrm{~mW}$. Para uma potência de bombeio de $280 \mathrm{~mW}$ (potência de limiar), obtêm-se um ganho Raman teórico de $84 \mathrm{~dB}$. Conclui-se, portanto, que utilizando-se um laser de bombeio com potência no limiar do ganho Raman, obtém-se ganho mais do que suficiente para suplantar as perdas ópticas do enlace com dispersão cromática compensada.

\subsection{Isolador óptico baseado em fibras microestruturadas}

Nesta seção é realizada uma investigação sobre a utilização das fibras microestruturadas para gerar isoladores e circuladores a fibra utilizando-se vidros com propriedades magneto-ópticas. Supondo o guia como sendo composto ao menos em parte por material com propriedades magneto-ópticas e que um campo magneto-estático seja aplicado na direção X. O tensor permissividade dielétrica para o material em questão pode ser escrito segundo [3.17]:

$$
\bar{\varepsilon}=\left[\begin{array}{ccc}
n_{x}{ }^{2} & 0 & 0 \\
0 & n_{y}{ }^{2} & -j \delta \\
0 & j \delta & n_{z}{ }^{2}
\end{array}\right]
$$

Os termos fora da diagonal principal causam o acoplamento entre as componentes de campo $E_{y}$ e $E_{z}$. Este acoplamento origina um efeito não recíproco no guia de onda, ou seja, o modo que se propaga na direção $+z$ viaja com uma velocidade diferente do mesmo modo propagando-se na direção $-z$. Este efeito não-recíproco pode ser utilizado para gerar dispositivos ópticos como isoladores e circuladores [3.18, 3.19]. Para a modelagem numérica desta estrutura, foi desenvolvido um formalismo baseado na técnica de diferenças finitas juntamente com o método da sobrerelaxação sucessiva (SOR). Utilizando o tensor descrito na equação 3.21, chega-se às seguintes equações acopladas (vide Apêndice II):

$$
\frac{d^{2}}{d y^{2}} E x+\frac{d^{2}}{d z^{2}} E x+k^{2} n_{x}{ }^{2} E x=\frac{d^{2}}{d x d y} E y+\frac{d}{d x}\left(\frac{d}{d z} E z\right)
$$




$$
\begin{gathered}
\frac{d^{2}}{d x^{2}} E y+\frac{d^{2}}{d z^{2}} E y+k^{2}\left(n_{y}{ }^{2} E y-j \delta E z\right)=\frac{d^{2}}{d y d x} E x+\frac{d}{d y}\left(\frac{d}{d z}(E z)\right) \\
\frac{d^{2}}{d x^{2}} E z+\frac{d^{2}}{d y^{2}} E z+k^{2}\left(n_{z}{ }^{2} E z+j \delta E y\right)=\frac{d^{2}}{d z d x} E x+\frac{d}{d z d y} E y
\end{gathered}
$$

Substituindo os operadores diferenciais por aproximações em diferenças finitas, pode-se montar um esquema SOR similar ao utilizado no formalismo SOR vetorial descrito no Apêndice I com a adição dos termos que representam o acoplamento entre as componentes $E_{y}$ e $E_{z}$ causado pela presença dos termos fora da diagonal principal no tensor permissividade. A descrição completa deste formalismo encontra-se no Apêndice II.

$\mathrm{O}$ isolador proposto baseia-se num acoplador utilizando fibras microestruturadas. $\mathrm{O}$ acoplador é constituído por dois defeitos gerados na estrutura pela retirada de dois furos de ar, como mostra a Figura 3.12.

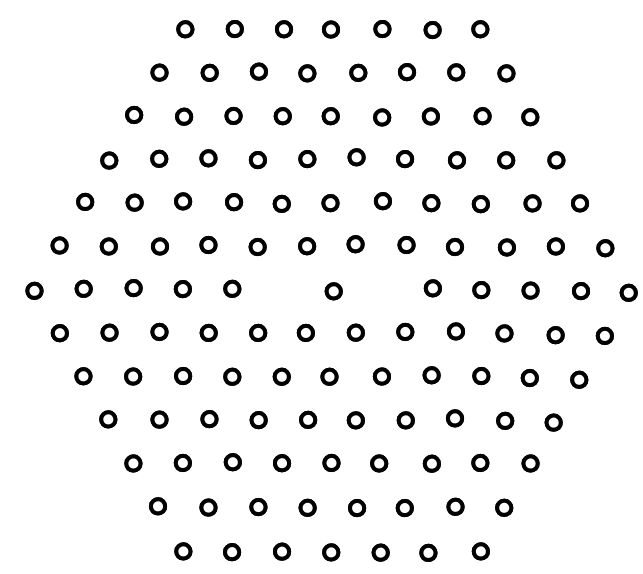

Figura 3.12- Seção transversal do isolador baseado em fibras microestruturadas.

Os defeitos gerados pela ausência dos furos de ar darão origem a um acoplador óptico. Supondo o acoplador como sendo composto de material magneto-óptico, a aplicação de um campo magnetostático transversal, acarretará num efeito não-recíproco, ou seja, haverá dois comprimentos de acoplamento diferentes conforme o sentido de propagação. A Figura 3.13 ilustra o funcionamento do isolador. 


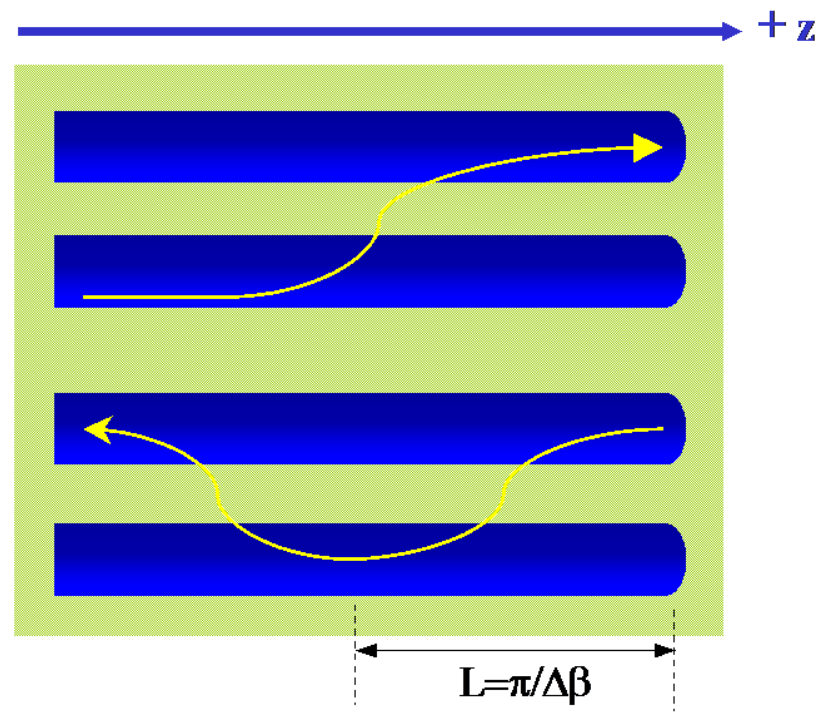

Figura 3.13 - Funcionamento do isolador. Existirão comprimentos de acoplamentos diferentes para cada direção de propagação.

Como pode ser observado, no sentido direto, o feixe é acoplado para o guia adjacente, enquanto que no sentido reverso, o feixe acopla duas vezes, retornando ao guia inicial. Ou seja, caso o feixe seja refletido, ele retornará para o guia adjacente, isolando a porta de entrada. Esta estrutura também pode ser usada como circulador óptico, dependendo da diferença entre o número de acoplamentos na direção $+Z$ e $-Z$. A Figura 3.14 mostra o funcionamento do circulador.
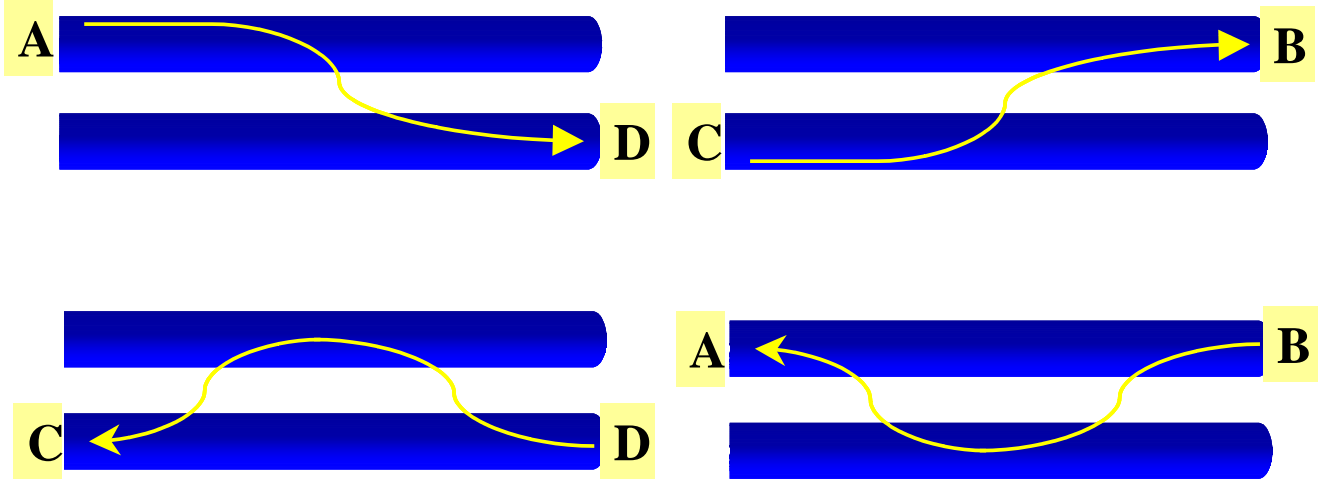

Figura 3.14 - Funcionamento do circulador.

Supondo um feixe entrando pela porta A, ele será acoplado ao guia oposto saindo pela porta D. Mas se um feixe entrar pela porta D ele sofrerá dois acoplamentos sucessivos, retornando pela porta $C$. Um feixe entrando pela porta $C$ sairá pela porta $B$ enquanto um 
feixe entrando pela porta B sairá pela porta A. Este é o princípio de funcionamento de um circulador óptico de quatro portas.

Outra possibilidade de aplicação para o dispositivo proposto é como sensor de campo magnético (ou corrente elétrica), vide Figura 3.15. Se o dispositivo for projetado com um comprimento tal que metade da potência óptica esteja presente em cada guia na saída, pode ser usado um esquema de medida diferencial de forma que sem campo magnético aplicado, a saída resultante seja nula. Com a aplicação de um campo magnético externo, haverá uma alteração no comprimento de acoplamento de forma que ocorra um descasamento na distribuição de potência em cada guia. Este descasamento causará uma variação na tensão de saída, que pode então ser usada para leitura do campo magnético aplicado.

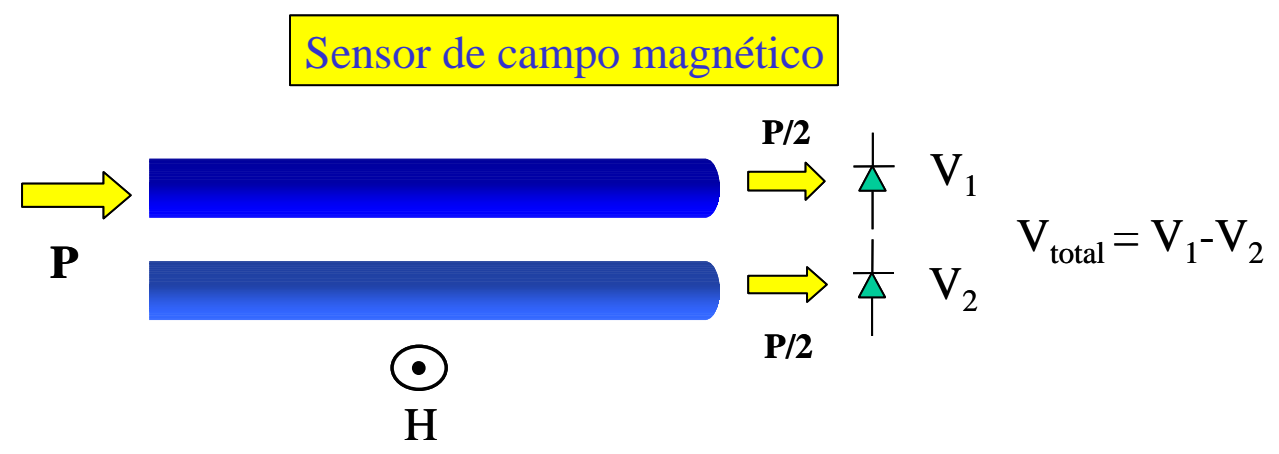

Figura 3.15 - Utilização do dispositivo como sensor de campo magnético.

Para o projeto do isolador, que é o elemento-chave destas aplicações, é necessário o cálculo do comprimento do acoplador, que pode ser estimado por [3.20]:

$$
L=\frac{\pi}{\left|\Delta \beta^{\text {Par }}-\Delta \beta^{\text {impar }}\right|}
$$

onde $\Delta \beta^{\text {Par }}$ e $\Delta \beta^{\text {impar }}$ são as diferenças entre as constantes de propagação nas direções $+\mathrm{Z}$ e -Z para o modo par e para o modo ímpar, respectivamente. Portanto, os parâmetros essenciais para a realização do projeto são as constantes de propagação dos modos fundamentais da estrutura. 


\subsubsection{Resultados}

Primeiramente, foi realizada uma análise acerca do acoplador isotrópico, ou seja, desconsiderando qualquer efeito não recíproco. A Figura 3.16 mostra o comprimento de acoplamento para o caso isotrópico em função do parâmetro d/ $\Lambda$.

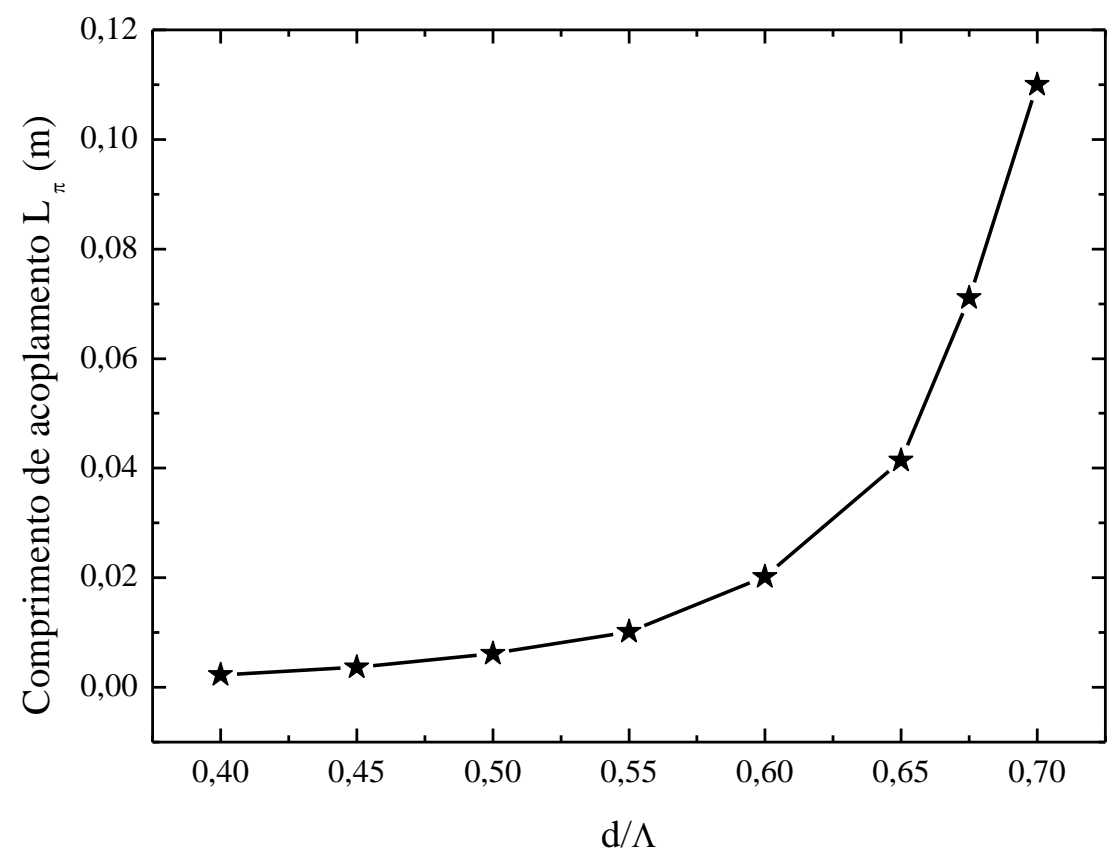

Figura 3.16 - Comprimento de acoplamento em função do parâmetro d/ $\Lambda$ para o acoplador isotrópico, supondo $\Lambda=3 \mu \mathrm{m}$.

Como pode ser observado, o comprimento de acoplamento cresce com o aumento de $\mathrm{d} / \Lambda$. Isto é explicado pelo maior confinamento óptico em cada núcleo, que ocorre com o aumento do diâmetro dos furos (d) para uma determinada distância entre furos $(\Lambda)$. Aqui pode ser mencionada uma grande vantagem das fibras microestruturadas, que é a possibilidade de usar diâmetros grandes de núcleo mantendo a condição monomodo. Desta forma, pode-se implementar isoladores que suportem elevada potência óptica.

Posteriormente, é estudada a influência do coeficiente magneto-óptico $\delta$, do material sobre o comprimento de acoplamento. A Figura 3.17 mostra esta influência para o caso específico de $\mathrm{d} / \Lambda=0,55$. 


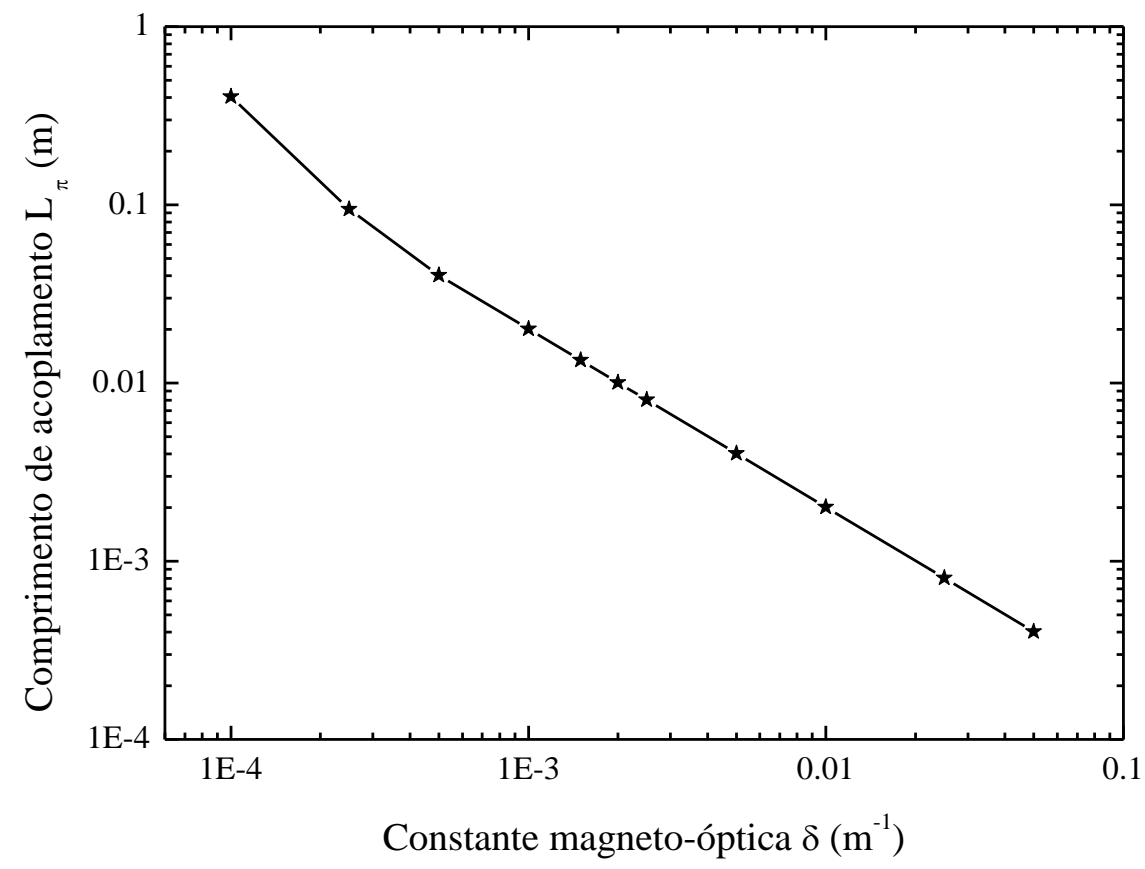

Figura 3.17 - Comprimento do isolador para o caso de $2 \mathrm{a} / \Lambda=0,55$ e $\Lambda=3,0 \mu \mathrm{m}$.

Pode-se concluir que o valor da constante magneto-óptica é um fator crucial, sendo que, para a geometria em questão, o comprimento do dispositivo pode variar de décimos de milímetro a quase um metro, dependendo do valor da constante magneto óptica do vidro a ser utilizado.

A viabilidade de implementação prática fica então vinculada à disponibilidade de vidros com constantes magneto-ópticas adequadas. Valores para $\delta$ já reportados na literatura incluem $\delta=5,310^{-8}$ para $\mathrm{H}_{0}=1 \mathrm{kOe}$ e $\lambda=1,33 \mu \mathrm{m}[3.19]$ e $\delta=1,110^{-6}$ para $\mathrm{H}_{0}=1 \mathrm{kOe}$ e $\lambda=1,06 \mu \mathrm{m}$ [3.21]. Note que para $10 \mathrm{kOe}$ (campo da ordem do existente em entreferro de motores) os valores são multiplicados por 10 e que, por outro lado, em 1,55 $\mu \mathrm{m}$ esses valores tendem a diminuir. 


\section{CONCLUSÕES}

Este trabalho consistiu no desenvolvimento de ferramentas computacionais para a modelagem das fibras microestruturadas. Foi desenvolvido um programa utilizando a técnica das diferenças finitas no domínio do tempo FDTD, que foi utilizado para calcular diversos diagramas de banda de cristais fotônicos bidimensionais. Foi também desenvolvida uma versão deste programa que utiliza técnicas de programação paralela. Além disso, foram desenvolvidos dois formalismos baseados na técnica da sobrerelaxação sucessiva SOR um para modelagem de guias de onda isotrópicos e outro para a modelagem de guias de onda magneto-ópticos. Foram ainda propostas e analisadas três aplicações para as fibras microestruturadas: compensação de dispersão, amplificação Raman e isolador óptico a fibra. Ainda, foi analisada a possibilidade de aproveitamento da fibra compensadora de dispersão com simultânea amplificação Raman.

Estudos visando a implementação prática de algumas das idéias propostas estão sendo realizadas no âmbito do projeto GIGA, em cooperação com o IQ-Unesp e a Fundação CPQD. 


\section{REFERÊNCIAS}

[1.1] M. Lonkar, T. Yoshie e A. Scherer, "Low threshold photonic crystal laser", Appl. Phys. Lett., vol. 81, no. 15, pp. 2680-2682, Outubro 2002.

[1.2] A. Mekis, J. Chen, I. Kurland, S. Fan, P. R. Velleneuve e J. D. Joannopoulos, "High transmission through sharp bends in photonic crystal waveguides", Phys. Rev. Lett., vol.77, no. 18, pp. 3787-3790, Outubro 1996.

[1.3] S. Fan, P. R. Villenueve e J. D. Joannopoulos, "Channel drop tunneling through localized states", Phys. Rev. Lett., vol. 80, no. 5, pp. 960-963, Fevereiro 1998.

[1.4] A. Sharkawy, S. Shi e D. Prather, "Multichannel wavelength division multiplexing with photonic crystals”, Appl. Opt. vol. 40, no. 14, pp. 2247-2251, Maio 2001.

[1.5] M. Koshiba, "Wavelength division multiplexing and demultiplexing with photonic crystal waveguide couplers", J. Lightwave Technol., vol. 19, no. 12, pp. 1970-1975 Dezembro 2001.

[1.6] J. C. Knight, T.A. Birks, P.S.J. Russell e D.M. Atkin, "All-silica single-mode optical fibre with photonic crystal cladding", Opt. Lett., vol. 21, pp. 1547-1549, Outubro 1996.

[1.7] J. C. Knight et al, "Properties of photonic crystal fiber and the effective index model", J. Opt. Soc. Am. A, vol. 15, no. 3, pp. 748-752, Março 1998.

[1.8] J. C. Knight, Broeng J, Birks TA e Russel PSJ, "Photonic Band Gap Guidance in Optical Fibers", Science, vol. 282 pp. 1476-1476, Novembro 1998.

[1.9] T. A. Birks, J. C. Knight e P. St. Russel, "Endlessly single-mode photonic crystal fiber", Opt. Lett., vol. 22, no. 13, pp. 961-963, Julho 1997.

[1.10] J. C. Knight, Birks TA, Cregan RF, Russell PS, de Sandro JP, "Large mode area photonic crystal fibre", Electron. Lett., vol. 21, pp. 1347-1348, Junho 1996.

[1.11] D. Mogilevtsev, T. A. Birks e P. St. Russel, "Group-velocity dispersion in photonic crystal fibers", Opt. Lett., vol. 23, no 21, pp. 1662-1664, Novembro 1998.

[1.12] R. F. Cregan, "Single-Mode Photonic Band Gap Guidance of Light in Air", Science, vol. 285, pp. 1537-1539, Setembro 1999.

[1.13] Y. Fink Ripin DJ, Fan SH, Chen CP, Joannopoulos JD e Thomas EL, "Guiding Optical Light in Air Using an All-Dielectric Structure", J. Lightwave Technol., vol. 17, no. 11, pp. 2039-2041, Novembro 1999. 
[1.14] M. Ibanescu, S. G. Johnson, M. Sojacic, J. D. Joannopoulos, Y. Fink, O. weisberg, T. D. Engeness, S. A. Jacobs e M. Skorobogatiy, "Analysis of mode structure in hollow dielectric waveguide fibers", Phys. Rev. E, vol. 67, no. 046608, pp. 1-8, Abril 2003.

[1.15] Eggleton BJ, Westbrook PS, Windeler RS, Spalter S e Strasser TA, "Grating resonances in air-silica microestructured optical fibers", Opt. Lett., vol. 24, no. 21, pp. 14601462, Novembro 1999.

[1.16] T. Sondergaard, "Photonic Crystal Distributed Feedback Fiber Lasers with Bragg Gratings”, J. Lightwave Technol., vol. 18, no. 4, pp. 589-597, Abril 2000.

[1.17] Xu JQ, Song J, Li C e Ueda K, "Cylindrically symetrical hollow fiber", Optics Comm., vol. 182, pp. 343-348, Agosto 2000.

[2.1] Ver referência 1.7.

[2.2] K. M. Ho, C. T. Chan e C. M. Soukoulis, "Existence of a Photonic Gap in Periodic Dielectric Structures", Phys. Rev. Lett., vol. 65, no 25, pp. 3152, Dezembro 1990.

[2.3] T. M. Monro, D.J. Richardson, N. G. R. Broberick e P. J. Bennet, "Holey Optical Fibers: An Efficient Modal Model”, J. Lightwave Technol., vol. 17, no. 6, pp. 1093-1102, Junho 1999.

[2.4] A. Ferrando, E Silvestre, J.J. Miret e P. Andres, "Full-vector analysis of a realistic photonic crystal fiber", Opt. Lett., vol. 24, no. 5, pp. 276-278, Março 1999.

[2.5] M. Midrio, M. P. Singh e C. G. Someda, "The space filling mode of holey fibers: an analytical vectorial solution", J. Lightwave Technol., vol. 18, no.7, pp. 1031-1037, Julho 2000 .

[2.6] K. Yee, "Numerical Solution of Initial Boundary Value Problems Involving Maxwell's Equations in Isotropic Media", IEEE Transactions on Antennas and Propagation, vol. AP14, no. 3, Maio 1966.

[2.7] M. Qiu e S. He, "FDTD algorithm for computing the off-plane band structure in a two dimensional photonic crystal with dielectric or metallic inclusions", Phys. Lett. A, vol. 278, pp. 348, Janeiro 2001.

[2.8] A. Asi e L. Shafai, "Dispersion analysis of anisotropic inhomogeneous waveguides using compact 2D-FDTD”, Elect. Lett., vol. 28, no. 15, pp. 1451, Julho 1992.

[2.9] U. Anderson, "Time-Domain Methods for Maxwell Equations", Tese de Doutorado, Royal Institute of Technology, Stockholm 2001.

[2.10] W. J. Buchanan, “Analysis of Electromagnetic Wave Propagation using the 3D FiniteDifference Time-Domain Method", Tese de Doutorado, Universidade Napier, Escócia, Março 1996. 
[2.11] V. Varadarajan e R. Mittra, "Finite-Difference Time-Domain (FDTD) Analysis Using Distributed Computing", IEEE Microwave and Guided Wave Letters, vol. 4, no. 5, pp. 144145, Maio 1994.

[2.12] S. D. Gedney, "Finite-Difference Time-Domain Analysis of Microwave Circuit Devices on High Performance Vector/Parallel Computers", IEEE Transactions on Microwave Theory and Technique., vol. 43, no. 10, pp. 2510-2514, Outubro 1995.

[2.13] N. Takada, K. Ando, K. Motojima, T. Ito e S. Kozaki, "New Distributed Implementation of the FDTD Method", Elect. Comm. in Japan, Part 2, vol. 80, no. 5, pp. 816, Fevereiro 1997.

[2.14] G. Guiffaut e K. Mahdjoubi, “A Parallel FDTD Algorithm Using the MPI Library”, IEEE Antennas and Propagation, vol. 43, no. 2, pp. 94-103, April 2001.

[2.15] N. Takada, T. Ito, K. Motojima, M. Ideo, T. Sato, S. Kozaki, "The High-Speed Computation on a Distributed Personal Computer Network by our Distributed FDTD Method", Microwave Conference, Asia-Pacific , pp. 273 -276, 2000.

[2.16] D. Hermann, M. Frank, K. Busch, e P. Wolfle, "Photonic band structure computations", Optics Express, vol. 8, no. 3, pp. 167-172, Janeiro 2001.

[2.17] Ver referência 2.7.

[2.18] J. D. Joannopoulos, R. D. Meade e J. Winn, "Photonic crystals molding the flow of light”, Princeton University Press, New Jersey, 1995.

[2.19] M. Qiu e S. He, "Large complete band gap in two-dimensional photonic crystals with elliptic air holes", Phys. Rev. B, vol. 60, no. 15, pp. 10610-10612, Outubro 1999.

[2.20] G. R. Hadley, "Transparent boundary condition for beam propagation", Optics Lett., vol. 16, no. 9, pp. 624-626, Maio 1991.

[2.21] M. S. Stern, "Semivectorial polarized H field solutions for dielectric waveguides with arbitrary index profiles”, IEE Proceedings, vol. 135, pp 333-338, 1998.

[2.22] W. Huang e H. A. Haus, "Analysis of Buried-Channel Waveguides and Couplers: Scalar Solution and Polarization Correction", J. Lightwave Technol., vol. 8, pp. 642-648, Maio 1990.

[2.23] D. M. Young, "Iterative Solution of Large Linear Systems", Academic Press, New York, 1971.

[2.24] C. Vassalo, "1993-1995 Optical mode solvers", Optical and Quantum Electronics, vol. 29, pp. 95-114, 1997.

[2.25] J. Yamauchi, G. Takahashi, e H. Nakano, "Modified Finite-Difference Formula for Semivectorial H-Field Solutions of Optical Waveguides", IEEE Photon. Technol. Lett., vol. 10, no. 8, pp. 1127-1129, Agosto 1998. 
[2.26] R. Hunsperger, "Photonic Devices and Systems", Newark, Marcel Dekker Inc., 1994. [2.27] M. Varnham, D. Payne, J. Love, "Fundamental limits to the transmission of linearly polarized light by birefringent optical fibres", Elect. Lett, vol. 20, no. 1, pp. 55-56, January 1984.

[2.28] Y. Hsueh, M Yang, H. Chang, "Three-Dimensional Noniterative Full-Vectorial Beam Propagation Method Based on the Alternating Direction Implicit Method", J. Lightwave Technol, vol. 17, no. 11, pp. 2389, Novembro 1999.

[2.29] F. Brechet, J. Marcou, D. Pagnoux e P. Roy, "Complete analysis of the Characteristics of Propagation into Photonic Crystal Fibers, by the Finite element Method", Optical Fiber Technology, vol. 6, pp. 181-191, 2000.

[2.30] Ver referência 2.4.

[2.31] M. J. Gander et al, "Experimental measurement of group velocity dispersion in photonic crystal fibre", Elect. Lett, vol. 35, no.1, pp. 63-64, Janeiro 1999.

[3.1] O. V. Butov, K. M. Golant, A. L. Tomashuk, M. J. N. Van Stralen, A. H. E. Breuls, "Refractive Index Dispersion of Doped Silica for Fiber Optics" Optics Communication, vol. 213, pp. 301-308, 2002.

[3.2] W.H. Reeves, J.C. Knight, P.S.J. Russell e P.J. Roberts, "Demonstration of UltraFlattened Dispersion in Photonic Crystal Fibers", Optics Express, vol. 10, no. 14, pp. 609613, Julho 2002.

[3.3] T.A. Birks, D. Mogilevtsev, J.C. Knight e P.S. Russell, "Dispersion Compensation Using Single-Material Fibers", IEEE Photon. Technol. Lett., vol. 11, no. 6, pp. 674-676, Junho 1999.

[3.4] L. P. Shen, W. P. Huang, G. X. Chen and S. S. Jian, "Design and Optimization of Photonic Crystal Fibers for Broadband Dispersion Compensation”, IEEE Photon. Technol. Lett, Vol. 15, No. 4, pp. 540-542, Abril 2003.

[3.5] F. Poli, A. Cucinota, M. Fuochi e S. Selleri, "Characterization of Microstructured Optical Fibers for Wideband Dispersion Compensation", J. Opt. Soc. Am. A, Vol. 20, No. 10, pp. 1958-1962, Outubro 2003.

[3.6] V. E. Nascimento, C. A. De Francisco, B. H. Borges e M .A. Romero, "Loss performance assessment in randomly perturbed photonic crystal fibers via a novel wideangle FD-BPM", artigo em preparação.

[3.7] A. Ferrando, E. Silvestre, P. Andrés, J. Miret e M. Andrés, "Designing the Properties of Dispersion-Flattened Photonic Crystal Fibers", Optics Express, Vol. 9, No. 13, pp. 687-697, Dezembro 2001. 
[3.8] K. Saitoh, M. Koshiba, T. Hasegawa and E. Sasaoka, "Chromatic Dispersion Control in Photonic Crystal Fibers: Application to Ultra-Flattened Dispersion", Optics Express, Vol. 11, No. 8, pp. 843-852, Abril 2003.

[3.9] J. B. Rosolem, comunicação pessoal.

[3.10] J.B. Rosolem, M.R.X. deBarros, A.A. Juriollo, J.C.R. Fernandes, M.R. Horiuchi e M.A. Romero, "Double Pass Erbium Doped Fiber Amplifier with na Embedded DCF Module for L Band DWDM Applications", OSA Topics on Optics and Photonics Series, Vol. 92, pp. 17-21, Dezembro 2003.

[3.11] M. N. Islam, "Raman Amplifiers for Telecommunications", IEEE J. Select. Topics Quantum Electron., vol. 8, no. 3, pp. 548-559, Maio/Junho 2002.

[3.12] Z. Yusoff, J. H. Lee, W. Belarti, T. M. Monro, P. C. Teh e D. J. Richardson, "Raman Effects in a Highly Nonlinear Holey Fiber: Amplification and Modulation”, Optics Letters, vol. 27, no. 6, pp. 424-426, Março 2002.

[3.13] G. P. Agrawal, Nonlinear Fiber Optics, New York: Academic Press, 1989.

[3.14] C. M. McIntosh, A. G. Grandpierre, D. N. Cristodoulides, J. Toulousse e J. P. Delavaux, "Eliminating SRS Chennel Depletion in Massive WDM Systems via Optical Filtering Techniques”, IEEE Photon. Technol. Lett., vol. 13, No. 4, pp. 302-304, Abril 2001. [3.15] M. Fuochi, F. Poli, S. Selleri, A. Cucinotta e L. Vincetti, "Study of Raman Amplification Properties in Triangular Photonic Crystal Fibers", J. Lightwave Technol, vol. 21, no. 10, pp. 2247-2254, Outubro de 2003.

[3.16] S. Cani, M. Freitas, R. Almeida e L.C. Calmon, "Limites em Amplificadores Raman com Fibras Compensadoras de Dispersão", XX Simpósio Brasileiro de Telecomunicações, Rio de Janeiro, Brasil, 2003.

[3.17] P. Hlawiczka, Gyrotropic waveguides, New York: Academic Press, 1981.

[3.18] R. Wolfe, W. Wang, D. DiGiovanni and A. Vengsarkar, "All-fiber magneto-optic isolator based on the nonreciprocal phase shift in asymetric fiber", Optics Letters, vol. 20, no. 16, August 1995.

[3.19] W. Wang, R. Wolfe, P. Anthony, "Analysis of Magneto-optic nonreciprocal phase shift in asymetric fibers for all-fibers isolators by variational vector-wave mode-matching method", J. Lightwave Technol, vol. 14, no. 5, May 1996.

[3.20] N. Bahlman, M. Lohmeyer, O. Zhuromskyy, H. Dotsch e P. Hertel, "Nonreciprocal coupled waveguides for integrated optical isolators and circulators for TM-modes", Optics Comm., vol. 161, pp. 330-337, Março 1999, 
[3.21] J. Ballato and E. Snitzer, "Fabrication of fibers with high rare-earth concentrations for

Faraday isolator applications", Applied Optics, vol. 34, no. 30, pp. 6648-6854, Outubro 1995. 


\section{APENDICES}

\section{Apêndice I: Método SOR vetorial}

O método SOR vetorial parte da equação de Helmholtz em sua forma vetorial. Para deduzirmos a equação de onda vetorial, partamos das equações de Maxwell :

$$
\begin{array}{lll}
\nabla \times E=-j \omega \mu_{0} H & (1) & \nabla \cdot\left(n^{2} E\right)=0 \\
\nabla \times H=-j \omega \varepsilon_{0} n^{2} E & \text { (2) } & \nabla \cdot H=0
\end{array}
$$

Aplicando-se o operador $\nabla \times$ em (1):

$$
\nabla \times \nabla \times E=-j \omega \mu_{0} \nabla \times H
$$

Substituindo (2) em (1) :

$$
\nabla \times \nabla \times E=\omega^{2} \mu_{0} \varepsilon_{0} n^{2} E
$$

e tomando $k=\omega \sqrt{\mu_{0} \varepsilon_{0}}$, temos :

$$
\nabla \times \nabla \times E=k^{2} n^{2} E
$$

Usando a identidade vetorial :

$$
\nabla \times \nabla \times E=\nabla(\nabla \cdot)-\nabla^{2}
$$

As componentes transversais de (5) reduzem-se a : 


$$
\nabla^{2} E_{t}+n^{2} k^{2} E_{t}=\nabla_{t}\left(\nabla_{t} \cdot E_{t}+\frac{d}{d z} E z\right)
$$

De (3) temos :

$$
\nabla \cdot\left(n^{2} E\right)=0
$$

Separando os termos transversais do termo longitudinal (z) :

$$
\nabla_{t} \cdot\left(n^{2} E_{t}\right)+\frac{d}{d z}\left(n^{2} E_{z}\right)=0
$$

resolvendo a derivada em $\mathrm{z}$ :

$$
\nabla_{t} \cdot\left(n^{2} E_{t}\right)+n^{2} \frac{d}{d z}\left(E_{z}\right)+E_{z} \frac{d}{d z}\left(n^{2}\right)=0
$$

Se o índice de refração varia lentamente em z, podemos negligenciar o termo $E_{z} \frac{d}{d z}\left(n^{2}\right)$, então, de (7), temos :

$$
\frac{d}{d z}\left(E_{z}\right)=-\frac{1}{n^{2}} \nabla_{t} \cdot\left(n^{2} E_{t}\right)
$$

Substituindo (8) em (6), as componentes transversais de (6), tornam-se:

$$
\nabla^{2} E_{t}+n^{2} k^{2} E_{t}=\nabla_{t}\left(\nabla_{t} \cdot E_{t}-\frac{1}{n^{2}} \nabla_{t} \cdot\left(n^{2} E_{t}\right)\right)
$$

Rescrevendo o lado direito de (9), e expandindo os operadores gradiente e divergente, chega-se a : 


$$
\begin{aligned}
& \frac{d^{2}}{d x^{2}} E x+\frac{d^{2}}{d y^{2}} E y+\frac{d^{2}}{d y d x} E x+\frac{d^{2}}{d x d y} E y-\frac{d}{d x}\left(\frac{1}{n^{2}}\left(\frac{d}{d x}\left(n^{2} E x\right)\right)\right) \\
& -\frac{d}{d x}\left(\frac{1}{n^{2}}\left(\frac{d}{d y}\left(n^{2} E y\right)\right)\right)-\frac{d}{d y}\left(\frac{1}{n^{2}}\left(\frac{d}{d x}\left(n^{2} E x\right)\right)\right)-\frac{d}{d y}\left(\frac{1}{n^{2}}\left(\frac{d}{d y}\left(n^{2} E y\right)\right)\right)
\end{aligned}
$$

Procedendo igualmente no lado esquerdo de (9) :

$$
\frac{d^{2}}{d x^{2}} E x+\frac{d^{2}}{d y^{2}} E x+\frac{d^{2}}{d z^{2}} E x+\frac{d^{2}}{d x^{2}} E y+\frac{d^{2}}{d y^{2}} E y+\frac{d^{2}}{d z^{2}} E y+n^{2} k^{2} E x+n^{2} k^{2} E y
$$

Tomando apenas as componentes na direção x, chega-se a :

$$
\frac{d^{2}}{d y^{2}} E x+\frac{d^{2}}{d z^{2}} E x+n^{2} k^{2} E x=\frac{d^{2}}{d x d y} E y-\frac{d}{d x}\left(\frac{1}{n^{2}}\left(\frac{d}{d x}\left(n^{2} E x\right)\right)\right)-\frac{d}{d x}\left(\frac{1}{n^{2}}\left(\frac{d}{d y}\left(n^{2} E y\right)\right)\right)
$$

Reagrupando os termos :

$$
\left(\frac{d^{2}}{d y^{2}}+\frac{d^{2}}{d z^{2}}+\frac{d}{d x} \frac{1}{n^{2}} \frac{d}{d x} n^{2}+n^{2} k^{2}\right) E x=\left(\frac{d^{2}}{d x d y}-\frac{d}{d x} \frac{1}{n^{2}} \frac{d}{d y} n^{2}\right) E y
$$

Da mesma forma, tomando as componentes na direção y, temos:

$$
\frac{d^{2}}{d x^{2}} E y+\frac{d^{2}}{d z^{2}} E y+n^{2} k^{2} E y=\frac{d^{2}}{d x d y} E x-\frac{d}{d y}\left(\frac{1}{n^{2}}\left(\frac{d}{d y}\left(n^{2} E y\right)\right)\right)-\frac{d}{d y}\left(\frac{1}{n^{2}}\left(\frac{d}{d x}\left(n^{2} E x\right)\right)\right)
$$

Ou, rescrevendo:

$$
\left(\frac{d^{2}}{d x^{2}}+\frac{d^{2}}{d z^{2}}+\frac{d}{d y} \frac{1}{n^{2}} \frac{d}{d y} n^{2}+n^{2} k^{2}\right) E y=\left(\frac{d^{2}}{d y d x}-\frac{d}{d y} \frac{1}{n^{2}} \frac{d}{d x} n^{2}\right) E x
$$

Supõe-se o campo com a seguinte dependência em z : 


$$
E=E^{\prime} \cdot e^{j \beta z}
$$

As derivadas primeira e segunda em relação a z podem ser escritas como:

$$
\begin{aligned}
& \frac{d}{d z} E=-j \beta E \\
& \frac{d^{2}}{d z^{2}} E x=-\beta^{2} E
\end{aligned}
$$

Substituindo (12) em (10) e (11), obtêm-se :

Equação (12) em equação (10) :

$$
\left(\frac{d^{2}}{d y^{2}}+\frac{d}{d x} \frac{1}{n^{2}} \frac{d}{d x} n^{2}+n^{2} k^{2}-\beta^{2}\right) E x=\left(\frac{d^{2}}{d x d y}-\frac{d}{d x} \frac{1}{n^{2}} \frac{d}{d y} n^{2}\right) E y
$$

Substituindo a equação (12) na equação (11) e procedendo analogamente, obtemos:

$$
\left(\frac{d^{2}}{d x^{2}}+\frac{d}{d y} \frac{1}{n^{2}} \frac{d}{d y} n^{2}+n^{2} k^{2}-\beta^{2}\right) E y=\left(\frac{d^{2}}{d y d x}-\frac{d}{d y} \frac{1}{n^{2}} \frac{d}{d x} n^{2}\right) E x
$$

Escrevendo os operadores em termos de suas aproximações em diferenças finitas, temos:

$$
\begin{aligned}
& L x x=\frac{d^{2}}{d x^{2}}=\frac{E y_{i+1, j}-2 E y_{i, j}+E y_{i-1, j}}{h} \\
& L y y=\frac{d^{2}}{d y^{2}}=\frac{E x_{i, j+1}-2 E x_{i, j}+E x_{i, j-1}}{h}
\end{aligned}
$$




$$
\begin{aligned}
& L x y=\left(\frac{d^{2}}{d x d y}-\frac{d}{d x} \frac{1}{n^{2}} \frac{d}{d y} n^{2}\right) E y= \\
& =\frac{1}{4 h^{2}} \cdot\left\{\begin{array}{l}
{\left[1-\frac{n^{2}{ }_{i+1, j+1}}{n^{2}{ }_{i+1, j}}\right] \cdot E y_{i+1, j+1}+\left[\frac{n^{2}{ }_{i+1, j-1}}{n^{2}{ }_{i+1, j}}-1\right] \cdot E y_{i+1, j-1}+} \\
{\left[\frac{n^{2}{ }_{i-1, j+1}}{n^{2}{ }_{i-1, j}}-1\right] \cdot E y_{i-1, j+1}+\left[1-\frac{n^{2}{ }_{i-1, j-1}}{n^{2}{ }_{i-1, j}}\right] \cdot E y_{i-1, j-1}}
\end{array}\right\} \\
& L y x=\left(\frac{d^{2}}{d y d x}-\frac{d}{d y} \frac{1}{n^{2}} \frac{d}{d x} n^{2}\right) E x= \\
& =\frac{1}{4 h^{2}} \cdot\left\{\begin{array}{l}
{\left[1-\frac{n^{2}{ }_{i+1, j+1}}{n^{2}{ }_{i, j+1}}\right] \cdot E x_{i+1, j+1}+\left[\frac{n^{2}{ }_{i-1, j+1}}{n^{2}{ }_{i, j-1}}-1\right] \cdot E x_{i-1, j+1}+} \\
{\left[\frac{n^{2}{ }_{i+1, j-1}}{n^{2}{ }_{i, j+1}}-1\right] \cdot E x_{i+1, j-1}+\left[1-\frac{n^{2}{ }_{i-1, j-1}}{n^{2}{ }_{i, j-1}}\right] \cdot E x_{i-1, j-1}}
\end{array}\right\}
\end{aligned}
$$

$$
\begin{aligned}
& \text { Lxnx }=\frac{d}{d x} \frac{1}{n^{2}} \frac{d}{d x} n^{2} E x=
\end{aligned}
$$

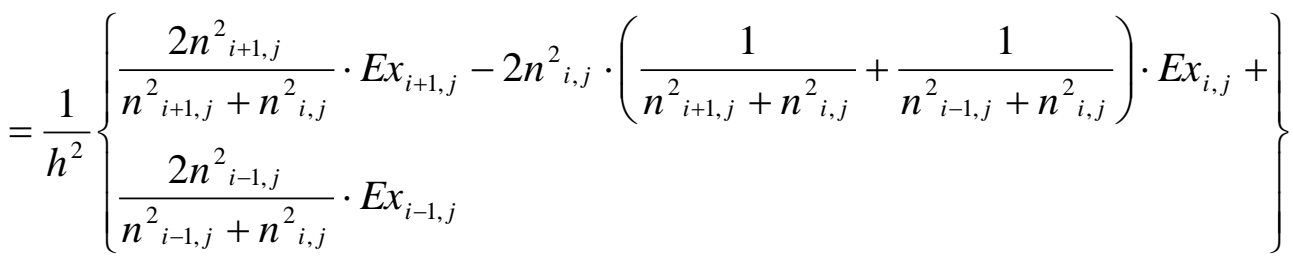

$$
\begin{aligned}
& \text { Lyny }=\frac{d}{d y} \frac{1}{n^{2}} \frac{d}{d y} n^{2} E y= \\
& =\frac{1}{h^{2}}\left\{\begin{array}{l}
\frac{2 n^{2}{ }_{i, j+1}}{n^{2}{ }_{i, j+1}+n^{2}{ }_{i, j}} \cdot E y_{i, j+1}-2 n^{2}{ }_{i, j} \cdot\left(\frac{1}{n^{2}{ }_{i, j+1}+n_{i, j}^{2}}+\frac{1}{n^{2}{ }_{i, j-1}+n_{i, j}^{2}}\right) \cdot E y_{i, j}+ \\
\frac{2 n_{i, j-1}}{n^{2}{ }_{i, j-1}+n^{2}{ }_{i, j}} \cdot E y_{i, j-1}
\end{array}\right\}
\end{aligned}
$$

onde podemos agrupar alguns termos da forma: 


$$
\begin{aligned}
& a=\frac{2 n_{i, j+1}^{2}}{n^{2}{ }_{i, j+1}+n_{i, j}^{2}} \\
& b=2 n_{i, j}^{2} \cdot\left(\frac{1}{n_{i, j+1}^{2}+n_{i, j}^{2}}+\frac{1}{n_{i, j-1}^{2}+n_{i, j}^{2}}\right) \\
& c=\frac{2 n_{i, j-1}^{2}}{n^{2}{ }_{i, j-1}+n_{i, j}^{2}}
\end{aligned}
$$

Rescrevendo Lxnx :

$\left[\left(n_{i, j}^{2} k^{2}-\beta^{2}\right)-\frac{2}{h^{2}}-\frac{b}{h^{2}}\right] E x_{i, j}^{*}=-\frac{1}{h^{2}}\left[E x_{i, j+1}+E x_{i, j-1}+a E x_{i+1, j}+c E x_{i-1, j}\right]+L x y E y$

e Lyny :

$$
\left[\left(n^{2}{ }_{i, j} k^{2}-\beta^{2}\right)-\frac{2}{h^{2}}-\frac{b}{h^{2}}\right] E y^{*}{ }_{i, j}=-\frac{1}{h^{2}}\left[E x_{i+1, j}+E x_{i-1, j}+a E x_{i, j+1}+c E x_{i, j-1}\right]+L y x E x
$$

Temos, para os valores centrais $i, j$ :

$$
\begin{aligned}
E x_{i, j}^{*} & =\frac{\frac{1}{h^{2}}\left[E x_{i, j+1}+E x_{i, j-1}+a E x_{i+1, j}+c E x_{i-1, j}\right]+L x y E y}{\left[\frac{2}{h^{2}}+\frac{b}{h^{2}}-\left(n^{2}{ }_{i, j} k^{2}-\beta^{2}\right)\right]} \\
E y^{*}{ }_{i, j} & =\frac{\frac{1}{h^{2}}\left[E y_{i+1, j}+E y_{i-1, j}+a E y_{i, j+1}+c E y_{i, j-1}\right]+L y x E x}{\left[\frac{2}{h^{2}}+\frac{b}{h^{2}}-\left(n^{2}{ }_{i, j} k^{2}-\beta^{2}\right)\right]}
\end{aligned}
$$

O método SOR é dado por:

$$
\begin{aligned}
& E x_{i, j}^{n}=\omega E x^{*}+(1-\omega) E x_{i, j}^{n-1} \\
& E y_{i, j}^{n}=\omega E y^{*}+(1-\omega) E y^{n-1}{ }_{i, j}
\end{aligned}
$$




\section{Apêndice II: SOR para meios magneto-ópticos com campo magnético aplicado na direção $X$}

Para deduzir a equação de Helmholtz correspondente para meios magneto-ópticos, procede-se de forma semelhante ao Apêndice I, mas considerando o tensor permissividade tendo a forma:

$$
\bar{\varepsilon}=\left[\begin{array}{ccc}
n_{x}{ }^{2} & 0 & 0 \\
0 & n_{y}{ }^{2} & -j \delta \\
0 & j \delta & n_{z}{ }^{2}
\end{array}\right]
$$

Parte-se então das equações de Maxwell:

$$
\begin{aligned}
& \nabla \times E=-j \omega \mu_{0} H \\
& \text { (1) } \nabla \cdot(D)=0 \\
& \nabla \times H=-j \omega \varepsilon_{0} D \\
& \text { (2) } \nabla \cdot H=0
\end{aligned}
$$

Aplicando-se o operador $\nabla \times$ em (1)

$$
\nabla \times \nabla \times E=-j \omega \mu_{0} \nabla \times H
$$

Substituindo (2) em (1):

$$
\nabla \times \nabla \times E=\omega^{2} \mu_{0} D
$$

e, tomando $k=\omega \sqrt{\mu_{0} \varepsilon_{0}}$, temos:

$$
\nabla \times \nabla \times E=k^{2} D r
$$

onde $\operatorname{Dr}=D / \varepsilon_{0}$. Usando a identidade vetorial: $\nabla \times \nabla \times E=\nabla(\nabla \cdot)-\nabla^{2}$, a equação (5) reduz-se a: 


$$
\nabla^{2} E+k^{2} D r=\nabla(\nabla \cdot E)
$$

Separando os termos em cada direção:

$$
\begin{gathered}
\frac{d^{2}}{d y^{2}} E x+\frac{d^{2}}{d z^{2}} E x+k^{2} n_{x}{ }^{2} E x=\frac{d^{2}}{d x d y} E y+\frac{d}{d x}\left(\frac{d}{d z} E z\right) \quad \text { direção x } \\
\frac{d^{2}}{d x^{2}} E y+\frac{d^{2}}{d z^{2}} E y+k^{2}\left(n_{y}{ }^{2} E y-j \delta E z\right)=\frac{d^{2}}{d y d x} E x+\frac{d}{d y}\left(\frac{d}{d z}(E z)\right) \quad \text { direção y } \\
\frac{d^{2}}{d x^{2}} E z+\frac{d^{2}}{d y^{2}} E z+k^{2}\left(n_{z}{ }^{2} E z+j \delta E y\right)=\frac{d^{2}}{d z d x} E x+\frac{d}{d z d y} E y \quad \text { direção z }
\end{gathered}
$$

De (3) temos que $\nabla \cdot(D r)=0$, expandindo, obtém-se:

$$
\frac{d}{d z} E z=-\frac{1}{n_{z}{ }^{2}}\left[\frac{d}{d x} n_{x}{ }^{2} E x+\frac{d}{d y}\left(n_{y}{ }^{2} E y-j \delta E z\right)+j \frac{d}{d z} \delta E y\right]
$$

Substituindo (8) em (5) e (6), temos:

$$
\Rightarrow(8) \text { em (5): }
$$

$$
\begin{aligned}
& \frac{d^{2}}{d y^{2}} E x+\frac{d^{2}}{d z^{2}} E x+\frac{d}{d x}\left(\frac{1}{n_{z}{ }^{2}} \frac{d}{d x} n_{x}{ }^{2} E x\right)+k^{2} n_{x}{ }^{2} E x=\frac{d^{2}}{d x d y} E y-\frac{d}{d x}\left(\frac{1}{n_{z}{ }^{2}} \frac{d}{d y} n_{y}{ }^{2} E y\right) \\
& +\frac{d}{d x}\left(\frac{1}{n_{z}{ }^{2}} \frac{d}{d y} j \delta E z\right)-\frac{d}{d x}\left(\frac{1}{n_{z}{ }^{2}} \frac{d}{d z} j \delta E y\right)
\end{aligned}
$$

$\Rightarrow$ (8) em (6): 


$$
\begin{aligned}
& \frac{d^{2}}{d x^{2}} E y+\frac{d^{2}}{d z^{2}} E y+\frac{d}{d y}\left(\frac{1}{n_{z}{ }^{2}} \frac{d}{d y} n_{y}{ }^{2} E y\right)+k^{2} n_{y}{ }^{2} E y=\frac{d^{2}}{d y d x} E x-\frac{d}{d y}\left(\frac{1}{n_{z}{ }^{2}} \frac{d}{d x} n_{x}{ }^{2} E x\right) \\
& +\frac{d}{d y}\left(\frac{1}{n_{z}{ }^{2}} \frac{d}{d y} j \delta E z\right)-\frac{d}{d y}\left(\frac{1}{n_{z}{ }^{2}} \frac{d}{d z} j \delta E y\right)+j k^{2} \delta E z
\end{aligned}
$$

Os termos contendo o parâmetro $\delta$ são os termos a serem adicionados ao formalismo SOR vetorial descrito no Apêndice I. Descrevendo os termos adicionais em diferenças finitas, obtemos:

=> Para a componente Ex:

$\frac{d}{d x}\left(\frac{1}{n_{z}{ }^{2}} \frac{d}{d y} j \delta E z\right)=\frac{2 j}{\Delta x \Delta y}\left[\begin{array}{l}\frac{\delta(i+1, j+1) E y(i+1, j+1)-\delta(i+1, j-1) E y(i+1, j-1)}{n_{z}{ }^{2}(i+1, j)+n_{z}{ }^{2}(i, j)} \\ \frac{\delta(i-1, j+1) E y(i-1, j+1)-\delta(i-1, j-1) E y(i-1, j-1)}{n_{z}{ }^{2}(i-1, j)+n_{z}{ }^{2}(i, j)}\end{array}\right]$

$\frac{d}{d x}\left(\frac{1}{n_{z}{ }^{2}} \frac{d}{d z} j \delta E y\right)=-\beta \frac{d}{d x} \frac{\delta}{n_{z}{ }^{2}} E y=\frac{-\beta}{2 \Delta x}\left[\frac{\delta(i+1, j) E y(i+1, j)}{n_{z}{ }^{2}(i+1, j)}-\frac{\delta(i-1, j) E y(i-1, j)}{n_{z}{ }^{2}(i-1, j)}\right]$

$=>$ Para a componente Ey:

$$
\frac{d}{d y}\left(\frac{1}{n_{z}^{2}} \frac{d}{d y} j \delta E z\right)=\frac{2 j}{\Delta y^{2}}\left[\begin{array}{l}
\frac{\delta(i, j+1) E z(i, j+1)-\delta(i, j) E z(i, j)}{n_{z}^{2}(i, j+1)+n_{z}^{2}(i, j)}- \\
\frac{\delta(i, j) E z(i, j)-\delta(i, j-1) E z(i, j-1)}{n_{z}^{2}(i, j)+n_{z}^{2}(i, j-1)}
\end{array}\right]
$$




$$
\begin{aligned}
\frac{d}{d y}\left(\frac{1}{n_{z}{ }^{2}} \frac{d}{d z} j \delta E y\right)=-\beta \frac{d}{d y} \frac{\delta}{n_{z}^{2}} E y & =\frac{-\beta}{2 \Delta y}\left[\frac{\delta(i, j+1) E y(i, j+1)}{n_{z}{ }^{2}(i, j+1)}-\frac{\delta(i, j-1) E y(i, j-1)}{n_{z}{ }^{2}(i, j-1)}\right] \\
j k^{2} \delta E z & =j k^{2} \delta(i, j) E_{z}(i, j)
\end{aligned}
$$

Adicionalmente ao que ocorre com o formalismo vetorial, têm-se uma equação para a componente de campo Ez. Escreve-se, então a eq. (7) em diferenças finitas e isola-se o termo central $(\mathrm{i}, \mathrm{j})$, resultando:

$$
\begin{array}{r}
E z(i+1, j)+E z(i-1, j)+E z(i, j+1)+E z(i, j-1)+k^{2} j \delta(i, j) E y(i, j) \\
E z(i, j)=\frac{-j \frac{\beta}{2 \Delta y}(E y(i, j+1)-E y(i, j-1))-j \frac{\beta}{2 \Delta x}(E x(i+1, j)-E x(i-1, j))}{4-k^{2} n_{z}{ }^{2}}
\end{array}
$$

\section{Cálculo do $\beta$ através do método variacional:}

A partir da eq. (6a), multiplicando ambos os lados pelo conjugado da componente de campo Ey e integrando sobre a seção transversal, chega-se a:

$$
\begin{aligned}
& \beta^{2} \iint|E y|^{2}+\beta \iint \frac{d}{d y}\left(\frac{\delta}{n_{z}{ }^{2}} E y\right) E y^{*}= \\
& \iint\left(\frac{d^{2}}{d x^{2}}(E y) E y^{*}+\frac{d}{d y}\left(\frac{1}{n_{z}{ }^{2}} \frac{d}{d y} n_{y}{ }^{2} E y\right) E y^{*}+k^{2} n_{y}{ }^{2}|E y|^{2}-\frac{d}{d y}\left(\frac{1}{n_{z}{ }^{2}} \frac{d}{d y} j \delta E z\right) E y^{*}-j k^{2} \delta E z E y^{*}\right)
\end{aligned}
$$

nota-se a semelhança com a equação definida para o método vetorial, com o acréscimo de alguns termos que correspondem ao acoplamento de campo originado pelo efeito magnetoóptico. Desta forma, define-se o método vetorial para meios magneto-ópticos. 


\section{Apêndice III: Cálculo do parâmetro ótimo de relaxação $\omega_{o p t}$}

O valor ótimo para o método SOR é dado por:

$$
\omega_{o p t}=2 \times\left[1+\left(1-\bar{\mu}^{2}\right)^{1 / 2}\right]^{-1}
$$

onde $\bar{\mu}$ é o maior autovalor do sistema considerado. Buscamos, então, uma equação para estimar o maior autovalor do sistema gerado pelo método SOR semivetorial. Partindo da equação semivetorial de Helmholtz;

$$
\frac{d^{2}}{d z^{2}} H x+\frac{d^{2}}{d x^{2}} H x+n^{2} \frac{d}{d y}\left(\frac{1}{n^{2}} \frac{d}{d y} H x\right)+\kappa^{2} n^{2} H x=0
$$

supondo o campo como sendo uma onda plana e escrevendo o campo como uma parte com variação lenta e uma parte de variação rápida em z (aproximação de envoltória lenta) podemos escrever:

$$
H=H^{\prime} e^{-j \beta z}
$$

onde o termo $H^{\prime}$ descreve a variação lenta e o termo $e^{j \beta z}$ descreve a variação rápida do campo (variação de fase). As derivadas primeira e segunda em relação a z podem então ser descritas como:

$$
\begin{aligned}
& \frac{d}{d z} H=-j \beta H \\
& \frac{d^{2}}{d z^{2}} H=-\beta^{2} H
\end{aligned}
$$

substituindo a derivada segunda em relação a z, tem-se: 


$$
-\beta^{2} H x+\frac{d^{2}}{d x^{2}} H x+n^{2} \frac{d}{d y}\left(\frac{1}{n^{2}} \frac{d}{d y} H x\right)+\kappa^{2} n^{2} H x=0
$$

supondo $\operatorname{Hy}(\mathrm{x}, \mathrm{y})=\mathrm{X}(\mathrm{x}) \mathrm{Y}(\mathrm{y})$ e substituindo em (2), tem-se:

$$
X(x) \cdot n^{2} \frac{d}{d y}\left(\frac{1}{n^{2}} \frac{d}{d y} Y(y)\right)+Y(y) \cdot \frac{d^{2}}{d x^{2}} X(x)+\left(-\beta+\kappa^{2} n^{2}\right) \cdot X(x) \cdot Y(y)=0
$$

Reescrevendo (2) em diferenças finitas, tem-se:

$-\beta^{2} H x_{i, j}+\frac{H x_{i+1, j}-2 H x_{i, j}+H x_{i-1, j}}{h^{2}}+\frac{a^{\prime} H x_{i, j+1}-2 b^{\prime} H x_{i, j}+c^{\prime} H x_{i, j-1}}{h^{2}}+\kappa^{2} n^{2} H x_{i, j}=0$

Da mesma forma podemos reescrever (3) em termos de diferenças finitas:

$$
\left(\frac{2}{h^{2}}+\frac{2 b}{h^{2}}+\beta^{2}-\kappa^{2} n^{2}\right) \cdot X_{i} \cdot Y_{j}=Y_{j} \cdot\left(X_{i+1}+X_{i-1}\right)+X_{i} \cdot\left(a^{\prime} Y_{j+1}+c^{\prime} Y_{j-1}\right)=0
$$

chamando $\lambda=\frac{2}{h^{2}}+\frac{2 b}{h^{2}}+\beta^{2}-\kappa^{2} n^{2}$, tem-se:

$$
X_{i} \cdot Y_{j}=\frac{Y_{j}}{\lambda} \cdot\left(X_{i+1}+X_{i-1}\right)+\frac{X_{i}}{\lambda} \cdot\left(a^{\prime} Y_{j+1}+c^{\prime} Y_{j-1}\right)=0
$$

Supondo o termo $\lambda$ constante, pode-se calcular o autovalor do sistema, que é equivalente a encontrarmos um termo $\mu$ tal que:

$$
\frac{Y_{j}}{\lambda} \cdot\left(X_{i+1}+X_{i-1}\right)+\frac{X_{i}}{\lambda} \cdot\left(a^{\prime} Y_{j+1}+c^{\prime} Y_{j-1}\right)=\mu \cdot X_{i} \cdot Y_{j}
$$

dividindo a Equação (7) por $X_{i} \cdot Y_{j}$, temos:

$$
\frac{X_{i+1}+X_{i-1}}{X_{i}}+\frac{a^{\prime} Y_{j+1}+c^{\prime} Y_{j-1}}{Y_{j}}=\lambda \cdot \mu
$$

pode-se então fazer: 


$$
\begin{gathered}
\frac{a^{\prime} Y_{j+1}+c^{\prime} Y_{j-1}}{Y_{j}}=\eta \\
\frac{X_{i+1}+X_{i-1}}{X_{i}}=\lambda \cdot \mu-\eta
\end{gathered}
$$

Supondo $X=\operatorname{sen}(p \pi x), Y=\operatorname{sen}(q \pi y)$ e tomando $h$ como o incremento nas direções $x$ e $y$, temos:

$$
\begin{aligned}
& \eta=\left(a^{\prime}+c^{\prime}\right) \cos (p \pi h) \\
& 2 \cos (q \pi h)=\lambda \mu-\eta
\end{aligned}
$$

substituindo (10) em (11):

$$
2 \cos (q \pi h)=\lambda \mu-\left(a^{\prime}+c^{\prime}\right) \cos (p \pi h)
$$

isolando $\mu$ e supondo $p=q=1$ :

$$
\mu=\frac{\left(2+a^{\prime}+c^{\prime}\right) \cos (\pi h)}{\frac{2}{h^{2}}+\frac{2 b}{h^{2}}+\beta^{2}-\kappa^{2} n^{2}}
$$

maximizando $\mu$ :

$$
\bar{\mu}=\frac{4 \cos (\pi h)}{\frac{4}{h^{2}}+\beta^{2}-\kappa^{2} n^{2}}
$$

o valor de $n$ é tomado como o índice de refração da estrutura que maximiza o auto valor e pode ser tomado uma como uma média dos índices ou como o menor deles. 


\section{Apêndice IV: Condição de contorno transparente}

A condição de contorno transparente é também conhecida por TBC do inglês "Transparent Boundary Condition". Esta condição de contorno supõe a onda eletromagnética que atinge a borda da janela computacional como uma onda plana que passa livremente através dela (daí o termo transparente).

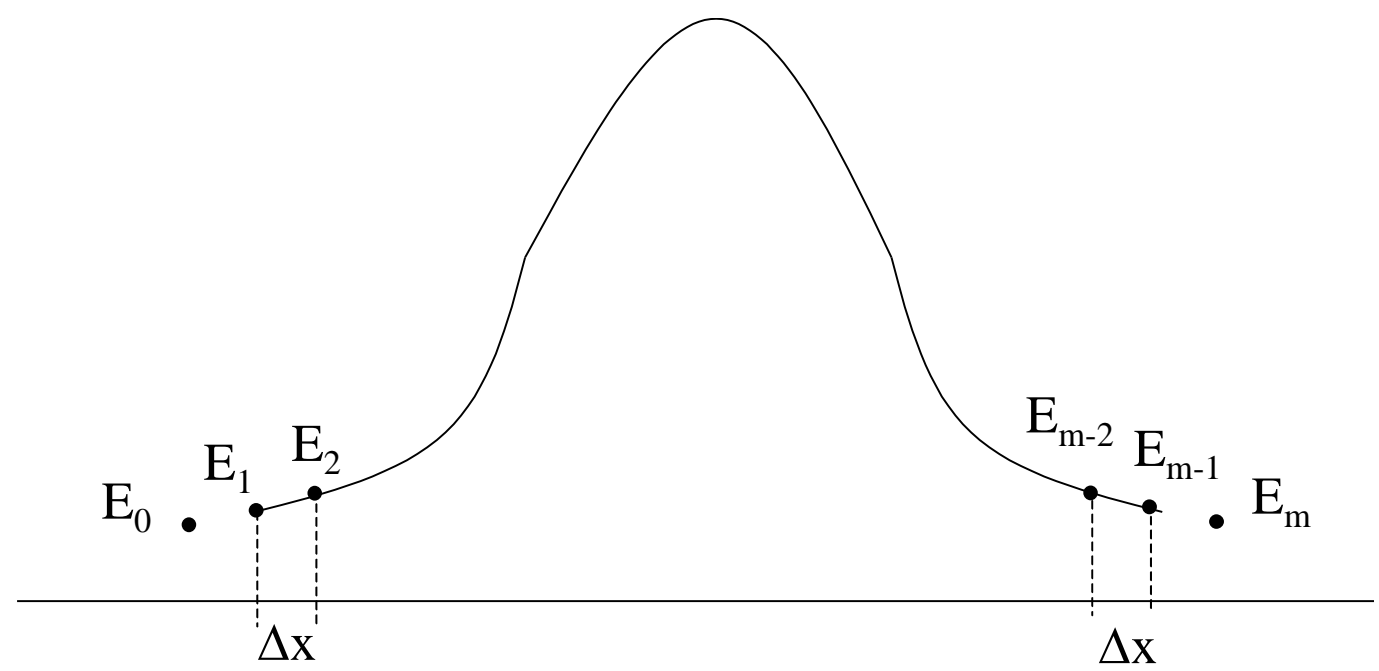

Figura 1- Representação de uma distribuição hipotética de campo numa janela computacional e seus pontos limites.

Nos pontos limites da janela computacional é necessária a utilização de pontos fora da mesma para o cálculo dos termos derivativos na Eq. (28). A condição de contorno transparente consiste em atribuirmos valores a esses pontos. Estes valores são calculados a partir da suposição de que a distribuição de campo fora da janela computacional seja exponencialmente decrescente. Para tanto, utiliza-se os valores de campo nos dois pontos mais próximos. Por exemplo, o ponto no extremo direito da janela (veja Figura A1) pode ser calculado por:

$$
E x_{N, j}=E x_{N-1, j} \exp \left(j k_{x} \Delta x\right)
$$

Sendo $k_{x}$ determinado por: 


$$
k_{x}=-\frac{j}{\Delta x} \cdot \ln \left(\frac{E x_{N-1, j}}{E x_{N-2, j}}\right)
$$

E no lado esquerdo por:

$$
E x_{0, j}=E x_{1, j} \exp \left(j k_{x} \Delta x\right)
$$

sendo $k_{x}$ :

$$
k_{x}=-\frac{j}{\Delta x} \cdot \ln \left(\frac{E x_{1, j}}{E x_{2, j}}\right)
$$

Da mesma forma, podemos calcular os valores nos extremos superior e inferior:

Extremo superior

$$
E x_{i, M}=E x_{i, M-1} \exp \left(j k_{y} \Delta y\right)
$$

onde $k_{y}$ é:

$$
k_{y}=-\frac{j}{\Delta y} \cdot \ln \left(\frac{E x_{i, M-1}}{E x_{i, M-2}}\right)
$$

Extremo inferior:

$$
E x_{i, 0}=E x_{i, 1} \exp \left(j k_{y} \Delta y\right)
$$

onde $k_{y}$ é:

$$
k_{y}=-\frac{j}{\Delta y} \cdot \ln \left(\frac{E x_{i, 1}}{E x_{i, 2}}\right)
$$


Desta forma os pontos com índice 0 e N+1 podem ser incluídos diretamente na formulação, implementando assim a condição de contorno transparente, também conhecida por TBC (do inglês, Transparent Boundary Condition). 